\title{
Análise de Modelos de Transporte Eletrônico em Transistores Orgânicos de Efeito de Campo
}

\author{
Por \\ Pedro Henrique Pereira Lira
}

Orientador:

Prof. Dr. Ismael Victor de Lucena Costa

Dissertação apresentada como requisito parcial para a obtenção do título de Mestre em Ciência de Materiais pelo Programa de Pós-Graduação em Ciência de Materiais da Universidade de Brasília.

$$
\text { UnB - FUP - Planaltina - DF }
$$


Ficha catalográfica elaborada automaticamente, com os dados fornecidos pelo(a) autor(a)

ANÁLISE DE MODELOS DE TRANSPORTE ELETRÔNICO EM TRANSISTORES ORGÂNICOS DE EFEITO DE CAMPO / PEDRO HENRIQUE PEREIRA LIRA; orientador ISMAEL VICTOR DE LUCENA COSTA. -- Brasília, 2016.

$96 \mathrm{p}$.

Dissertação (Mestrado - Mestrado em Ciência de Materiais) -- Universidade de Brasília, 2016.

1. OFET. 2. TRANSISTOR ORGÂNICO DE EFEITO DE CAMPO. 3. PENTACENO. 4. VISSENBERG-MATTERS. I. COSTA, ISMAEL VICTOR DE LUCENA, orient. II. Título. 


\section{UNIVERSIDADE DE BRASÍLIA \\ FACULDADE UnB PLANALTINA \\ MESTRADO EM CIÊNCIA DE MATERIAIS}

Termo de Aprovação

"ANÁLISE DE MODELOS DE TRANSPORTE ELETRÔNICO EM TRANSISTORES ORGÂNICOS DE EFEITO DE CAMPO".

Pedro Henrique Pereira Lira

Banca Examinadora

Simael Victor de $l$. costa

Prof. Dr. Ismael Victor de Lucena Costa

Presidente (FUP/UnB)
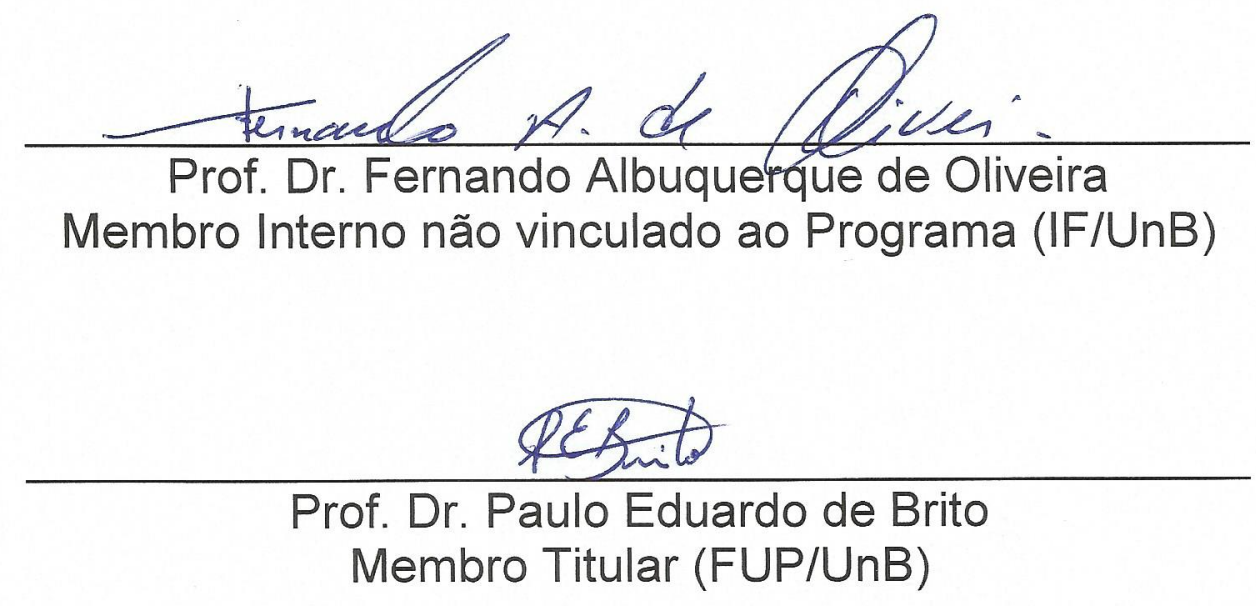
Dedico este trabalho ao

meu irmão, Wendel bania. 


\section{Agradecimentos}

Agradeço, primeiramente, a Deus, pela paciência e por me dar as condições necessárias à vida. Falta-me vocábulos, inspirações, aspirações, amor e poesia para descreverTe.

Ao professor Ismael, também, pela paciência (rs) e, acima de tudo, pela infindável disposição e solicitude em sempre me ajudar, não somente nesta orientação de pósgraduação, mas sim em toda minha formação, desde a graduação em Ciências Naturais, durante disciplinas do curso de Ciências de Materiais e até aqui, neste trabalho. Peça fundamental, sem a qual não teria dado um passo sequer.

À IURD e à FJU por toda a ajuda que me fornecem. Sempre com o braço estendido para me ajudar, me ensinar e me exortar. Amizades preciosas encontrei em vocês. Constituem-se pedra angular e rocha de esquina em minha vida. Minha caminhada será sempre com vocês.

À minha família (qualquer comentário sobre vocês careceria de arte para explicar o que representam para mim).

Aos meus alunos e às minhas alunas do CED 03 brejão (2014) e do CEF 05 (2015) que, sem dúvidas, me deram muitíssimo ânimo, alegria e momentos maravilhosos durante esses dois anos ("amooor"); também agradeço às excelentes diretoras de tais escolas.

Ao professor Leszek Majewski por nos ceder os preciosos dados dos testes feitos com o ofet estudado.

A todos meus amigos da FUP e aos meus companheiros da turma CIMA 2014. Vocês são show.

A todos meus professores(as) de Ciências Naturais e de Ciência de Materiais e, por fim, ao professor Stefan Blawid e à minha colega Vilany do Laboratório de Dispositivos e Circuitos Integrados do Departamento de Engenharia Elétrica da UnB. 


\section{Resumo}

O presente estudo analisa os mecanismos que governam o transporte eletrônico em semicondutores orgânicos, aplicando-os em transistores orgânicos de efeito de campo (OFET). O semicondutor utilizado nos testes foi o pentaceno em um OFET de arquétipo "bottom-gate".

As teorias abordadas para o transporte eletrônico incluíram o acoplamento elétronfônon, polarons, mecanismo de hopping e percolação. Realizamos a análise dos dados por meio da metodologia de Aproximação de Canal Gradual (GCA). As simulações computacionais que fizemos foram baseadas no mecanismo de condutividade por percolação desenvolvido por Vissenberg-Matters (VM) [1].

Por meio da GCA, demonstramos que o OFET estudado tem uma razão on/off de $10^{2}$ a $10^{3}$ para uma voltagem de $-30 \mathrm{~V}$ aplicada no dreno. Sendo que o fim do regime linear se deu logo após os -9V e o início do regime de saturação ocorreu logo após -16V.

A mobilidade de cargas calculada no canal do OFET durante o regime de saturação foi de $0,42 \mathrm{~cm}^{2} /$ V.s e de $0,96 \mathrm{~cm}^{2} / V . s$ durante o regime linear.

Pelas simulações feitas do modelo VM, obtivemos um bom ajuste ao comportamento linear do transistor operado, conseguindo explicar quantitativamente o transporte de cargas em sistemas desordenados, tais como são os vistos em materiais orgânicos.

PALAVRAS-CHAVE: OFET, Transistor Orgânico de Efeito de Campo, Pentaceno, Vissenberg-Matters. 


\begin{abstract}
The present dissertation is focused on analizing the mechanisms that govern the electronic transport in organic semiconductors, applying these concepts in organic fieldeffect transistors (OFET). The chosen semiconductor was pentacene, which was the semiconducting layer in an OFET built under the "bottom-gate" archetype.

The theories analised to describe the electronic transport comprise the electronphonon coupling, polarons, hopping and percolation mechanisms. The data analysis was performed by the Gradual Channel Approximation (GCA) method. The computational simulations were based on the percolation theory for conductivity developed by Vissenberg and Matters (VM) [1].

By means of the GCA, it is shown that the analyzed OFET has an on/off ratio ranging from $10^{2}$ to $10^{3}$ when submitted to a voltage of $-30 \mathrm{~V}$ applied to the drain terminal. The linear regime occured until $-9 \mathrm{~V}$ and the saturation regime started after $-16 \mathrm{~V}$.

The carrier mobility in the OFET channel while operating at the saturation regime was $0.42 \mathrm{~cm}^{2} / V . s$, and $0.96 \mathrm{~cm}^{2} / V . s$ while operating at the linear regime.

A fine adjustment to the transistor linear regime was obtained by the VM model simulations. This approach was able to explain quantitatively the charge transport in disordered systems, such as in organic materials.
\end{abstract}

KEYWORDS: OFET, Organic Field-Effect Transistor, Pentacene, VissenbergMatters. 


\section{Lista de Figuras}

1 Principais indicadores do setor eletroeletrônico. Tabela publicada pela ABINEE [2]. $\quad$. . 13

2 a) Válvula Tríodo criada em 1906 por Lee De Forest. Foto feita por Gregory F. Maxwell < gmaxwell@gmail.com> na exposição "The History of Audio: The Engineering of Sound" (2006-2007), exibida no Museu do Aeroporto de São Francisco, Califórnia, EUA. Licença GNU de Documentação Livre, versão 1.2, via Creative Commons. b) Réplica do primeiro transistor de ponto de contato feito em 1947 na Bell Labs. Licença de Domínio Público via Creative Commons. c) Circuitos integrados do processador Intel Xeon Haswell-E5 v3. Alfinete como escala. Crédito e fabricação: Intel Corporation. . 19

3 a) Display orgânico flexível. Crédito: electroSome. Licensa de Domínio Público. b) Display orgânico flexível de pulso que ganhou o prêmio "OLED Innovation Excellence" no ano de 2014. Crédito e fabricação: Plastic Logic Germany. c) Células fotovoltaicas orgânicas flexíveis formando o teto de uma parada de ônibus. Crédito e fabricação: Konarka Technologies, Inc. . . . . . . . . . . . . . . . . . . . . . . . 21

4 Modelo do OFET feito com nanotubo de carbono, em 2004. Crédito e fabricação: Infineon Technologies AG (FSE/NYSE: IFX) Copyright. . . . . . . . . . . . . . . . . 22

5 Formas ressonantes do benzeno. Retirada da referência [3]. . . . . . . . . . . . . . . . 23

6 Diagrama dos níveis de energia para a) um poliacetileno teórico infinito em uma dimensão e b) representação mais real da molécula de poliacetileno dimerizada. A molécula em (a) não apresenta bandgap por ser infinita. Mas em (b) vemos como o gap entre HOMO-LUMO existe independentemente do espaço infinito da molécula devido à Instabilidade de Peierls. Retirada da referência [4]. . . . . . . . . . . . . . . . . . . . 26

7 Três semicondutores orgânicos poliméricos. a) Polipirrol, b) Politiofeno e c) PEDOT (poli (3,4-etilenodioxitiofeno)). Todas essas três moléculas têm em comum a estrutura conjugada de ligações $\mathrm{sp}^{2}$, similar ao poliacetileno. Nessas partes estruturais da molécula que são observadas delocalização de portadores e atividade elétrica. Retirada da referência [3]. . . . . . . . . . . . . . . . . . . . . . . . . 26

8 Duas formas ressonantes do poliacetileno. Retirada da referência [4]. . . . . . . . . . . . 27

9 Sóliton carregado positivamente na fronteria entre duas estruturas ressonantes de poliacetileno. Retirada da referência [4]. . . . . . . . . . . . . . . . . . . . . 27

10 Modelo de átomos formando a estrutura da molécula de pentaceno. Crédito: International Business Machines Corporation - IBM Research, Zurich. . . . . . . . . . . . . . . 29 
11 Arquétipos de OFET. Retirada da referência [5]. . . . . . . . . . . . . 30

12 Curvas características de Corrente x Voltagem em OFETs. a) Curva de Transferência, mostrando a Voltagem de Limiar (limiar entre os estados desligado e ligado do dispositivo). b) Curva de Saída, mostrando a diferença entre os regimes (ou regiões) linear e de saturação. Retirada da referência $[6] \ldots \ldots \ldots$. . . . . . . . . . 32

13 Foto de uma molécula real de pentaceno. Imagem captada por meio de microscopia de força atômica. Retirada da referência $[7] . \ldots \ldots \ldots \ldots$. . . . . . . . . 34

14 Variação do Canal em OFET. A) representa o transistor com cargas depletadas, sem formação do canal entre fonte e dreno. B) representa o transistor operando no regime linear, com canal formado e uniforme. C) representa o canal disforme, quando o transistor está operando no regime de saturação. Retirada da referência [8] . . . . . . . . . . . 36

15 Extrapolação da Voltagem de Limiar feita na curva de transferência. Retirada da refe-

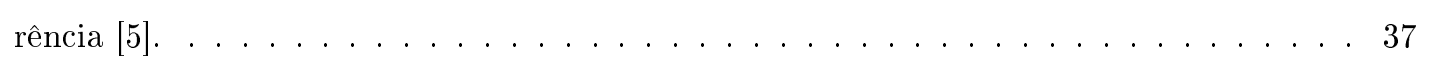

16 Limitações da obtenção da Voltagem de Limiar por extrapolação da curva de transferência. A região $A$ mostra que já existe corrente significativa antes da $V_{L}$ ser alcançada. A região B mostra um aumento não-linear abrupto, causando erros para se definir o local de extrapolação. Retirada da referência [5] . . . . . . . . . . . . . . . 38

17 Dimensões de um OFET de arquitetura Bottom-Gate Top-Contacts. O eixo X representa L, o comprimento do canal e do transistor como um todo. O eixo Y é a espessura do transistor, sendo que Ly é a espessura apenas do canal. O eixo Z é a largura do transistor e, consequentemente, do próprio canal também. Retirada da referência [9]. . . 41

18 Curva de transferência. $\mathrm{Vd}=-30 \mathrm{~V} . \ldots \ldots \ldots \ldots \ldots \ldots$

19 Curva $\sqrt{ } \operatorname{Id} x \operatorname{Vg}$ linearizada no regime de saturação. . . . . . . . . . . . . . . 48

20 Ponto de interceptação ao eixo x. . . . . . . . . . . . . . . . 48

21 Extrapolação da curva de saída no regime de saturação. Corrente elétrica de $-911,1 \mu A$. 49

23 Família de curvas de saída com extrapolação ao eixo y das curvas no regime de saturação.

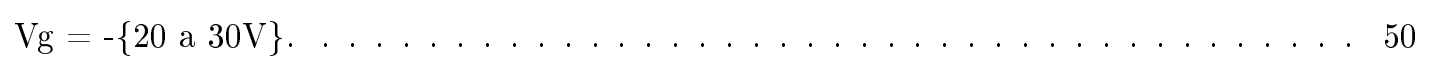

24 Família de curvas de saída com extrapolação ao eixo y das curvas no regime de saturação.

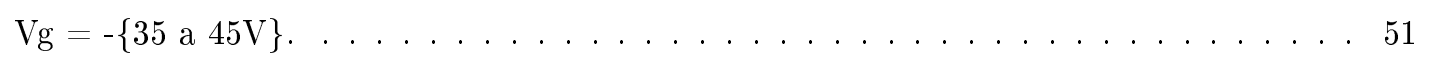

25 Família de curvas de saída com extrapolação ao eixo y das curvas no regime de saturação.

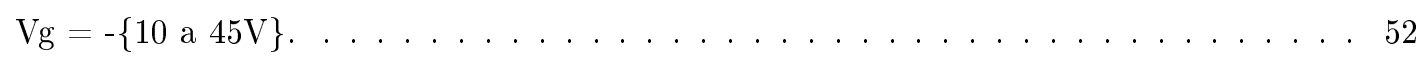


26 Raizes de corrente elétrica no dreno durante o regime de saturação para diferentes valores de voltagem na porta do transistor. . . . . . . . . . . . . . . . . . 53

27 Plot semilog da curva de transferência. . . . . . . . . . . . . . . . . . 54

28 Fase trasiente on/off do transistor operando com $\mathrm{Vd}=-30 \mathrm{~V}$. . . . . . . . . . . . 55

29 Família de curvas de saída ajustadas no regime linear de operação do transistor. Vg $=$

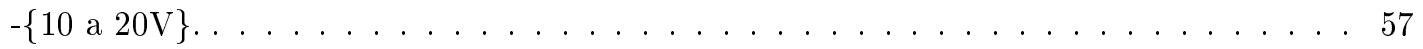

30 Família de curvas de saída ajustadas no regime linear de operação do transistor. Vg = $-\{25$ a $35 \mathrm{~V}\} \ldots \ldots \ldots \ldots \ldots \ldots$

31 Família de curvas de saída ajustadas no regime linear de operação do transistor. Vg $=$

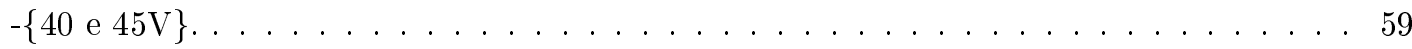

32 Mobilidade $\mu\left(\mathrm{cm}^{2} / V . s\right)$ durante o regime linear de operação do transistor para valores

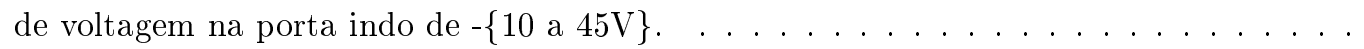

33 Esquema de transporte de cargas via hopping segundo o preenchimento de estados localizados. A) quando a interface semicondutor-isolante não está totalmente acumulada e os portadores ocupam os estados energéticos mais profundos, necessitando de maior energia de ativação para tunelar para um estado localizado vizinho. B) quando os estados mais profundos estão preenchidos e as cargas subsequentes preenchem estados mais energéticos, próximos da barreira energética de mobilidade, tendo, portanto, mais facilidade de locomoção. Por isso, a mobilidade mostra ser função da densidade de estados localizados. Retirada da referência [10]. . . . . . . . . . . . . . . . . 62

34 Discretização do semicondutor. . . . . . . . . . . . . . . . . . . . . . . 63

35 Malha de pontos. ......................... 69

36 Discretização da malha em termos de i,j . . . . . . . . . . . . . . . . . . . 71

37 Discretização das voltagens em termos de i,j . . . . . . . . . . . . . . . . . . 72

38 Camadas semicondutora e isolante na malha i,j. Presença de seis regiões de contorno

39 Distribuição gaussiana para a Densidade de Estados Localizados e uma aproximação exponencial para o início da curva, onde ocorre o regime linear de operação do OFET. Os termos das equações são descritos nas subseções anteriores. Imagem retirada da referência [9]. . . . . . . . . . . . . . . . . . . . . . . . . 76

40 Curva de saída obtida pela simulação computacional do modelo de Vissenberg-Matters. 78 


\section{Sumário}

1 Introdução 12

1.1 Indústria Eletrônica e Economia . . . . . . . . . . . . . . . . . . . . . . . . . . 12

1.2 Sobre este trabalho ............................. 13

2 Semicondutores, Transistores e suas historicidades na Eletrônica Orgânica 15

2.1 Semicondutores .............................. . . 15

2.2 Transistor ............................... . . 17

2.3 Eletrônica Orgânica . . . . . . . . . . . . . . . . . . . . . . . . . 19

2.4 Contexto Histórico do Transistor Orgânico de Efeito de Campo . . . . . . . . . . . . . . 22

3 Transporte eletrônico em materiais orgânicos 23

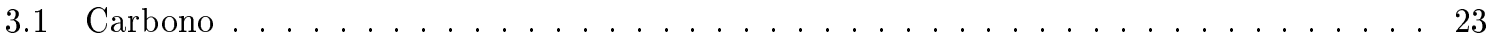

3.2 Moléculas conjugadas vistas como Poço de potencial . . . . . . . . . . . . . . . . 23

3.3 Níveis de energia em polímeros semicondutores . . . . . . . . . . . . . . . . 25

3.4 Portadores de carga e energia em moléculas conjugadas . . . . . . . . . . . . . 26

3.5 Portadores tipo-p e tipo-n em semicondutores orgânicos e mecanismo de transporte . . . 28

4 Transistor Orgânico de Efeito de Campo (OFET) 30

4.1 Estrutura Física Geral . . . . . . . . . . . . . . . . . . . . . 30

4.2 Sobre o Transistor estudado . . . . . . . . . . . . . . . . . . . . . . 32

4.2.1 Características físicas . . . . . . . . . . . . . . . . . 32

4.2.2 Semicondutores de moléculas pequenas - Pentaceno . . . . . . . . . . . 33

4.3 Parâmetros de operação de um OFET . . . . . . . . . . . . . . . . . . . . 34

4.3.1 Mobilidade $(\mu) \ldots \ldots . \ldots \ldots \ldots \ldots \ldots$

4.3.2 Voltagem de Limiar . . . . . . . . . . . . . . . . . . . 36

4.4 Caracterização de um OFET . . . . . . . . . . . . . . . . . . 38

4.4.1 Curva de transferência . . . . . . . . . . . . . . . . . . . . 39

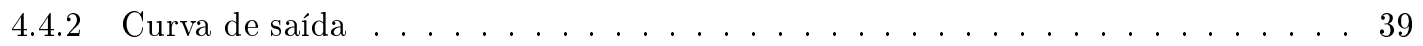

5 Modelos de Transporte Eletrônico em OFET 40

5.1 Aproximação de Canal Gradual . . . . . . . . . . . . . . . . . . . . . . . 40

5.1.1 Obtenção da corrente elétrica em função das voltagens e dimensões do transistor 40 
5.1 .2 Obtenção da corrente em regimes lineares: $V_{d} \ll V_{e f} \ldots \ldots \ldots \ldots \ldots$

5.1 .3 Obtenção da corrente na região de saturação: $V_{d} \geq V_{e f} \ldots \ldots \ldots \ldots \ldots$

5.2 Análise dos dados . . . . . . . . . . . . . . . . . . 46

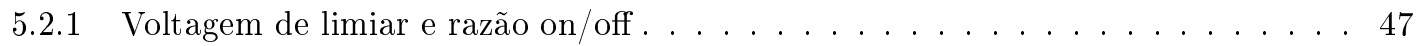

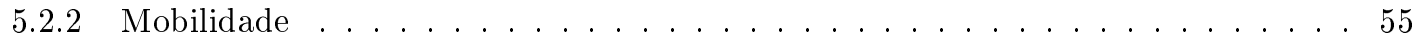

5.3 Modelo de Vissenberg-Matters f . . . . . . . . . . . . . . . . . . 61

5.3.1 Noções do modelo matemático de Vissenberg-Matters . . . . . . . . . . . . . . 62

5.3 .2 Expressão para a Condutividade . . . . . . . . . . . . . . . . . 65

5.3.3 Expressão para a Ocupação de Cargas, Equação de Poisson e Corrente Elétrica

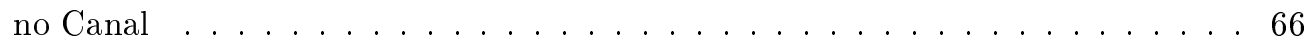

5.4 Métodos numéricos para aplicação do modelo de Vissenberg-Matters . . . . . . . . . . 67

5.4 .1 Método das Diferenças Finitas . . . . . . . . . . . . . . . . . 69

5.4.2 Método de Gauss-Seidel para obtenção da voltagem nos pontos da malha 2D $\quad$. 73

5.4 .3 Simulação computacional . . . . . . . . . . . . . . . . . . 75

5.4.4 Algoritmo em Português Estruturado . . . . . . . . . . . . . . . . . 78

6 Conclusão $\quad 82$

7 Referências $\quad 84$

A Apêndice - Proposta de programa em linguagem C para modelo de transporte eletrônico em OFET (Vissenberg-Matters) 


\section{Introdução}

\subsection{Indústria Eletrônica e Economia}

A indústria eletrônica se estabeleceu nas últimas décadas como sendo, sem dúvidas, um dos pilares da economia moderna. A isso se deve o fato da inumerável quantidade de aplicabilidades tecnológicas advindas desse ramo industrial que possui por razão precípua o desenvolvimento do humano e da sociedade em nossos dias. Assim, não é sem reflexão o fato de chamarmos nosso período histórico de "era tecnológica". Tal denominação explicita bem a interligação estabelecida ao longo das últimas décadas entre as pessoas e os aparatos eletrônicos que, cada vez mais, se tornam indispensáveis ao modus operandi da sociedade.

Segundo pesquisa da Consumer Electronics Association (CEA), a venda global de smartphones, por exemplo, teve estimativa para o ano de 2014 de 1,2 bilhão de unidades, mas em 2015 a previsão é de totalizar cerca de 1,5 bilhão de unidades, obtendo uma receita global de mais de US\$ 400 bilhões [11]. Para efeitos de comparação, as vendas de smartphones no Brasil contabilizaram 54,6 mil unidades [2]. De acordo com a Associação Brasileira da Indústria Elétrica e Eletrônica (ABINEE), o faturamento brasileiro no ano de 2014 foi de pouco mais de $\mathrm{R} \$ 150$ bilhões (2,8\% do PIB) nesse ramo e o número de empregos gerados ficou em torno de 174 mil postos.

Na esfera política, em 14 de julho de 2015, o Senado Federal aprovou o projeto de lei que torna permanente os benefícios tributários para o setor de semicondutores e componentes eletrônicos, percebendo-os como estratégicos para a economia brasileira. O projeto estende ainda esses benefícios à fabricação de cartões inteligentes, displays para smartphones e tablets [12]. O presidente da ABINEE, Humberto Barbato, diz que renovação da Lei da Informática e a Lei do Bem (Lei 11.196/05) (concede incentivos fiscais às empresas que investem em CTI) se constituem como algumas das principais 
ações de estímulo ao setor [13].

\begin{tabular}{|c|c|c|c|}
\hline Indicador & 2013 & 2014 & $\frac{2014 X}{2013}$ \\
\hline Faturamento Nominal (RS milhões) & 156.745 & 153.816 & $-2 \%$ \\
\hline Faturamento (US\$ milhões) & 72.574 & 65.322 & $-10 \%$ \\
\hline Exportações (US\$ milhões) & 7.218 & 6.552 & $-9 \%$ \\
\hline Importações (US\$ milhões) & 43.599 & 41.150 & $-6 \%$ \\
\hline Saldo (US\$ milhões) & -36.381 & -34.598 & $-5 \%$ \\
\hline № de Empregados (mil) & 177,9 & 174,1 & $-2 \%$ \\
\hline
\end{tabular}

Figura 1: Principais indicadores do setor eletroeletrônico. Tabela publicada pela ABINEE [2].

\subsection{Sobre este trabalho}

Tendo em vista a importância econômica desse setor e sua rápida expansão nos últimos anos, intensificou-se também a pesquisa científica nessa área, além da procura por novos materiais e a criação de dispositivos que possam entregar às pessoas novas tecnologias para uso cotidiano. Uma das áreas, dentro das pesquisas em eletrônica, que teve grande avanço nos últimos anos e está em rápida propagação científica e comercial é a eletrônica orgânica.

Este trabalho tem por razão precípua a contribuição para a essa área de pesquisa, a qual está buscando equiparar-se em níveis de conhecimento com a já bem estabelecida eletrônica inorgânica. No Capítulo 2 são introduzidos os conceitos de semicondutores e transistores, além disso, é feita uma contextualização histórica tanto da eletrônica orgânica como do Transistor Orgânico de Efeito de Campo (OFET). No Capítulo 3 são apresentadas algumas teorias para o transporte eletrônico em materiais orgânicos, 
bem como a caracterização energética de moléculas orgânicas. O Capítulo 4 mostra a caracterização dos OFETs, dando enfoque em sua estrutura física e em seus parâmetros operacionais. Uma das subseções desse capítulo detalha pormenorizadamente todas as características do OFET que foi construído e testado para objeto de estudo deste trabalho. Em seguida, no capítulo 5, detalhamos os dois principais modelos de mobilidade eletrônica em OFET, a Aproximação de Canal Gradual (GCA) e o modelo de condutividade por percolação de Vissenberg-Matters. Apresentamos todos os dados colhidos pelos testes feitos com o OFET na Faculdade de Engenharia Elétrica e Eletrônica da Universidade de Manchester, Inglaterra. Além disso, aplicamos a GCA para obter todos os parâmetros necessários para a caracterização de um OFET segundo a norma atual estabelecida pela organização internacional IEEE (Instituto de Engenheiros Eletricistas e Eletrônicos) e propomos um novo método para se obter a Voltagem de Limiar por meio das curvas de saída obtidas nos testes com o transistor. Na última subseção do capítulo, explicamos os métodos numéricos utilizados no modelo de Vissenberg-Matters e detalhamos uma proposta de caracterização operacional do transistor com vistas à aplicação de tal modelo; sendo que, ao final, elaboramos um algoritmo didático em Português Estruturado para facilitar a compreensão acerca da programação do modelo e criamos um programa em linguagem $\mathrm{C}$, no qual realizamos várias simulações com o intuito de testar a veridicidade quantitativa do modelo, as quais resultaram em valores condizentes com os observados na literatura científica. 


\section{Semicondutores, Transistores e suas histori- cidades na Eletrônica Orgânica}

\subsection{Semicondutores}

O pilar que sustenta a indústria eletrônica são os dispositivos semicondutores feitos com materiais inorgânicos, sendo o Silício o principal deles. Suas propriedades semicondutoras e o seu custo o tornam insumo eletrônico ótimo para as aplicações cotidianas. No entanto, a indústria eletrônica está demandando a utilização de novos materiais para tornar possível a fabricação de dispositivos com características específicas, atendendo às aplicações advindas do processo inovativo que ocorre intensamente nesse campo de pesquisa.

Semicondutores, como o próprio nome sugere, são materiais que possuem condutividade intermediária entre os materiais isolantes (vidro, por exemplo) e os condutores (cobre, por exemplo). Essa característica permite que alguns procedimentos possam ser feitos com o objetivo de controlar, por exemplo, a direção de passagem da corrente elétrica [14]. Semicondutores intrínsecos são definidos como aqueles com propriedades semicondutoras inerentes a eles. Os semicondutores intrínsecos mais utilizados, além do Silício, são o Germânio (Ge) e o Arseneto de Gálio (GaAs).

Analisando pela teoria de bandas, os semicondutores são aqueles com valor de gap entre a banda de valência e a banda de condução menor que $2 \mathrm{eV}$. Em um semicondutor como o cristal de silício, por exemplo, cada átomo se une por meio de ligações covalentes a outros quatro átomos. Se a temperatura for suficientemente baixa, próxima do zero absoluto, todas as ligações covalentes estão "firmes" de maneira tal que não há elétrons disponíveis para possibilitar a condução de corrente elétrica, consequentemente fazendo com que o cristal se comporte como um isolante. Se considerarmos esse mesmo cristal, mas em temperatura ambiente, já existe energia térmica suficiente 
para quebrar algumas ligações covalentes, fazendo com que elétrons fiquem disponíveis para conduzir corrente elétrica quando submetidos a uma diferença de potencial. Tal processo é conhecido como excitação térmica. A passagem do elétron para a banda de condução deixa um "buraco" na banda de valência do átomo; esse buraco pode ser considerado como uma carga positiva, que também se "movimenta", a partir de uma diferença de potencial, em sentido contrário ao do elétron. Isso é um dos aspectos que indica a dependência que a condutividade dos semicondutores intrínsecos tem com a temperatura; característica que pode não ser desejável para alguns fins práticos. Outra característica dos semicondutores intrínsecos é que a concentração de portadores de carga em temperatura ambiente é muito pequena para criar corrente elétrica desejável $[5]$.

Uma alternativa para esse problema são os semicondutores extrínsecos - semicondutores aos quais são adicionados outros átomos (denominados impurezas), processo chamado de dopagem, com intuito de aumentar o número de portadores de carga e, consequentemente, a mobilidade eletrônica. Para obter esse efeito, um material de silício, por exemplo, recebe uma quantidade de outro átomo com cinco elétrons de valência, como o fósforo; quatro desses cinco elétrons se ligam covalentemente aos quatro elétrons de valência do silício, porém o quinto elétron do átomo de fósforo fica fracamente atraído pelo seu núcleo, sendo considerado um elétron livre. Assim, cada átomo de fósforo aumenta uma unidade de portador de carga no material, sendo que nenhum buraco é criado. Haverá então uma grande quantidade de elétrons (portadores majoritários) e pouca quantidade de buracos (portadores minoritários). O material resultante desse tipo de dopagem, na qual se aumenta a concentração de elétrons, é chamado de semicondutor tipo n (negativo), e a impureza é chamada de doadora de cargas. Caso a dopagem no cristal de silício tivesse ocorrido com um átomo que tem três elétrons na camada de valência, como o boro, haveria três ligações covalentes e um estado de ocu- 
pação disponível, que funcionaria como um buraco. Nesse caso, o material resultante seria um semicondutor do tipo p (positivo), e o átomo de boro seria considerado uma impureza receptora de elétrons; além disso, os portadores de carga majoritários seriam os buracos, considerados cargas positivas, e os minoritários seriam os elétrons. A partir desses materiais são produzidos os dispositivos que sustentam a base da eletrônica moderna, tais como os diodos e os transistores.

\subsection{Transistor}

O transistor, com certeza, foi uma das maiores invenções do século passado. O princípio básico do transistor é a aplicação de certa voltagem em dois terminais para manipular o valor de corrente elétrica obtido em um terceiro terminal. Suas funções mais práticas são a amplificação de sinais elétricos e o chaveamento.

Até os anos 50, o dispositivo mais usado para se obter tal efeito era a válvula triodo, formada por um tubo a vácuo com um cátodo que emite elétrons, um ânodo que os recebe e, entre eles, um terceiro eletrodo formado por uma grade de fios metálicos. A corrente elétrica do cátodo para o ânodo varia de acordo com a voltagem aplicada na grade, tornando a válvula triodo um dispositivo ativo de controle [15].

Em 1930, Julius Edgar Lilienfeld registrou uma patente (US Patent 879,532) de um dispositivo triodo similar ao transistor de efeito de campo, contudo, não conseguiu demonstrar em termos práticos o funcionamento desse amplificador de sinais [9].

Em 1947, nos Estados Unidos, mais especificamente na AT\&T Bell Laboratories, Brattain e Bardeen estudavam propriedades de germânio com dois contatos de ouro depositados sobre ele e viram que a corrente elétrica no material semicondutor era modulada pela corrente elétrica que passava em um dos dois terminais de ouro. Assim, juntamente com o chefe do laboratório, William Shockley, criaram um novo dispositivo 
e deram-no o nome de transistor [16]. Em reconhecimento por tal descoberta, eles ganharam o prêmio Nobel de Física em 1956 por "sua pesquisa em semicondutores e pela descoberta do efeito transistor" [17]. Porém, o transistor de ponto de contato era muito frágil, degradava-se com umidade e tinha considerável ruído interno. Um ano depois, Shockley propôs teoricamente a estrutura do transistor de junção. No mesmo ano, os alemães Herbert Mataré e Heinrich Welker criaram um dispositivo parecido com o transistor e o nomearam transistron [18], que foi primeiramente utilizado em telefones franceses.

No ano de 1954, Morris Tanenbaum criou o primeiro transistor de silício, mas foi Gordon Teal, da Texas Instruments, quem fez o primeiro uso comercial do dispositivo. Em 1959, Dawon Kahng e Martin Atalla, também da AT\&T Bell Laboratories, criaram o transistor de efeito de campo metal-óxido-semicondutor (MOSFET). Mais tarde esses transistores foram fabricados de maneira complementar, criando os circuitos CMOS (Complementary Metal-Oxide-Semiconductor), com portas lógicas atuando no processamento de dados, constituindo-se, até os dias de hoje, como padrão em eletrônica digital.

O primeiro processador de 8 bits da Intel (Intel 8008), fabricado em abril de 1972, tinha 3500 transistores com 10 um. Em 2014, a Intel lançou o processador Xeon HaswellE5, que tem pouco mais de 5,5 bilhões de transistores fabricados com tecnologia de $22 \mathrm{~nm}$ [19]. 


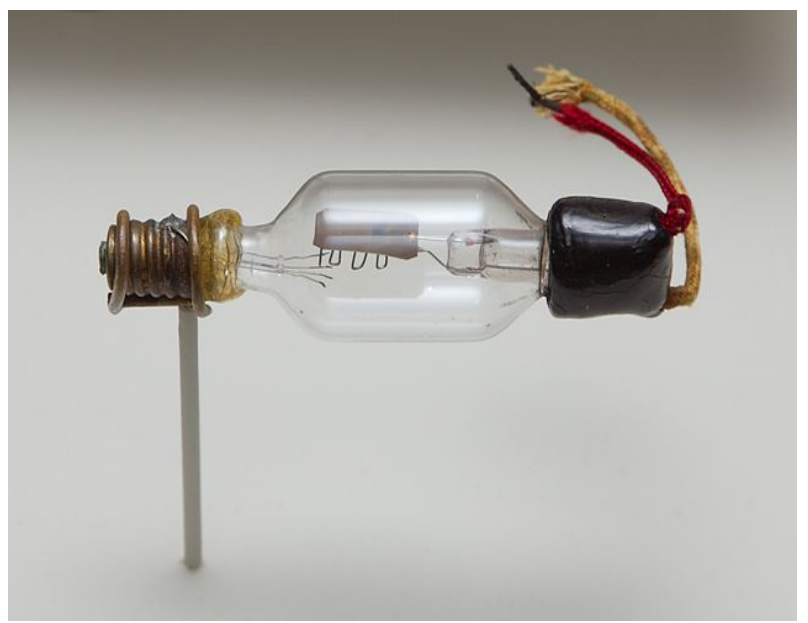

(a) Válvula Tríodo

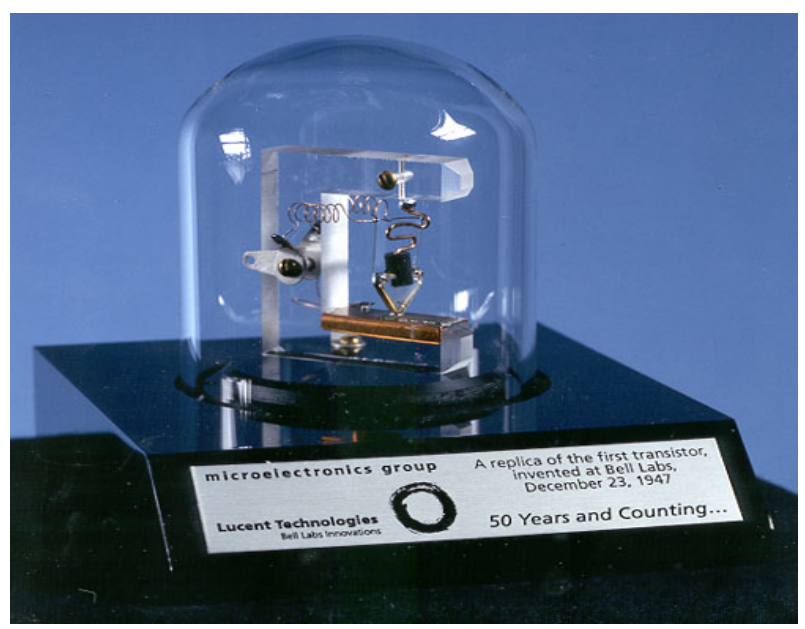

(b) Transistor de ponto de contato.

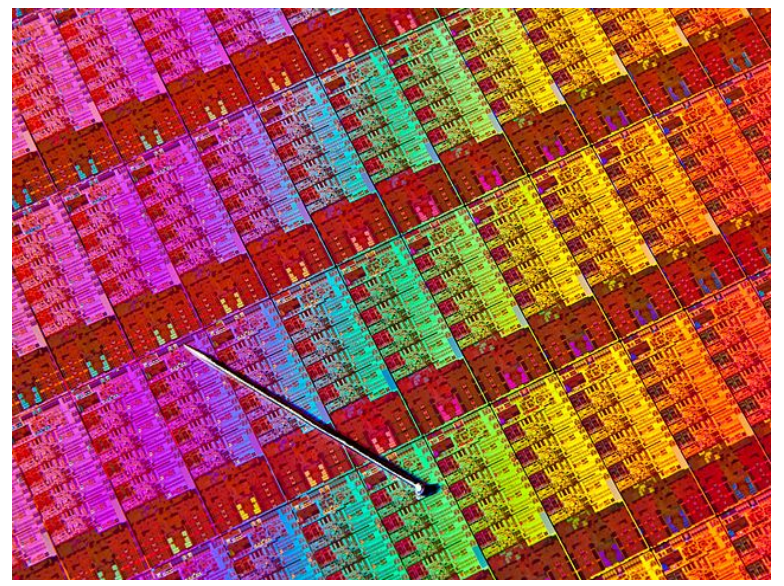

(c) Substrato de um processador com circuitos integrados, tecnologia Haswell de 22 nanômetros.

Figura 2: a) Válvula Tríodo criada em 1906 por Lee De Forest. Foto feita por Gregory F. Maxwell <gmaxwell@gmail.com> na exposição "The History of Audio: The Engineering of Sound" (2006-2007), exibida no Museu do Aeroporto de São Francisco, Califórnia, EUA. Licença GNU de Documentação Livre, versão 1.2, via Creative Commons. b) Réplica do primeiro transistor de ponto de contato feito em 1947 na Bell Labs. Licença de Domínio Público via Creative Commons. c) Circuitos integrados do processador Intel Xeon Haswell-E5 v3. Alfinete como escala. Crédito e fabricação: Intel Corporation.

\subsection{Eletrônica Orgânica}

Os semicondutores orgânicos são materiais à base de carbono que apresentam propriedades elétricas próprias de um material classificado como semicondutor. Os primeiros estudos em eletrônica orgânica datam do começo do século 20 [14]. Nos anos 60 passou- 
se a estudar bastante as propriedades de fotocondução de semicondutores orgânicos. Em 1963, Pope, Kallman e Magnante, após aplicar uma tensão de 400 V em cristais orgânicos de antraceno, puderam observar a emissão de luz desse material [14]. Mas foi nos anos 70 que grandes avanços foram dados.

Em 1977, Hideki Shirakawa, Alan Heeger e Alan MacDiarmind descobriram que propriedades condutoras de um filme poliacetileno poderiam ser drasticamente alteradas pelo processo de dopagem [20]. O dopante foi o iodo, dando ao material propriedades condutoras similares aos metais. Assim, abriu-se espaço para a ideia de que plásticos considerados isolantes poderiam então ser modificados para uso como condutor. No ano de 2000, os três autores foram agraciados com o prêmio Nobel "pelo descobrimento e desenvolvimento de polímeros condutores" [21].

Em 1987, Ching Tang e Steven VanSlyke apresentaram, pela Eastman Kodak, o primeiro dispositivo emissor de luz eficiente baseado em materiais orgânicos funcionando a tensões da ordem de $10 \mathrm{~V}$ ou menos (TANG, 1987 apud CGEE [14]). Este dispositivo ficou conhecido como OLED, do inglês Organic Light Emiting Diode (Diodo Orgânico Emissor de Luz).

Atualmente, a eletrônica orgânica é um vasto campo de pesquisa, sendo que alguns materiais são vistos até com certa facilidade em nosso dia a dia. Podemos citar alguns exemplos de aplicabilidades da eletrônica orgânica, tais como telas de smartphones e faróis de automóveis (feitas com OLED), células fotovoltaicas, telas curvas de televisores e outros aparelhos, identificadores de rádio frequência - RFId (Radio Frequency Identification), dispositivos eletroluminescentes, baterias impressas, células de combustível, sensores impressos, dispositivos de memória e processamento lógico, dentre outros.

Embora semicondutores de moléculas orgânicas e polímeros ainda não possam competir com seus concorrentes inorgânicos em termos de desempenho de transporte de cargas e desenvolvimento industrial, eles detêm como trunfo uma série incomparável 
de vantagens: redução dos custos de produção, versatilidade dos processos de síntese e compatibilidade com uma vasta gama de substratos, tal como o vidro transparente e materiais poliméricos flexíveis. Na verdade, empresas de alta tecnologia têm investido significativamente em dispositivos eletrônicos à base de materiais orgânicos baratos e de alto desempenho, um mercado de bilhões de dólares do qual se espera crescimento rápido.

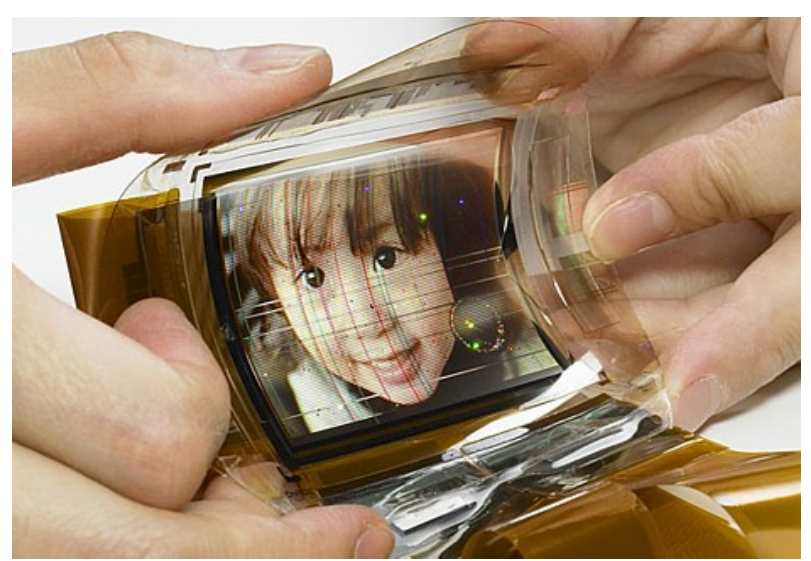

(a) Display flexível

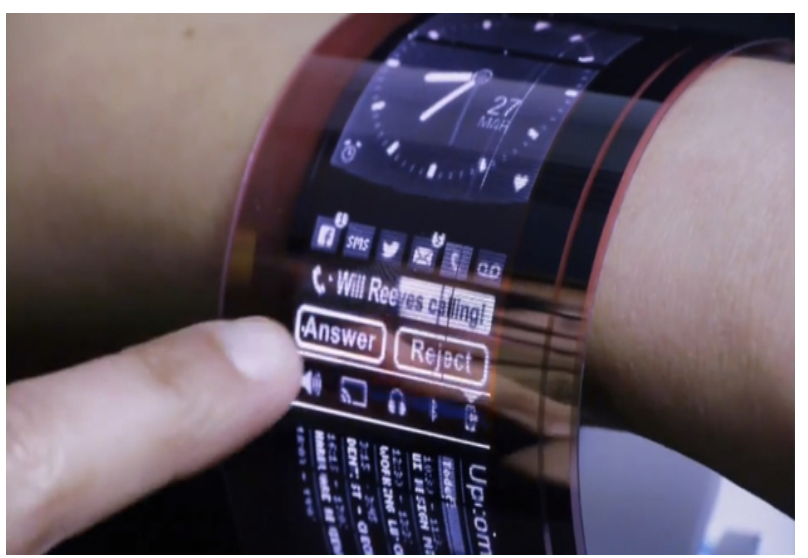

(b) Display AMOLED (Active-Matrix Organic Light-Emitting Diode)

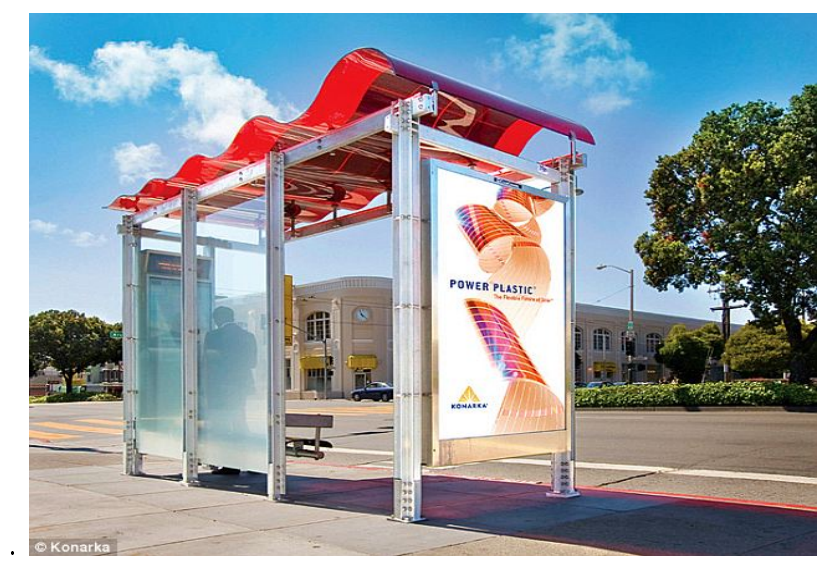

(c) Parada de ônibus com teto de células fotovoltaicas

Figura 3: a) Display orgânico flexível. Crédito: electroSome. Licensa de Domínio Público. b) Display orgânico flexível de pulso que ganhou o prêmio "OLED Innovation Excellence" no ano de 2014. Crédito e fabricação: Plastic Logic Germany. c) Células fotovoltaicas orgânicas flexíveis formando o teto de uma parada de ônibus. Crédito e fabricação: Konarka Technologies, Inc. 


\subsection{Contexto Histórico do Transistor Orgânico de Efeito de Campo}

O primeiro Transistor Orgânico de Efeito de Campo (OFET) só foi desenvolvido em 1986 por Tsumura, Koezuka e Ando, todos da Mitsubishi Chemical.

Os OFETs constituem a base de vários circuitos integrados e das telas flexíveis. O diferencial com relação ao transistor comum é que ele possui, no mínimo, o material semicondutor orgânico. Durante a operação, um terminal chamado Porta é usado para controlar a corrente elétrica entre o terminal Dreno e o terminal Fonte. Geralmente, o que se espera é que quanto maior a voltagem aplicada na porta, maior será a corrente elétrica entre a fonte e o dreno. O material semicondutor necessário para um rápido chaveamento deve ter alta mobilidade de portadores de carga e uma alta razão on/off (tais parâmetros serão discutidos no capítulo 4). Para transistores que lidam com pixels de uma tela, por exemplo, é necessária uma mobilidade maior que $0.1 \mathrm{~cm}^{2} / \mathrm{Vs}$ e uma razão on/off maior que $10^{6}$ [22].

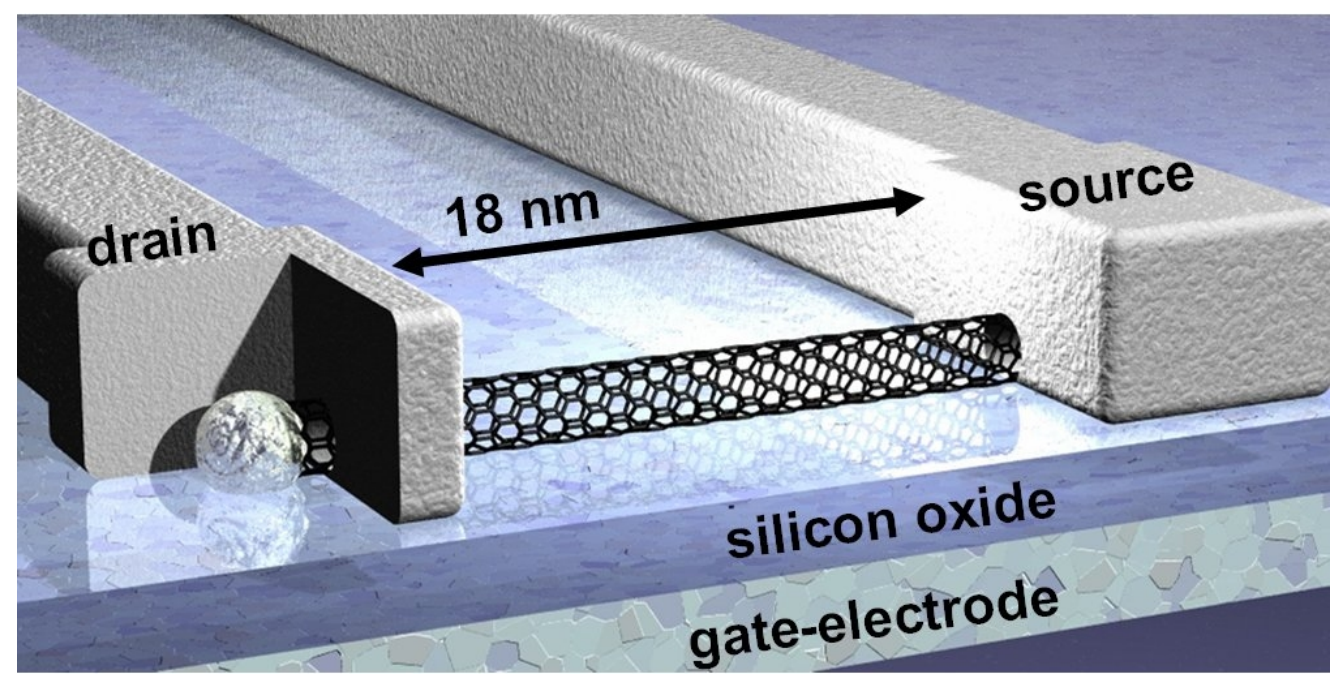

Figura 4: Modelo do OFET feito com nanotubo de carbono, em 2004. Crédito e fabricação: Infineon Technologies AG (FSE/NYSE: IFX) Copyright. 


\section{Transporte eletrônico em materiais orgâni- $\cos$}

\subsection{Carbono}

O carbono é atipicamente rico em suas propriedades químicas devido a alguns fatores, tais como:

- Tamanho relativamente pequeno. Isso reduz os efeitos estéricos [3] nas moléculas orgânicas permitindo que um maior número de substâncias diferentes sejam formadas;

- Eletronegatividade moderada. Isso permite a formação de ligações covalentes com vários outros materiais, incluindo os próprios átomos de carbono;

- Hibridiza em variadas formas, permitindo-se obter alto número de configurações de ligações diferentes, como ligações simples, dupla, tripla, bem como uma série de formas ressonantes.

É por essas e outras propriedades que a química orgânica é capaz de desenvolver uma vasta gama de materiais baseados nesse elemento químico.

\subsection{Moléculas conjugadas vistas como Poço de poten- cial}

Assim que as moléculas crescem em tamanho, sua densidade eletrônica torna-se mais complexa de se caracterizar. Há certa ambiguidade quando estão presentes ligações simples e duplas na molécula. Se pensarmos no benzeno, por exemplo, há duas formas ressonantes, mostradas na figura 5. 


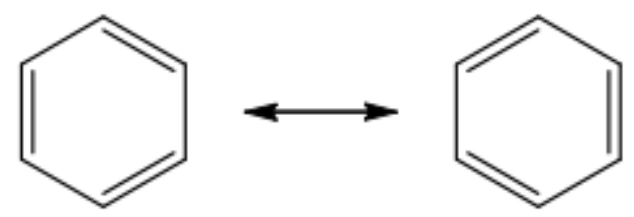

Figura 5: Formas ressonantes do benzeno. Retirada da referência [3].

Nas duas formas ressonantes a ligação simples (sigma) sempre permanece entre os átomos de carbono. A ligação PI é capaz de se locomover entre os sítios atômicos e por isso está delocalizada em relação aos outros átomos da molécula. As alternâncias vistas na molécula de benzeno entre as ligações simples e duplas são uma indicação de que os átomos de carbono estão hibridizados na forma $\mathrm{sp}^{2}$. Os materiais nos quais átomos de carbono vizinhos são hibridizados na forma $\mathrm{sp}^{2}$, formando nuvens delocalizadas de elétrons de ligações do tipo PI são denominados moléculas conjugadas [6, 23]. Se tomarmos como exemplo outras moléculas grandes, existem muitas outras formas ressonantes que carecem da organização simétrica da molécula de benzeno e algumas serão energeticamente mais favoráveis do que as outras [24].

Ressonância é a representação da superposição de vários estados dentro do limitado modelo estrutural químico; em outras palavras, os elétrons não estão presos dentro de uma rígida e particular configuração, ao contrário, podem estar delocalizados de uma maneira intensa ou fraca dentro da molécula. Essa delocalização dos elétrons das ligações PI forma uma situação de poço de potencial - os elétrons seriam as partículas e a molécula a caixa. Os níveis de energia dessa configuração são determinados pela ocupação e extensão da caixa e podem ser modeladas, em uma primeira abordagem, pela tradicional formulação de partícula em uma caixa. Em uma molécula isolada, esses níveis de energia são discretos e conhecidos como orbitais moleculares. Eles são produto da combinação de orbitais atômicos que formam a molécula. Alguns orbitais moleculares serão preenchidos por elétrons quando a molécula estiver no estado fundamental, 
assim, níveis de energia maiores estarão vazios.

Os dois estados mais interessantes para fins teóricos e práticos são o HOMO e LUMO [25, 26]. Essas abreviações vêm do idioma inglês. HOMO (highest occupied molecular orbital) é o mais alto orbital molecular ocupado, enquanto LUMO (lowest unoccupied molecular orbital) é o mais baixo orbital molecular desocupado. A diferença de energia entre esses dois níveis é chamada de bandgap. Em uma comparação tosca, o HOMO é para semicondutores orgânicos o que o topo da banda de valência é para materiais inorgânicos. A mesma analogia pode ser empregada para comparar o LUMO e o fundo da banda de condução. A criação e absorção de pacotes de energia (incluindo fótons) é governada por transições entre orbitais vazios e cheios. Quanto maior for a rede conjugada em molécula, menor será o bandgap, por causa do aumento de extensão do poço de potencial.

\subsection{Níveis de energia em polímeros semicondutores}

A tentativa de se caracterizar como livres os portadores de carga em ligações PI é um tanto quanto simplista. Apesar de ser útil para alguns casos, quando se trata de polímeros, ela não se adéqua muito bem. Poderíamos pensar que em um sistema infinito de ligações $\mathrm{sp}^{2}$, como um polímero conjugado, não haveria bandgap. Tanto que Little [27] sugeriu que talvez fosse possível sintetizar um supercondutor à temperatura ambiente usando materiais orgânicos nos quais os elétrons seriam transportados em longas cadeias 1D. No entanto, mesmo polímeros conjugados infinitos 1D têm um bandgap finito devido a um fenômeno de dimerização da molécula, conhecido por Instabilidade de Peierls [28].

A figura 6 mostra que o bandgap existe independentemente da extensão da molécula devido à instabilidade de Peierls que dimeriza a molécula e separa bandas na fronteira da zona de Brillouin [28, 4], criando o HOMO e LUMO, e torna-a energeticamente mais 
estável em (b) do que em (a). A primeira visualização desse efeito ocorreu na década de 1970, quando foram feitos e testados vários materiais orgânicos quasi-1D; porém, ao diminuir a temperatura, esses materiais tornavam-se isolantes, bem ao contrário do que se esperava.
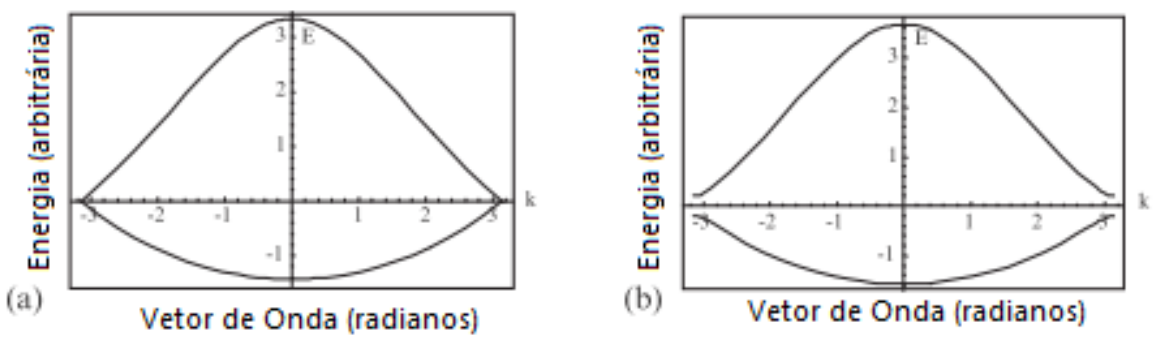

Figura 6: Diagrama dos níveis de energia para a) um poliacetileno teórico infinito em uma dimensão e b) representação mais real da molécula de poliacetileno dimerizada. A molécula em (a) não apresenta bandgap por ser infinita. Mas em (b) vemos como o gap entre HOMO-LUMO existe independentemente do espaço infinito da molécula devido à Instabilidade de Peierls. Retirada da referência [4].

\subsection{Portadores de carga e energia em moléculas conju- gadas}

Certo número de portadores de carga e energia pode ser encontrado tanto em polímeros quanto em pequenas moléculas orgânicas semicondutoras. Virtualmente, todos semicondutores poliméricos orgânicos têm uma parte conjugada com a mesma configuração $\mathrm{sp}^{2}$ do poliacetileno. A figura 7 mostra três materiais representativos disso.

(a)
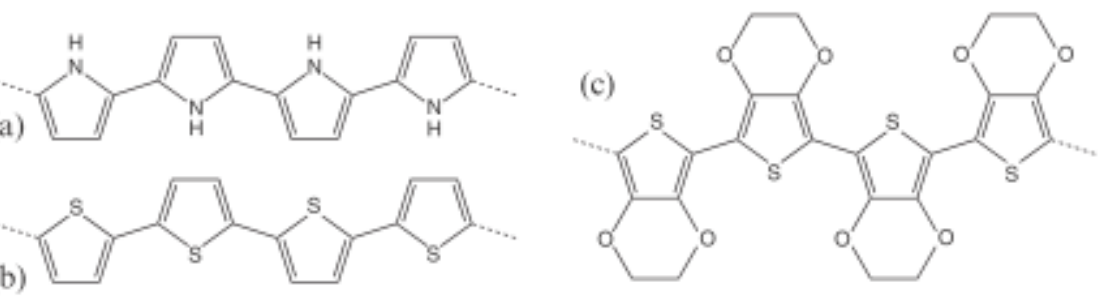

Figura 7: Três semicondutores orgânicos poliméricos. a) Polipirrol, b) Politiofeno e c) PEDOT (poli (3,4-etilenodioxitiofeno)). Todas essas três moléculas têm em comum a estrutura conjugada de ligações $\mathrm{sp}^{2}$, similar ao poliacetileno. Nessas partes estruturais da molécula que são observadas delocalização de portadores e atividade elétrica. Retirada da referência [3]. 
Pela análise das formas ressonantes de moléculas conjugadas pode-se explicar a formação de portadores de cargas em semicondutores orgânicos. A estrutura do poliacetileno na figura 8 mostra dois estados que são energeticamente degenerados.

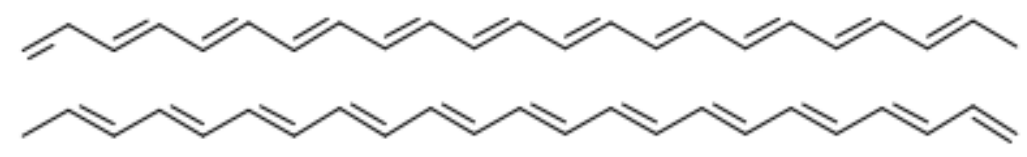

Figura 8: Duas formas ressonantes do poliacetileno. Retirada da referência [4].

É possível para esses dois estados coexistirem em uma mesma cadeia com uma simples fronteira entre eles. Na fase transiente entre esses estados é possível existir um defeito na cadeia polimérica, chamado sóliton [29, 10, 4]. É nesse defeito que as cargas introduzidas por dopagem irão se localizar, tornando o sóliton carregado, ilustrado na figura 9. Algo similar também foi previsto por Landau [30], afirmando que a distorção na rede pode causar um defeito que se comporta como uma armadilha para o elétron.

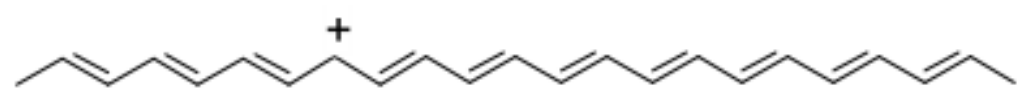

Figura 9: Sóliton carregado positivamente na fronteria entre duas estruturas ressonantes de poliacetileno. Retirada da referência [4].

Outro efeito semelhante pode ser obtido por dopagem, na qual o dopante oxida ou reduz uma das ligações na cadeia molecular, criando um elétron ou uma carga positiva. Quando há dopagem, a adição ou remoção de portadores de carga na estrutura da molécula causa um efeito de distorção estrutural para que haja reorganização geométrica da rede energética [31]. Com a distorção na rede causada pelas cargas, a própria distorção também irá interagir com os portadores, sendo que esse fenômeno pode ser visto como uma entidade apenas, denominada polaron [29, 10, 30, 4]. As distorções, como as vibrações na rede, tem seus quanta conhecidos como fônons, e a interação destes com elétrons é conhecida como acoplamento elétron-fônon. A interação 
entre acoplamento elétron-fônon e polarons também pode ser utilizada para descrever as propriedades condutoras dos materiais orgânicos. Diferentemente dos materiais inorgânicos, o acoplamento elétron-fônon é bem mais forte devido às fracas forças de Van der Waals, resultando numa amplitude vibracional maior e, portanto, uma maior variação na sobreposição das funções de onda, o que acarreta numa mobilidade bem menor para materiais orgânicos.

\subsection{Portadores tipo-p e tipo-n em semicondutores or- gânicos e mecanismo de transporte}

Em semicondutores orgânicos, o transporte dos portadores de carga é geralmente descrito pelo mecanismo de tunelamento via hopping [32, 33, 1], que significa saltos entre estados energéticos; sendo estudado pelos modelos utilizados em sistemas altamente desordenados. A densidade de estados desses sistemas geralmente é assimétrica e apresenta uma alta barreira energética para a formação de apenas um ou outro tipo de portador. Isto é, a maioria dos semicondutores orgânicos somente apresenta condutividade para cargas ou positivas ou negativas, não para as duas ao mesmo tempo. Em semicondutores cristalinos, como dito na introdução, os termos tipo-p e tipo-n se referem ao dopante e, portanto, aos portadores majoritários do material. Nos cristalinos, tanto cargas negativas como positivas podem ser transportadas. No entanto, sistemas eletrônicos desordenados somente suportam ou são fortemente favoráveis a apenas um único tipo de portador, sendo diferenciados como portadores positivos ou portadores negativos [34]. Apesar disso, é comum na literatura referir-se aos semicondutores orgânicos transportadores de cargas positivas também como sendo do tipo-p, e a recíproca tipo-n para elétrons devido ao fato de essa representação indicar o tipo dos portadores majoritários no semicondutor. 
Se tomarmos como exemplo o pentaceno, popular semicondutor orgânico, vemos que os átomos de hidrogênio ao redor da estrutura central formada pelos átomos de carbono são menos eletronegativos que a cadeia carbônica e, portanto, contribuem para o aumento da densidade eletrônica da nuvem de ligações PI delocalizadas. Assim, a molécula conjugada apresenta dificuldade em receber mais elétrons; mas, é capaz de perder alguns elétrons com certa facilidade. Como consequência, temos que as cargas positivas dominam o transporte em pentaceno.

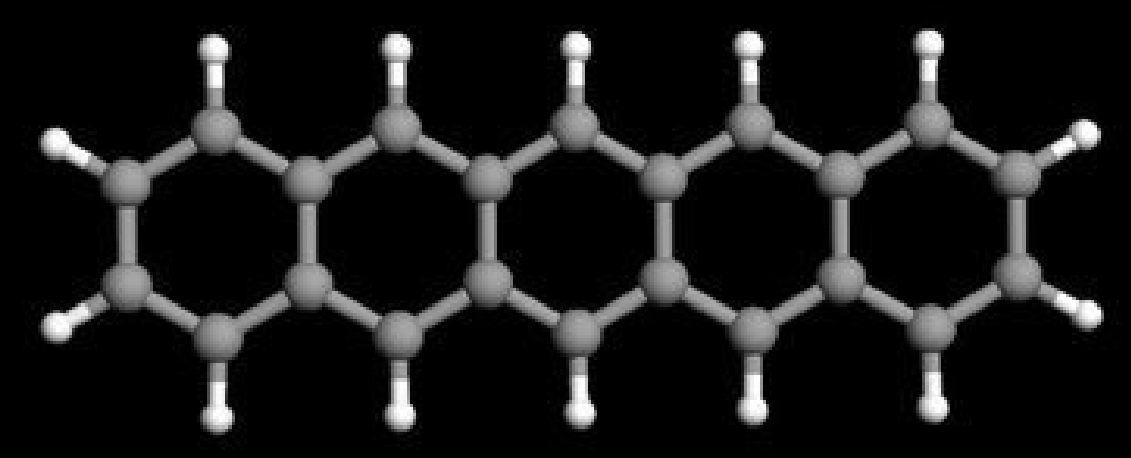

Figura 10: Modelo de átomos formando a estrutura da molécula de pentaceno. Crédito: International Business Machines Corporation - IBM Research, Zurich. 


\section{Transistor Orgânico de Efeito de Campo (OFET)}

\subsection{Estrutura Física Geral}

Um OFET (do inglês, Organic Field-Effect Transistor) consiste em uma camada semicondutora, uma camada dielétrica e mais quatro terminais: a porta $(\mathrm{G})$, a fonte (S), o coletor ou dreno (D) e o substrato ou corpo (B). Existem quatro configurações possíveis para os transistores orgânicos de efeito de campo, mostradas na figura 11.

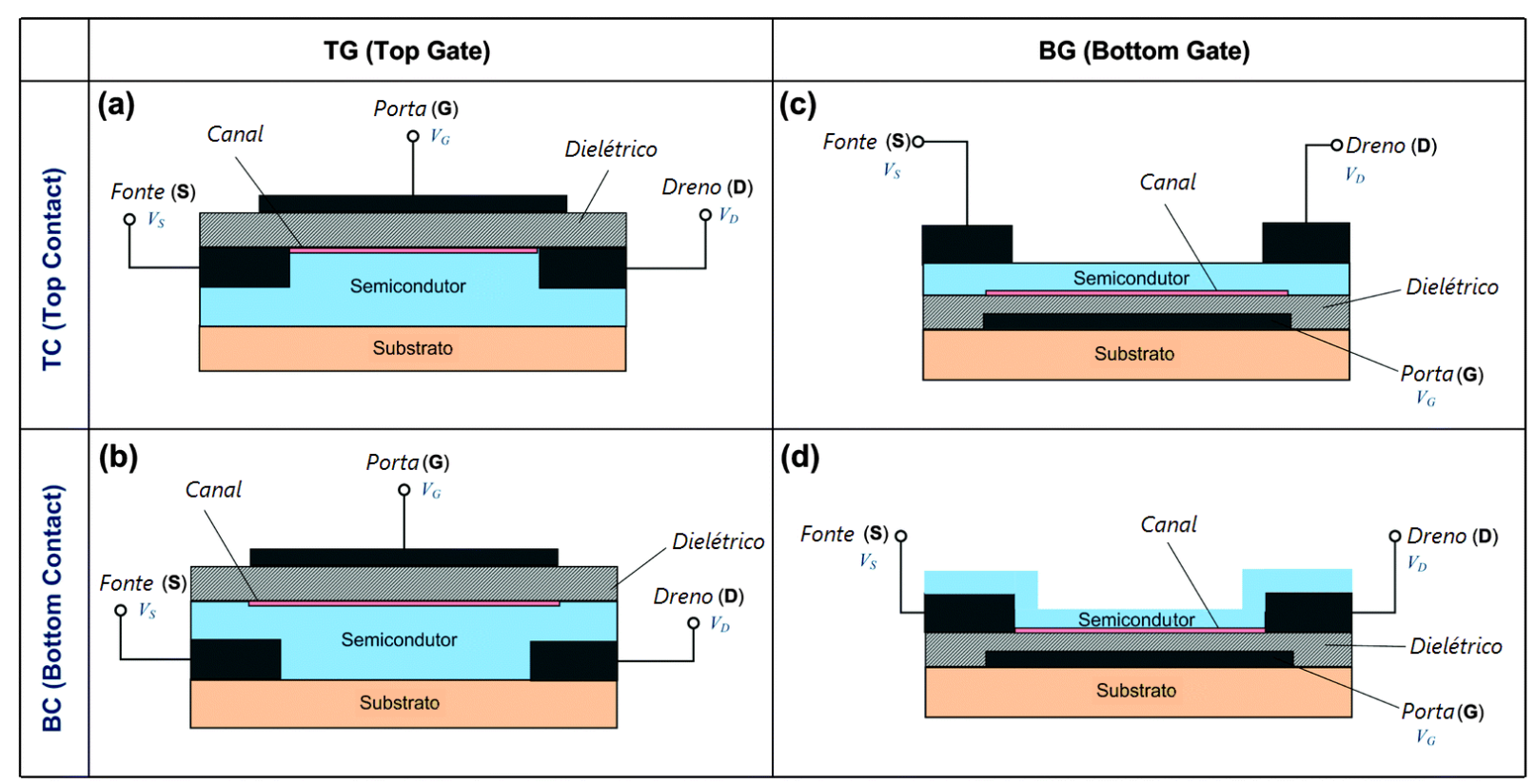

Figura 11: Arquétipos de OFET. Retirada da referência [5].

O substrato geralmente é considerado como não tendo efeito na operação do dispositivo, restando então apenas três terminais passíveis de controle: a porta, o dreno e a fonte. Uma voltagem é aplicada na porta. Um campo elétrico é então criado na direção vertical do transistor. É esse campo elétrico que controla a quantidade de cargas entre os terminais fonte e dreno e, portanto, determina a condutividade do material. Essa é a origem do nome "transistor de efeito de campo" (FET, em inglês, Field-Effect Transistor). A voltagem na porta controla também o fluxo de cargas positivas entre a fonte e o 
dreno. Essa corrente flui em direção longitudinal fonte-dreno, criando uma região denominada "canal". Essa região tem um comprimento L (length) e uma largura W (width), dois parâmetros importantes para a caracterização do dispositivo. Os terminais fonte e dreno estão conectados ao semicondutor, enquanto a porta está isolada do semicondutor pela camada dielétrica. Voltagem é aplicada apenas na porta (Vg) e no dreno (Vd), enquanto a fonte permanece aterrada $(\mathrm{Vs}=0 \mathrm{~V})$. A corrente $(\mathrm{Id})$ entre a fonte e o dreno depende tanto da variação de voltagem da porta quanto no próprio dreno; assim, dois regimes de operação podem ser realizados. Em transistores inorgânicos, duas regiões altamente dopadas com impurezas tipo-n ou tipo-p criam os terminais fonte e dreno; e contatos metálicos são colocados sobre essas regiões. No entanto, em transistores orgânicos é mais comum utilizar-se do próprio metal (por exemplo, ouro) para criar tais regiões. Uma fina camada isolante (de espessura "tox") é depositada sobre o substrato ou sobre o semicondutor, dependendo da arquitetura do OFET. Outros contatos metálicos são feitos à porta e ao substrato. Quando uma voltagem negativa é aplicada na porta, cargas positivas se acumulam na interface semicondutor-isolante criando o canal que permite o fluxo dessas cargas. Porém, quando uma voltagem positiva é aplicada na porta, ocorre a depleção das cargas positivas, 'desligando' o transistor orgânico. A transição entre os estados de operação On/Off do dispositivo pode ser vista na curva de transferência, Figura 12 (a), explicada mais adiante.

A voltagem à porta, na qual o transistor muda do estado de depleção de cargas positivas para o acúmulo das mesmas é chamada de Voltagem de Limiar $\left(\mathrm{V}_{L}\right)$. Quando uma voltagem negativa é aplicada no dreno após a porta ter ultrapassado a Voltagem de Limiar, temos o fluxo de cargas positivas da fonte ao dreno. Quando a voltagem no dreno é muito menor que a voltagem na porta, a corrente depende linearmente dessas duas voltagens. A corrente satura quando a voltagem no dreno é maior que a voltagem efetiva. O regime linear e de saturação podem ser vistos nas curvas de saída, Figura 12 
(b).
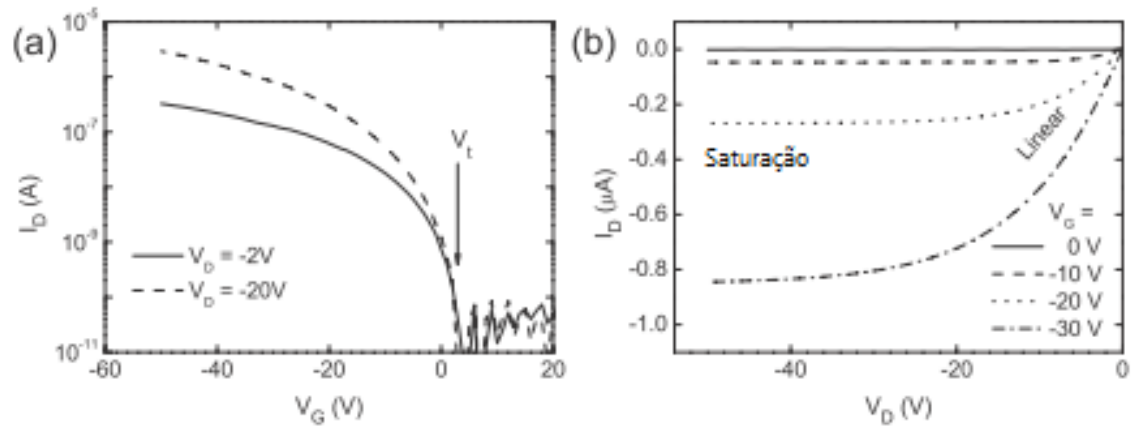

Figura 12: Curvas características de Corrente x Voltagem em OFETs. a) Curva de Transferência, mostrando a Voltagem de Limiar (limiar entre os estados desligado e ligado do dispositivo). b) Curva de Saída, mostrando a diferença entre os regimes (ou regiões) linear e de saturação. Retirada da referência [6].

A corrente em ambos os regimes é geralmente analisada usando as equações analíticas aplicadas para dispositivos metal-óxido-semicondutor. Essas equações são derivadas usando o que a literatura chama de Aproximação de Canal Gradual (GCA) [9, 35], a qual assume que o campo elétrico perpendicular à corrente, induzido pela voltagem na porta, é muito maior que o campo elétrico entre fonte e dreno[36].

\subsection{Sobre o Transistor estudado}

\subsubsection{Características físicas}

O transistor orgânico estudado funciona em modo de acumulação e transporte de cargas positivas. O dispositivo foi fabricado em um substrato de cristal único de silício, que fornece suporte físico para o transistor (e para um circuito inteiro caso tivesse sido montado em estrutura de circuito integrado). O material orgânico semicondutor foi o pentaceno, abordado na próxima subseção. O material dielétrico foi o dióxido de silício, cuja permissividade é de 3.9 e capacidade dielétrica é $10^{7} \mathrm{~V} / \mathrm{cm}[15]$. A estrutura do 
dispositivo é do tipo Bottom-Contact. A espessura do dielétrico é de $100 \mathrm{~nm}$. O comprimento L do canal é de 20 um e a largura W do canal é de 2000 um. As medidas foram realizadas com o aparelho "Keithley 2400 Source Meter" da Keithley. Os dados obtidos pelas medições foram cedidos cortesmente pelo professor Leszek Majewski, integrante do Centro de Inovação em Materiais Orgânicos da Faculdade de Engenharia Elétrica e Eletrônica da Universidade de Manchester, Inglaterra.

\subsubsection{Semicondutores de moléculas pequenas - Pentaceno}

Assim como em materiais orgânicos poliméricos, a variedade de materiais feitos a partir de moléculas pequenas é riquíssima. Moléculas pequenas são leves e podem ser purificadas e depositadas por meio de processos de evaporação térmica. Muitos semicondutores orgânicos baseados em moléculas pequenas já foram transformados em solúveis e podem ser depositados por meio de processos de solução. Tais materiais formam filmes policristalinos quando depositados em temperatura próxima à temperatura ambiente [37]. Essa melhor ordem estrutural, que pode ter melhor sobreposição de ligações pi delocalizadas entre moléculas vizinhas, melhora a condutividade e a performance do transistor orgânico.

Tetraceno e pentaceno são particularmente interessantes para aplicação em OFETs. Ambos se organizam de modo policristalino e têm boas propriedades condutoras quando depositados em substratos isolantes, além de poder formar cristais em certas condições. Pentaceno, com certeza, é o mais famoso semicondutor orgânico para fabricação de OFETs. Contudo, ele não é ideal. O pentaceno é facilmente oxidado em algumas posições, o que prejudica o transporte e cristalização em alguns dispositivos. Além disso, o pentaceno pode se condensar em duas fases cristalinas diferentes [38], que são muito parecidas, porém não iguais. Isto pode acarretar em crescimento polimórfico, gerando grãos descontínuos e, assim, diminuindo o desempenho do transistor [39]. 


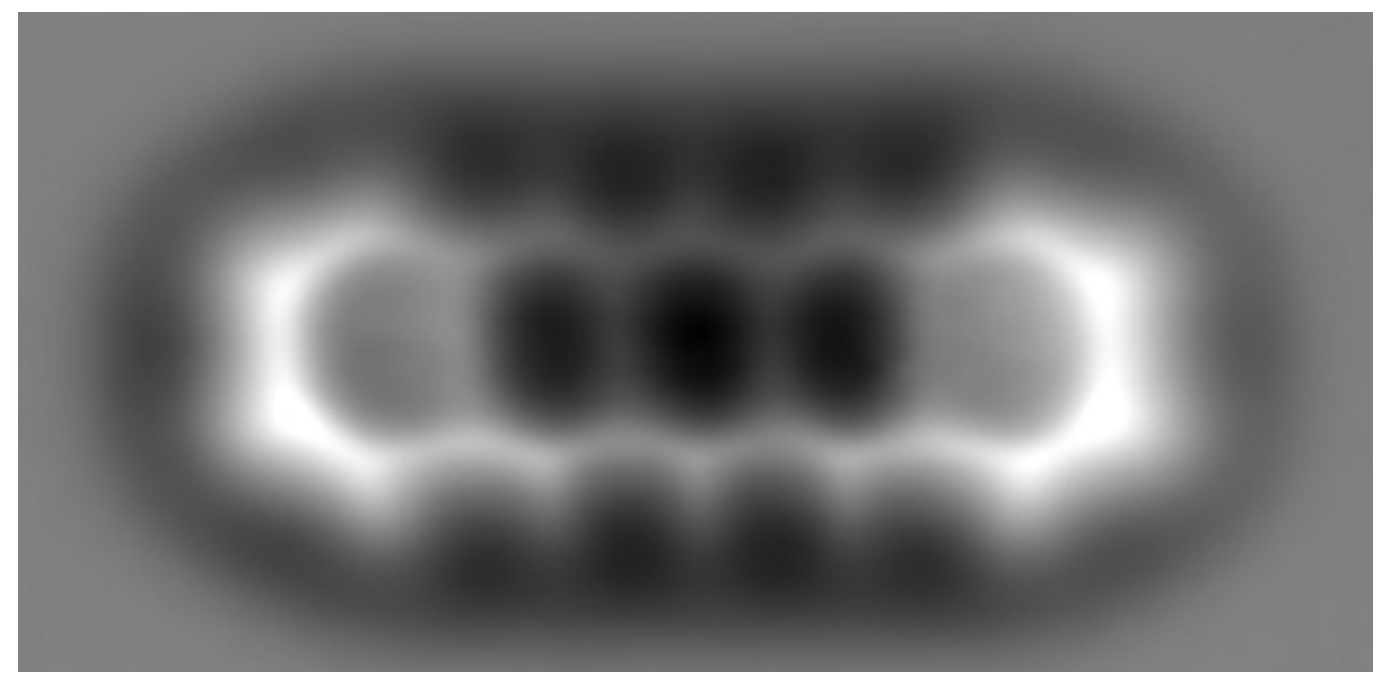

Figura 13: Foto de uma molécula real de pentaceno. Imagem captada por meio de microscopia de força atômica. Retirada da referência [7].

\subsection{Parâmetros de operação de um OFET}

\subsubsection{Mobilidade $(\mu)$}

Mobilidade é a relação entre a velocidade dos portadores em um material e a força aplicada pelo campo elétrico. Microscopicamente, portadores aceleram devido à força do campo elétrico e se difundem, experimentando um fenômeno de transferência de momento. Isso ocorre rapidamente entre um grande número de portadores, sendo a mobilidade do material considerada como a média da mobilidade dos portadores. Macroscopicamente, a velocidade seria apenas um processo de fluxo em materiais sólidos. A velocidade é constante para certo valor de campo elétrico e depende linearmente dele. A mobilidade, então, é definida como:

$$
\mu=\frac{\text { velocidade }}{E}
$$

Como consequência, as unidades mais utilizadas da mobilidade são em $\mathrm{cm}^{2} / V s$.

Em semicondutores cristalinos, a relação entre velocidade e campo elétrico é não 
linear para campos elétricos muito fortes. Além desse fator, temos que a mobilidade, inclusive em semicondutores orgânicos, é dependente da concentração de portadores. Isso torna a interpretação da mobilidade em OFET um tanto quanto mais complicada do que um simples ajuste a um modelo linear. É possível medir a mobilidade de portadores diretamente no regime linear de operação [5]. Essa é uma alternativa à extração de mobilidade pelo método de ajuste. Esse método, porém, tem suas limitações. Também só se mostra eficaz quando no regime linear, onde a densidade dos portadores é aproximadamente constante ao longo do canal, por exemplo, quando a voltagem no dreno $(V d)$ é pequena. Como a carga é conservada no canal, ocorre que a corrente do canal vale:

$$
I d=\frac{Q(x)}{x} E(x) \mu(x)
$$

onde $x$ é a posição do portador com relação à direção do fluxo, $E$ é o campo elétrico entre fonte e dreno, e $I d$ é a corrente no canal - constante em relação a $x$ devido à conservação de cargas. Para pequenos valores de $V d, Q(x)$ é aproximadamente constante porque o campo elétrico porta-fonte e porta-dreno são similares. A velocidade $E(x) \mu(x)$ dos portadores é, portanto, constante também. Quando as voltagens aplicadas aumentam e o dispositivo começa a entrar no modo de saturação, $Q(x)$ aumenta a dependência com relação a $x$, assim, a velocidade $E(x) \mu(x)$ dos portadores não é mais constante ao longo do comprimento total do canal; tornando esse modelo inválido. 


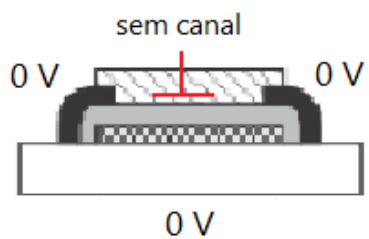

a)

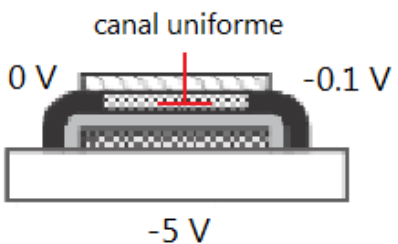

b)

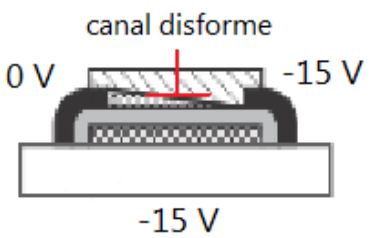

c)

Figura 14: Variação do Canal em OFET. A) representa o transistor com cargas depletadas, sem formação do canal entre fonte e dreno. B) representa o transistor operando no regime linear, com canal formado e uniforme. C) representa o canal disforme, quando o transistor está operando no regime de saturação. Retirada da referência [8].

\subsubsection{Voltagem de Limiar}

Em se tratando de OFET, não há uma definição completamente aceita para o que seria a voltagem de limiar [40] como ela existe para transistores inorgânicos. A conceituação mais aceita é a que já foi predita. Em semicondutores inorgânicos, uma voltagem aplicada à porta causaria depleção de cargas de um sinal, e formaria um canal condutor com cargas de sinal contrário, sendo esse processo chamado de Inversão [15]. No entanto, semicondutores orgânicos não alcançam a inversão por motivos já discutidos; estritamente falando, o que acontece é apenas o alcance de uma voltagem na qual o dispositivo começa a funcionar. Apesar disso, o termo Voltagem de Limiar $\left(V_{L}\right)$ ou Threshold Voltage $\left(V_{T}\right)$, em inglês, é utilizado na eletrônica orgânica para especificar a voltagem aplicada à porta na qual a corrente começa a fluir entre os terminais fonte e dreno; o que acontece no patamar de inversão para transistores inorgânicos e no patamar de acumulação para transistores orgânicos.

Um dos métodos de extração do valor dessa voltagem é realizar uma extrapolação da curva $\sqrt{I d} \times V g$ até a interceptação no eixo $\mathrm{x}(V g)$. Em uma primeira abordagem, isso indica a voltagem na qual há aumento na corrente e o dispositivo alterna de um estado inativo para um estado de condução de cargas. Esse é um método simples de se 
implementar e fornece uma definição de voltagem de limiar que é razoável do ponto de vista de fluxo de cargas - quando a corrente começa a fluir, $V g$ é maior do que $V_{L}$.

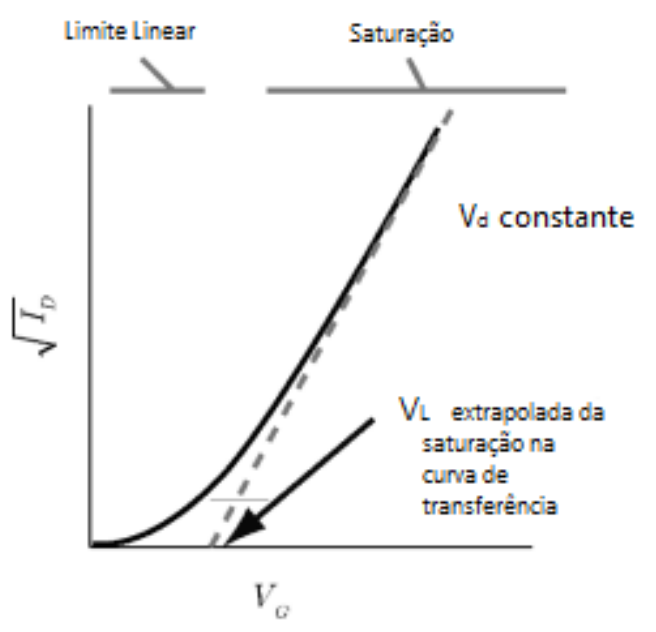

Figura 15: Extrapolação da Voltagem de Limiar feita na curva de transferência. Retirada da referência [5].

Existem algumas limitações para esse método:

- A diferenciação dos regimes linear e de saturação não ocorre tão abruptamente quanto nos materiais cristalinos inorgânicos. Corrente pode fluir mesmo no regime linear.

- A parte linear da curva pode não se comportar tão linearmente como é esperado que ocorra; ocasionando ambiguidade no resultado.

- A extrapolação não tem sentido físico muito bem definido. Além de poder existir uma extrapolação para uma região onde o modelo não se aplica. 


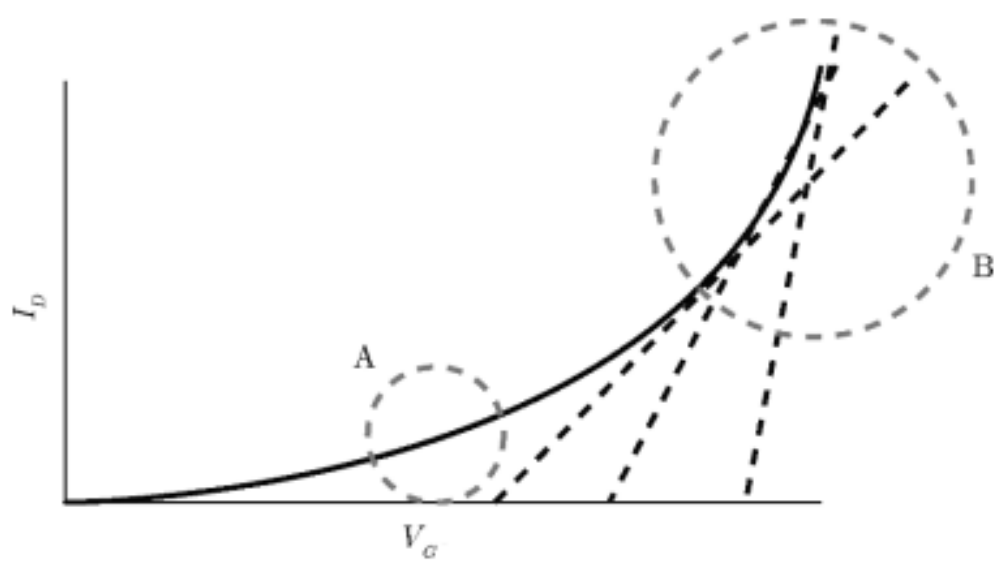

Figura 16: Limitações da obtenção da Voltagem de Limiar por extrapolação da curva de transferência. A região A mostra que já existe corrente significativa antes da $\mathrm{V}_{L}$ ser alcançada. A região $\mathrm{B}$ mostra um aumento não-linear abrupto, causando erros para se definir o local de extrapolação. Retirada da referência [5].

\subsection{Caracterização de um OFET}

A caracterização e modelagem de OFET são essenciais para a compreensão do seu comportamento e uso práticos em dispositivos e circuitos eletroeletrônicos. A extensa pesquisa que já vem sendo feita em transistores inorgânicos é um ótimo ponto de partida, porém um obstáculo para criação de modelos mais precisos. Enquanto o comportamento macroscópico é parecido, os mecanismos de transporte são muito distintos. Observações experimentais e considerações teóricas tem permitido aumentarmos o entendimento acerca do funcionamento de OFETs e sobre como caracterizá-los.

As características principais requeridas da análise de um OFET são a mobilidade, a Voltagem de Limiar, e a razão On/Off do transistor. Além disso, é necessário fornecer os valores de W, L, e demais dados para o cálculo da capacitância. Outras informações do ambiente também são importantes, tais como a umidade relativa e a temperatura. Esse padrão (1620-2008 - IEEE Standard for Test Methods for the Characterization of Organic Transistors and Materials) foi criado pela organização internacional IEEE - 
Instituto de Engenheiros Eletricistas e Eletrônicos, sediada nos EUA.

\subsubsection{Curva de transferência}

Essa curva é obtida mantendo-se um valor de voltagem $(V d)$ constante no dreno e alterando o valor de voltagem $(V g)$ aplicado na porta. Ao menos uma medição com uma voltagem no dreno deve ser feita para testar o transistor no regime linear e outra no regime de saturação. Para transistores de pentaceno, que são desenvolvidos para operar em $20 \mathrm{~V}$, essas curvas podem ser obtidas com $V d=-0.1 \mathrm{~V}$ para o regime linear e -20V para o regime de saturação. Enquanto isso, a voltagem na porta pode ser variada de 0 a -20V ou mais. A região linear é plotada em termos de $I d \times V g$. A região de saturação é plotada em termos de $\sqrt{I d} \times V g$ ou em uma curva linear. A extrapolação da voltagem de limiar também pode ser plotada em conjunto nesses gráficos. A região linear deve ser medida com os menores valores de $V d$ possíveis. Como já dito, é somente para pequenos valores de $V d$ que o campo elétrico e a densidade de cargas no canal são uniformes e a medição da mobilidade é válida. Além disso, a mobilidade varia significativamente com os valores de $V g$. Assim, ela deve ser obtida individualmente para cada valor de $V g$. Figura 12 (a).

\subsubsection{Curva de saída}

Essa curva é obtida mantendo-se um valor de voltagem ( Vg) constante na porta e variando a voltagem (Vd) no dreno. Para um transistor de pentaceno, a voltagem na porta pode ser mantida constante em valores como $-\{0 \mathrm{~V}, 4 \mathrm{~V}, 8 \mathrm{~V}, 12 \mathrm{~V}, 16 \mathrm{~V}$ e $20 \mathrm{~V}\}$, enquanto a voltagem no dreno transcorre de 0 a -20V. A condutância também pode ser

obtida a partir desse gráfico. A característica da curva de saída é apresentada como uma prova qualitativa de que um transistor foi formado. Figura 12 (b). 


\section{Modelos de Transporte Eletrônico em OFET}

\subsection{Aproximação de Canal Gradual}

\subsubsection{Obtenção da corrente elétrica em função das voltagens e dimensões do transistor}

Essa subseção tem por objetivo calcular a corrente $I$ que vai do dreno à fonte pelo canal. A corrente elétrica, por definição, é a variação de carga em uma seção reta para um intervalo de tempo. Porém, considera-se que o canal é, de fato, um espaço plano, e não volumétrico, de modo que as cargas se locomovem apenas na interface semicondutor-isolante. Assim, a corrente elétrica no canal será

$$
I=\frac{d Q}{d t}
$$

onde $d Q$ é a variação de carga no canal no intervalo de tempo $d t$. Para calcular esta variação utilizaremos a função densidade superficial de cargas na interface semicondutorisolante, $\sigma(x, y)$. Assim, a quantidade de cargas na interface semicondutor-isolante, $Q_{i s i}$, vale

$$
Q_{i s i}=\int_{0}^{L} \int_{0}^{L_{y}} \sigma(x, y) d y d x=L_{y} \int_{0}^{L} \sigma(x) d x
$$

na qual $L$ é o comprimento do canal, $L_{y}$ é a largura do canal. Na resolução acima, como a densidade de carga não depende da variável y, ou seja, há isotropia do sistema no eixo y, a densidade $\sigma(x, y)$ será expressa como $\sigma(x)$. A densidade de cargas no canal não é uniforme ao longo do eixo x, já que o maior valor de densidade localiza-se próxima da fonte. 


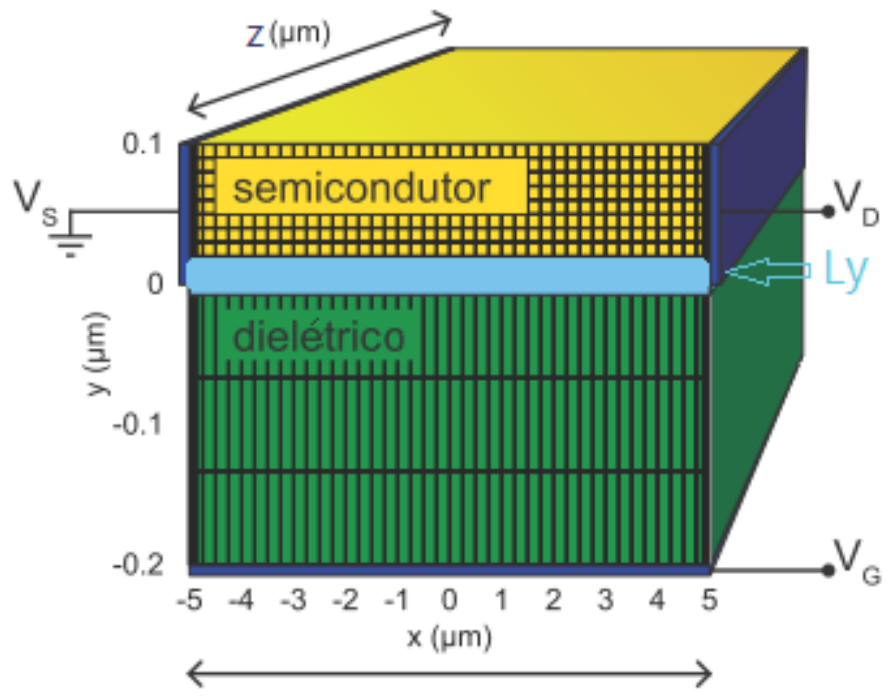

Figura 17: Dimensões de um OFET de arquitetura Bottom-Gate Top-Contacts. O eixo X representa $\mathrm{L}$, o comprimento do canal e do transistor como um todo. O eixo $\mathrm{Y}$ é a espessura do transistor, sendo que Ly é a espessura apenas do canal. $\mathrm{O}$ eixo $\mathrm{Z}$ é a largura do transistor e, consequentemente, do próprio canal também. Retirada da referência [9].

O tempo necessário para as cargas atravessarem o comprimento do canal, ou seja, do dreno até a fonte, é obtido por $\Delta t=\frac{L}{V_{d}}$, sendo $V_{d}$ a velocidade de deriva dos elétrons. Essa velocidade é relacionada com a mobilidade dos elétrons, $\mu$, pela definição: $V_{d}=\mu E$, onde E é o campo elétrico. Assim, podemos reescrever o tempo como sendo

$$
\Delta t=\frac{L}{\mu E}
$$

Considera-se que, no tempo necessário para os elétrons se deslocarem em todo o comprimento do canal, equação 5.3, a quantidade de cargas $Q_{i s i}$ da superfície, equação 5.2, chegará até a fonte. Assim, substituindo as equações 5.2 e 5.3 na equação 5.1, temos que a corrente elétrica será dada por

$$
I=L_{y} \frac{\mu E}{L} \int_{0}^{L} \sigma(x) d x
$$


Neste modelo, há algumas considerações:

1) o campo elétrico entre a fonte e o dreno é paralelo e constante em todo o canal,

2) A mobilidade também é constante em todo o canal.

O próximo passo é calcularmos a densidade de cargas, $\sigma(x)$. Para isso utiliza-se a definição de capacitância, pois a estrutura metal-óxido-semicondutor forma exatamente um capacitor. A capacitância $C$ é definida por $C=\frac{\Delta Q}{\Delta V}$, onde $\Delta V$ é a variação de potencial elétrico entre as duas superfícies do capacitor. Como a voltagem no canal depende da posição x, é mais útil trabalhar com a capacitância por unidade de área, $C_{\Delta S}(x)$. Assim, de acordo com a definição, tem-se que a capacitância na área $L_{y} d x$ será

$$
C(x)=\frac{\sigma(x) L_{y} d x}{\Delta V(x)}
$$

Logo, a densidade de capacitância, isto é, a capacitância por unidade de área do isolante será obtida dividindo a capacitância pela área $L_{y} d x$ :

$$
C_{\Delta S}(x)=\frac{\sigma(x)}{\Delta V(x)}
$$

Como visto anteriormente, o potencial aplicado à porta para formar um canal efetivo deve exceder a voltagem de limiar $V_{L}$. Esse potencial consiste na voltagem efetiva $V_{e f}$, ou seja, $V_{e f}=V_{g}-V_{L}$, e consiste no valor do potencial elétrico que atuará na porta. Assim, a voltagem no capacitor será $\Delta V(x)=V(x)-V_{e f}$, de modo que a equação 5.6, torna-se

$$
C_{\Delta S}=\frac{\sigma(x)}{V(x)-V_{e f}}
$$

A densidade de cargas será, então

$$
\sigma(x)=C_{\Delta S}\left[V(x)-\left(V_{g}-V_{L}\right)\right]
$$


Substituindo a equação 5.8 na equação 5.4, e rearranjando-a, a corrente elétrica no canal será

$$
I=\mu E C_{\Delta S} \frac{L_{y}}{L} \int_{0}^{L}\left[V(x)-V_{e f}\right] d x
$$

O campo elétrico definido para um sistema unidimensional é $E=-\frac{d V}{d x}$. Considerando-o como sendo uniforme ao longo do canal e sabendo que o potencial diminui da fonte para o dreno, temos

$$
E=-\frac{\Delta V}{\Delta x}
$$

e o campo elétrico será

$$
E=-\frac{\left(V_{d}-V_{S}\right)}{L}
$$

onde $V_{d}$ é a voltagem no dreno e $V_{S}$ é a voltagem na fonte (source). Ao considerar que o campo elétrico é uniforme, é possível também obter o potencial para qualquer posição $x$. Para isso utiliza-se a equação 5.10, de modo que $E=-\frac{\Delta V}{\Delta x}=-\frac{\left(V(x)-V_{s}\right)}{x-0} \mathrm{e}$ usando a equação 5.11, obtem-se

$$
V(x)=\frac{\left(V_{d}-V_{S}\right)}{L} x+V_{S}
$$

Assim, $\mathrm{V}(\mathrm{x})$ varia linearmente com relação a $\mathrm{x}$.

Na continuação do modelo, consideraremos um transistor no qual a voltagem da fonte seja mantida em zero, $V_{S}=0$. Assim, substituindo as equações 5.11 e 5.12 na equação 5.9, temos que a corrente elétrica será:

$$
I=-\mu \frac{V_{d}}{L} C_{\Delta S} \frac{L_{y}}{L} \int_{0}^{L}\left(\frac{V_{d}}{L} x-V_{e f}\right) d x
$$


Resolvendo a integral: $I=-\left.\mu \frac{V_{d}}{L} C_{\Delta S} \frac{L_{y}}{L}\left(\frac{V_{d}}{L} \frac{x^{2}}{2}-V_{e f} x\right)\right|_{0} ^{L}$, o resultado será:

$$
\begin{aligned}
I & =\mu C_{\Delta S} \frac{L_{y}}{L}\left(-\frac{V_{d}^{2}}{2}+V_{e f} V_{d}\right) \quad \text { ou } \\
& =\mu C_{\Delta S} \frac{L_{y}}{L}\left[-\frac{V_{d}^{2}}{2}+\left(V_{g}-V_{t}\right) V_{d}\right]
\end{aligned}
$$

Assim, obtivemos a equação que fornece a corrente elétrica no canal do transistor para este modelo.

\subsubsection{Obtenção da corrente em regimes lineares: $V_{d} \ll V_{e f}$}

Quando os valores da voltagem no dreno são muito menores do que a voltagem efetiva, $V_{d} \ll V_{e f}$, de acordo com a equação 5.15 , o termo $-\frac{V_{d}^{2}}{2}$ pode ser desprezado e a corrente será

$$
\begin{aligned}
I & =\left[\mu C_{\Delta S} \frac{L_{y}}{L} V_{e f}\right] V_{d} \quad \text { ou } \\
& =\left[\mu C_{\Delta S} \frac{L_{y}}{L}\left(V_{g}-V_{L}\right)\right] V_{d} .
\end{aligned}
$$

Ou seja, a curva de saída do transistor se comporta linearmente. Esta equação da corrente no regime linear é muito útil para se obter diversas informações do modelo, entre elas a mobilidade. Perceba que mantendo $V_{g}$ constante, ocorre que a corrente varia linearmente com a voltagem do dreno, indicando o comportamento segundo a Lei de Ohm. Neste sentido, como a condutância por definição vale $g=\frac{d I}{d V}$, tem-se que a 
condutância $g_{c}$ do canal pode ser encontrada calculando-se a inclinação da curva de saída $\left(I_{d} \times V_{d}\right)$. Assim,

$$
g_{c}=\frac{d I}{d V_{d r}}=\mu C_{\Delta S} \frac{L_{y}}{L} V_{e f}
$$

De posse de $g_{c}$ obtida por um processo de linearização no gráfico $I_{d} \mathrm{x} V_{d}$, a mobilidade das cargas no canal durante o comportamento linear será

$$
\mu=\frac{g_{c} L}{L_{y} C_{\Delta S} V_{e f}}
$$

A mobilidade pode ser obtida também a partir da curva de transferência, $I_{d} \mathrm{x} V_{g}$. Neste sentido, a transcondutância $g_{t}$ do canal pode ser encontrada calculando-se a inclinação da curva de transferência $I_{d} \times V_{g}$. Tem-se que $g_{t}=\frac{d I}{d V_{g}}=\left[\mu C_{\Delta S} \frac{L_{y}}{L}\right] V_{d}$ e, portanto, a mobilidade será

$$
\mu=\frac{g_{m} L}{L_{y} C_{\Delta S} V_{d}}
$$

\subsubsection{Obtenção da corrente na região de saturação: $V_{d} \geq V_{e f}$}

Para valores de voltagem no dreno maiores que a voltagem efetiva, $V_{d}>V_{e f}$, não se observa variações significativas na corrente elétrica no canal e nem em sua densidade de cargas, ou seja, a corrente satura. Isto ocorre aproximadamente quando $V_{d}=V_{e f}$. Assim, substituindo $V_{d}=V_{e f}$ na equação 5.15 , temos que

$$
I_{s a t}=\mu C_{\Delta S} \frac{L_{y}}{L} \frac{V_{d}^{2}}{2}
$$


$\mathrm{Ou}$

$$
\sqrt{I_{\text {sat }}}=\sqrt{\frac{\mu C_{\Delta S} L_{y}}{2 L} V_{d}}
$$

Fazendo $V_{d}=V_{e f}$ e, portanto, $V_{d}=V_{g}-V_{L}$, a equação acima também pode ser escrita como

$$
\sqrt{I_{\text {sat }}}=\sqrt{\frac{\mu C_{\Delta S} L_{y}}{2 L}}\left(V_{g}-V_{L}\right)
$$

A transcondutância $g_{t}$ do canal no regime de saturação pode ser obtida calculando-se a inclinação da curva de transferência $\sqrt{I_{s a t}} \times V_{g}$, resultando em

$$
g_{t}=\sqrt{\frac{\mu C_{\Delta S} L_{y}}{2 L}}
$$

Assim, a mobilidade das cargas durante o regime de saturação será

$$
\mu=\frac{g_{t}^{2} 2 L}{C_{\Delta S} L_{y}}
$$

\subsection{Análise dos dados}

A caracterização do transistor estudado se deu por meio dos dados colhidos pelo professor Leszek Majewski, no Centro de Inovação em Materiais Orgânicos da Faculdade de Engenharia Elétrica e Eletrônica da Universidade de Manchester, Inglaterra, e das equações do modelo de Aproximação de Canal Gradual, isto tanto para o regime linear quanto para o regime de saturação. Em nossas análises, utilizamos o software de licença livre gnuplot. Por meio do comando "fit", que usa o método dos mínimos quadrados, ajustamos as curvas utilizando apenas 3 ou 4 pontos dos dados obtidos para os dois 
regimes de operação do transistor.

\subsubsection{Voltagem de limiar e razão on/off}

A primeira abordagem tentou obter o valor da voltagem de limiar pela curva de transferência segundo o método proposto na figura 15, o qual propõe a extrapolação da curva $\sqrt{I_{d}} \times V_{g}$ até o ponto de interceptação no eixo $x$. Pelos testes colhidos, uma curva de transferência foi obtida, com voltagem constante no dreno igual a -30V. A curva de transferência mostrou-se do seguinte modo:

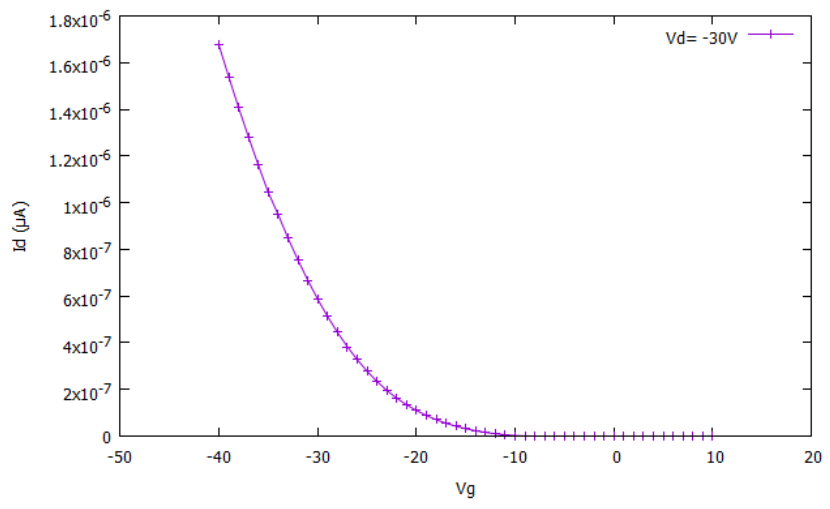

Figura 18: Curva de transferência. Vd $=-30$ V.

A variação de voltagem na porta ocorreu de $10 \mathrm{~V}$ a -40V. A parte positiva é interessante de ser aplicada porque demonstra se há portadores negativos no material. Como já discutido, o esperado é que em pentaceno apenas portadores positivos tenham efeito na condutividade do material, o que foi confirmado nos testes e ilustrado no gráfico de transferência. O passo seguinte foi a obtenção da raiz dos valores de voltagem para discriminar a voltagem de limiar. 


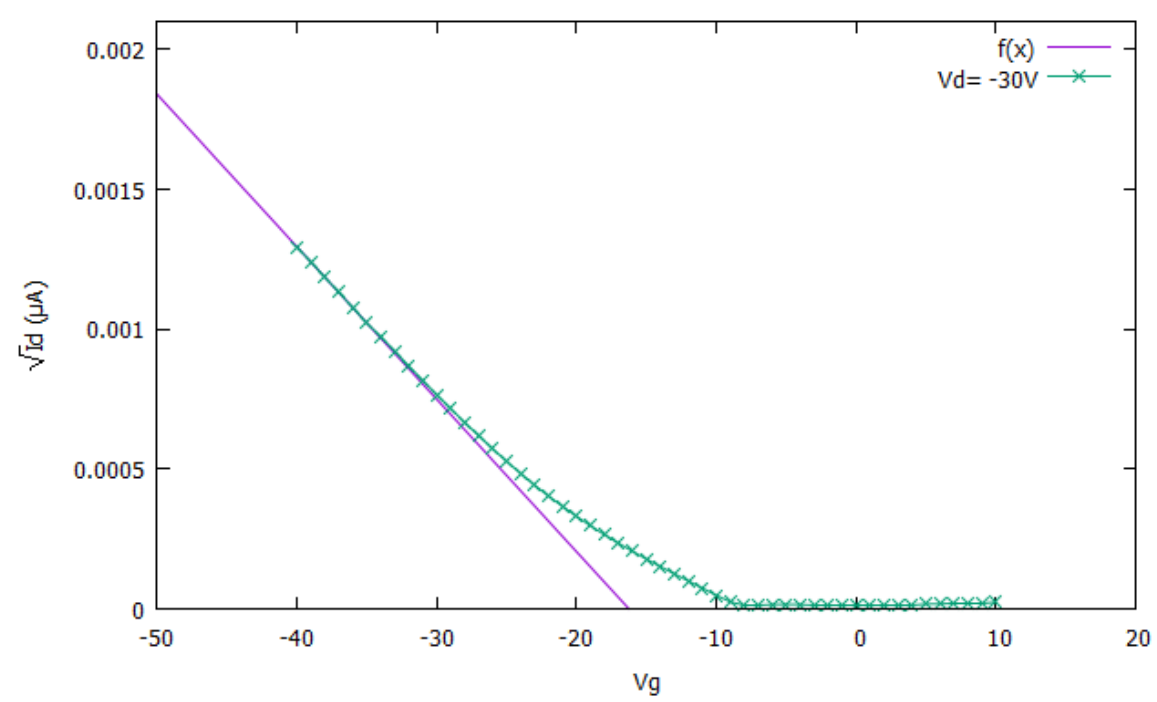

Figura 19: Curva $\sqrt{ } \operatorname{Id} x$ Vg linearizada no regime de saturação.

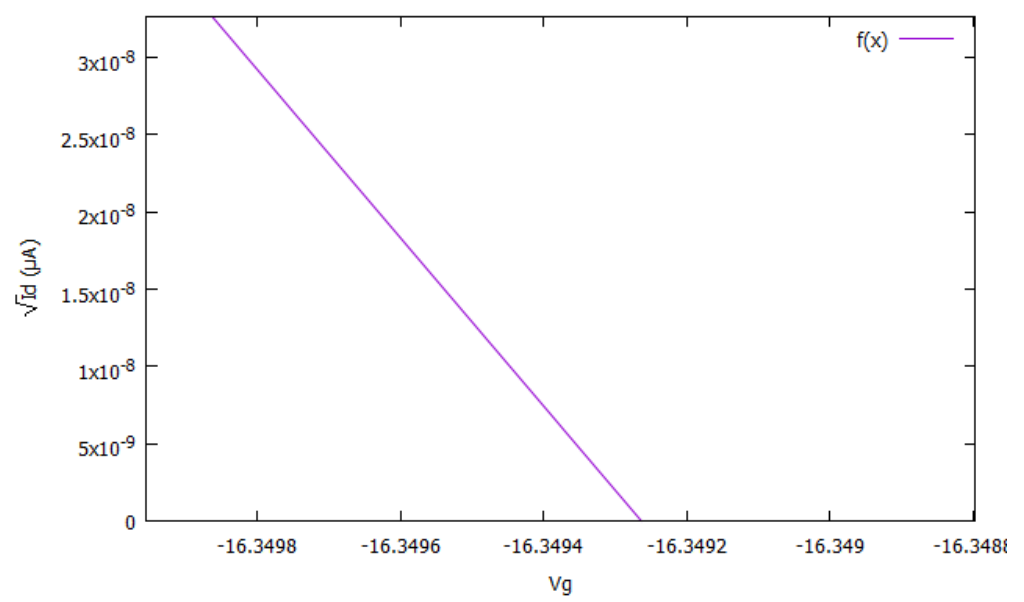

Figura 20: Ponto de interceptação ao eixo x.

Por meio desse método, verificou-se a voltagem de limiar como sendo de aproximadamente $-16,3 \pm 0,1 \mathrm{~V}$. No entanto, para obter esta informação é necessário considerar o problema inerente ao método de escolher a região para realizar a extrapolação da reta, assunto discutido na seção 4.3.2 e ilustrada na figura 16. Como será visto adiante, esse valor correspondeu ao início do regime de saturação, e não ao fim do regime linear de operação do transistor. A extrapolação foi realizada com $V_{g}$ entre $-35 \mathrm{~V}$ e $-41 \mathrm{~V}$. 
Outro método proposto para se obter a voltagem de limiar foi, por meio das curvas de saída, extrapolá-las na região de saturação até o ponto no qual intercepta-se o eixo y, obtendo, assim, um valor de corrente elétrica para cada uma das diferentes voltagens aplicadas na porta. Um exemplo é visto a seguir:

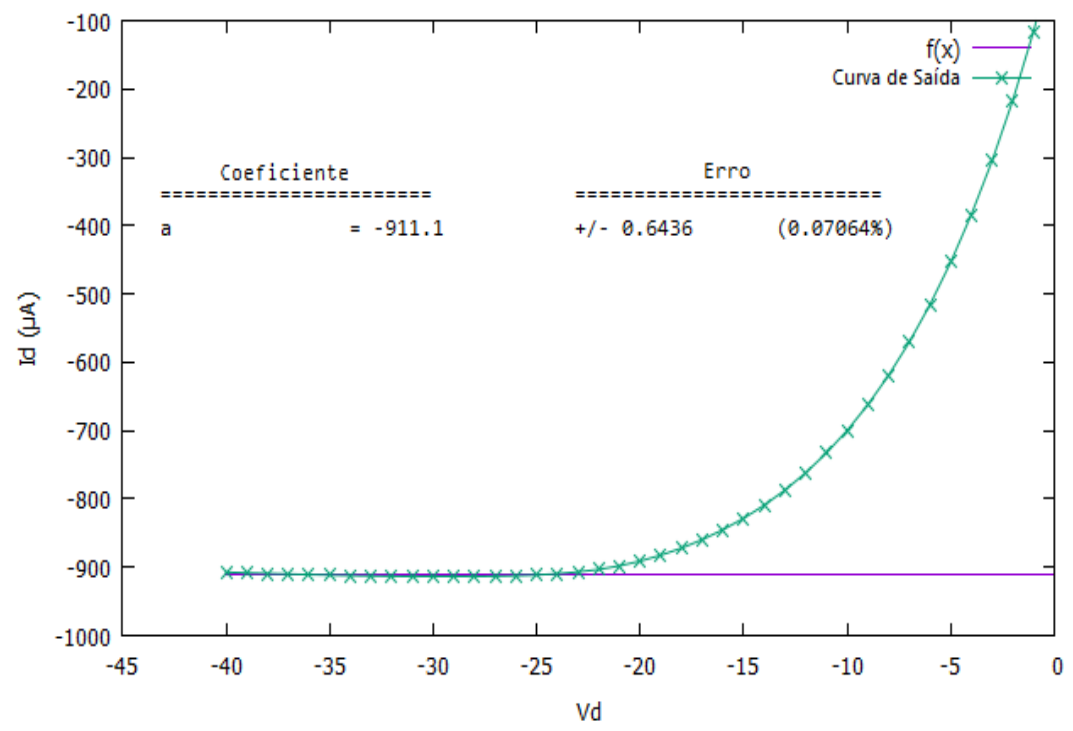

Figura 21: Extrapolação da curva de saída no regime de saturação. Corrente elétrica de $-911,1 \mu A$.

A ideia é obter esses valores de corrente elétrica durante o regime de saturação para, por meio deles, aplicar-se a resolução da equação 5.23 e obter a voltagem de limiar. Isso foi feito para toda a família de curvas de saída, variando a voltagem no dreno Vd para os seguintes valores fixos de voltagem na porta - Vg $\{10,15,20,25,30$, $35,40$ e $45 \mathrm{~V}\}$.

A família de curvas se mostrou da seguinte maneira: 


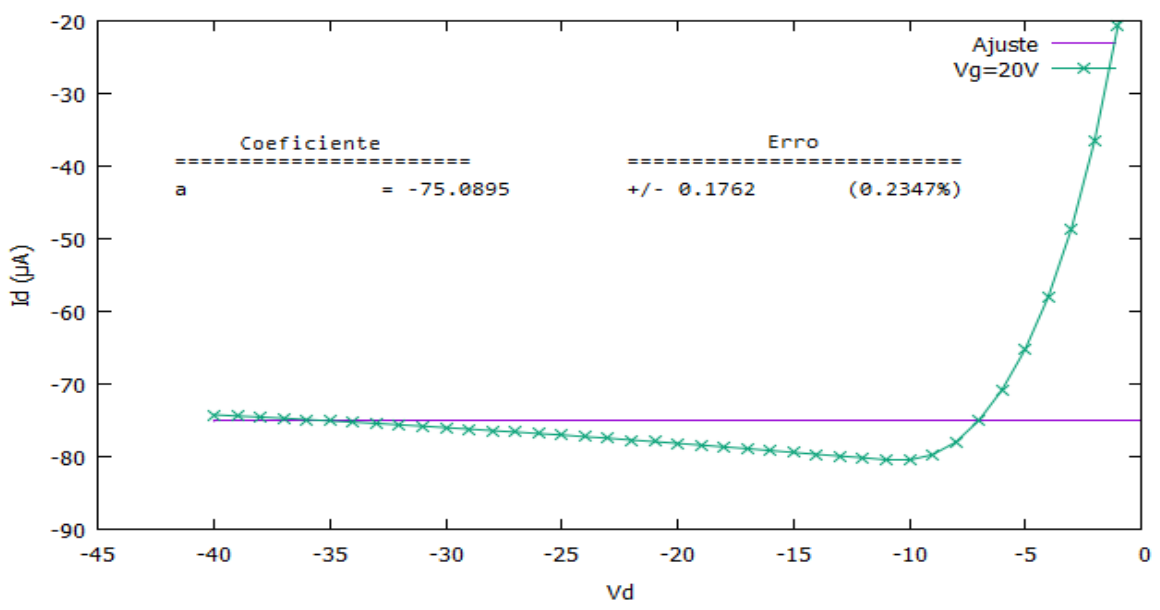

(a)

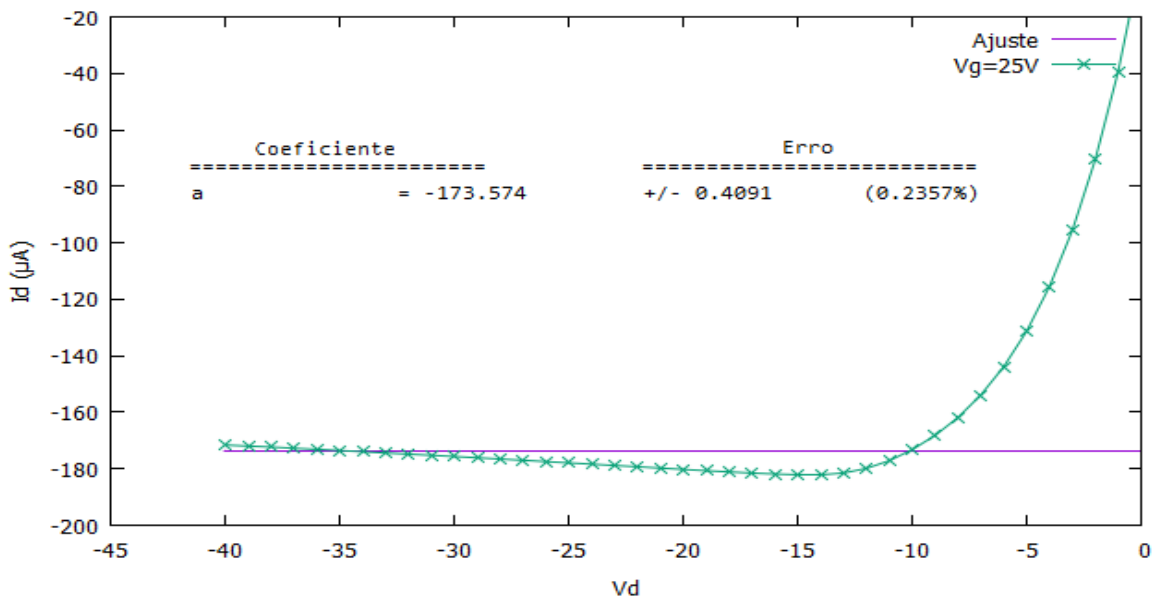

(b)

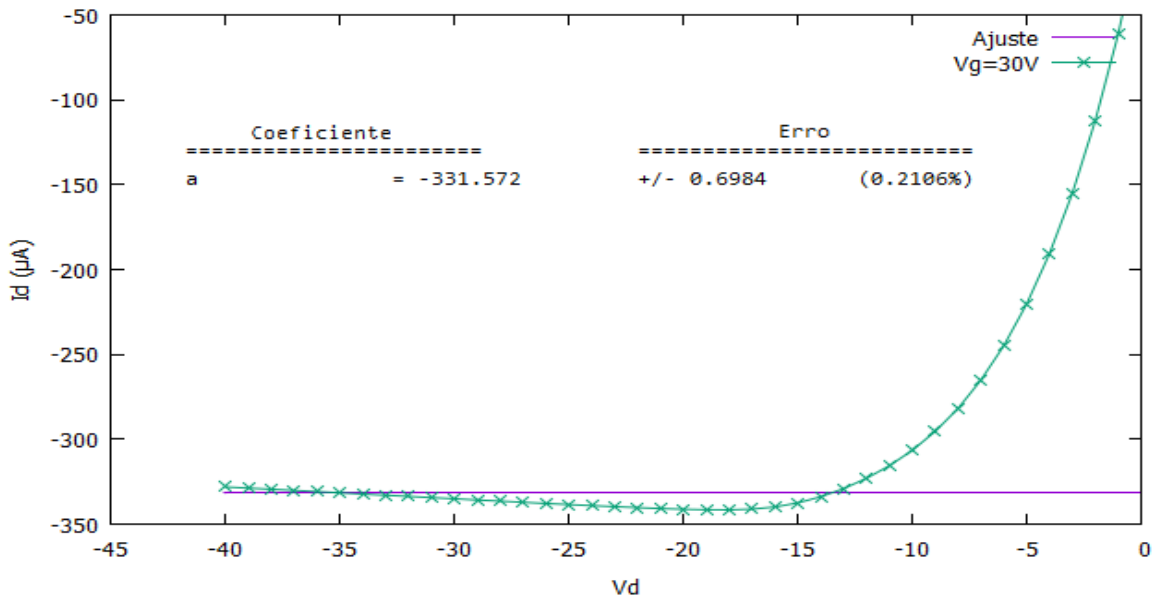

(c)

Figura 23: Família de curvas de saída com extrapolação ao eixo y das curvas no regime de saturação. $\mathrm{Vg}=-\{20$ a $30 \mathrm{~V}\}$. 


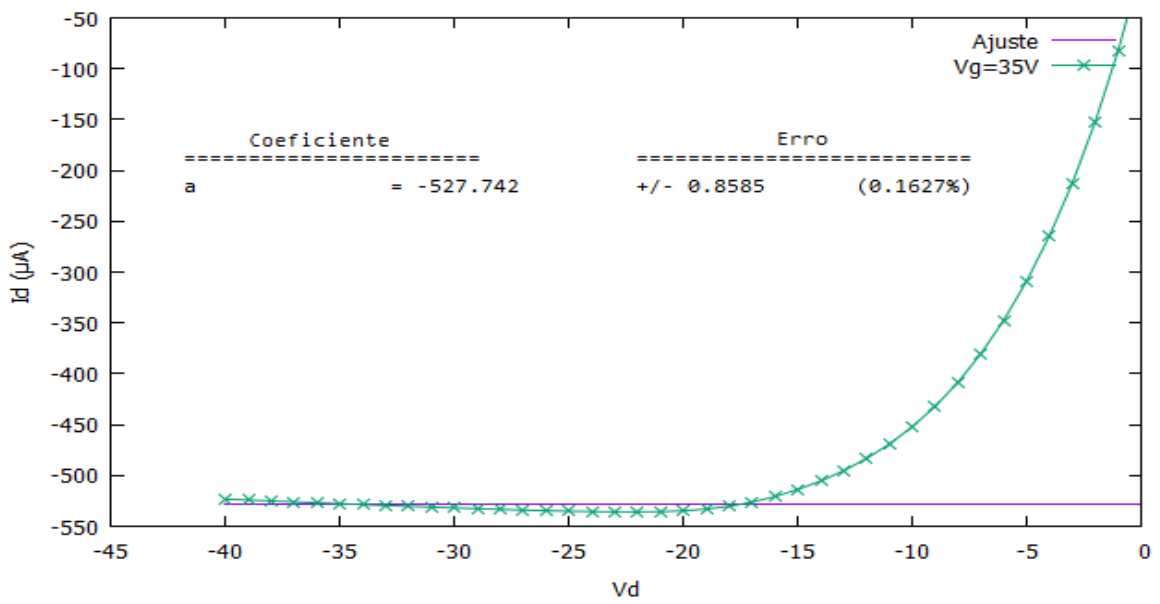

(a)

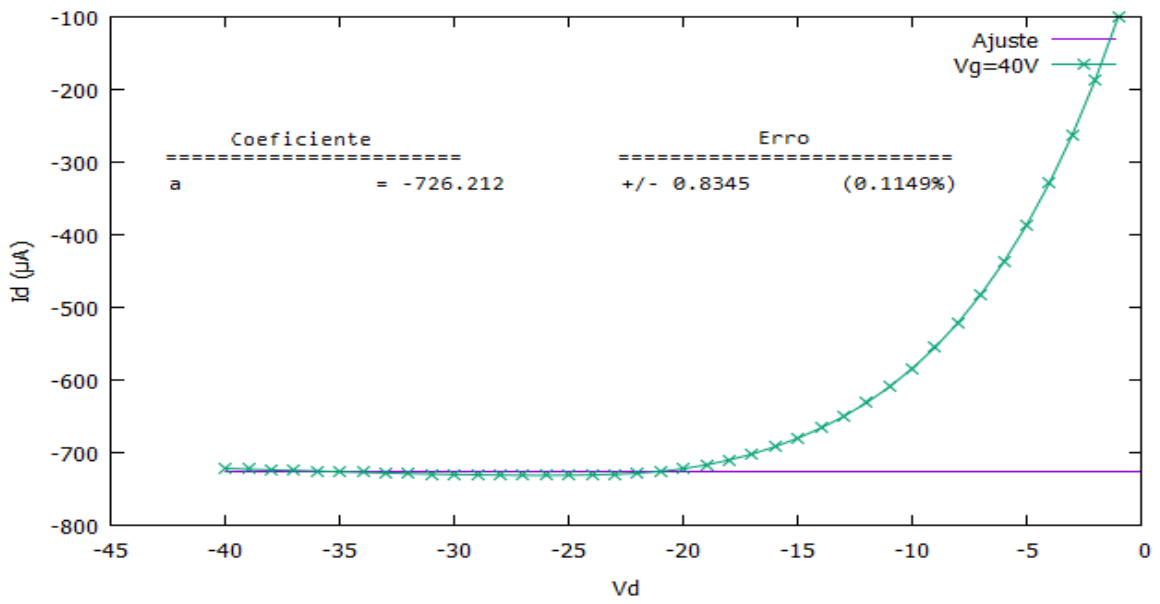

(b)

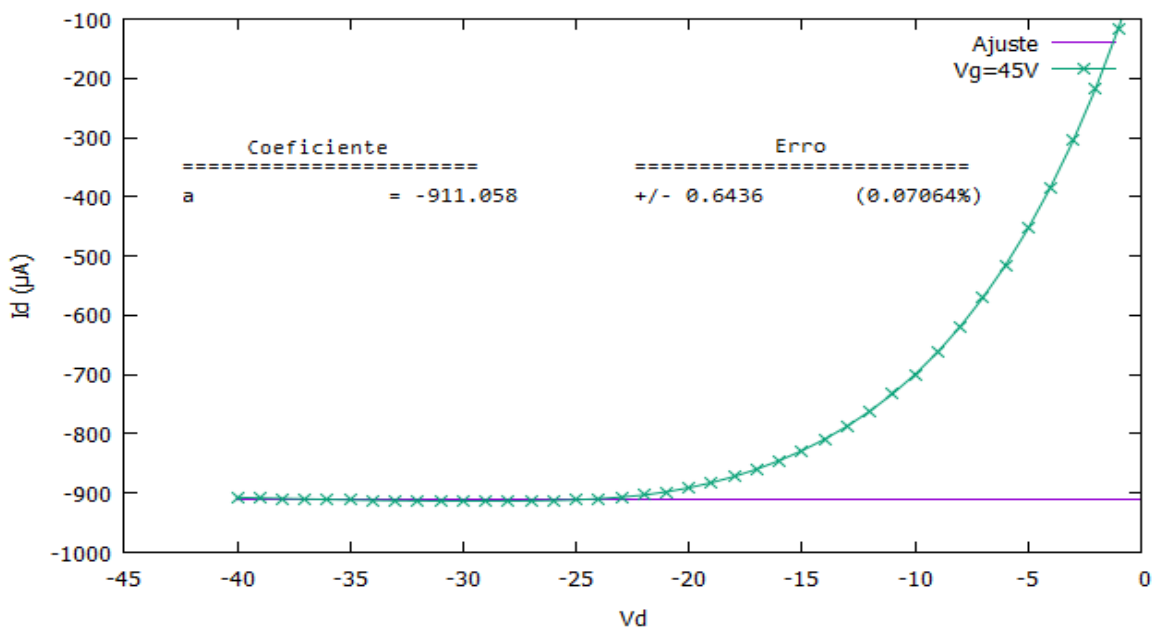

(c)

Figura 24: Família de curvas de saída com extrapolação ao eixo y das curvas no regime de saturação. $\mathrm{Vg}=-\{35$ a $45 \mathrm{~V}\}$. 
Resumidamente, temos:

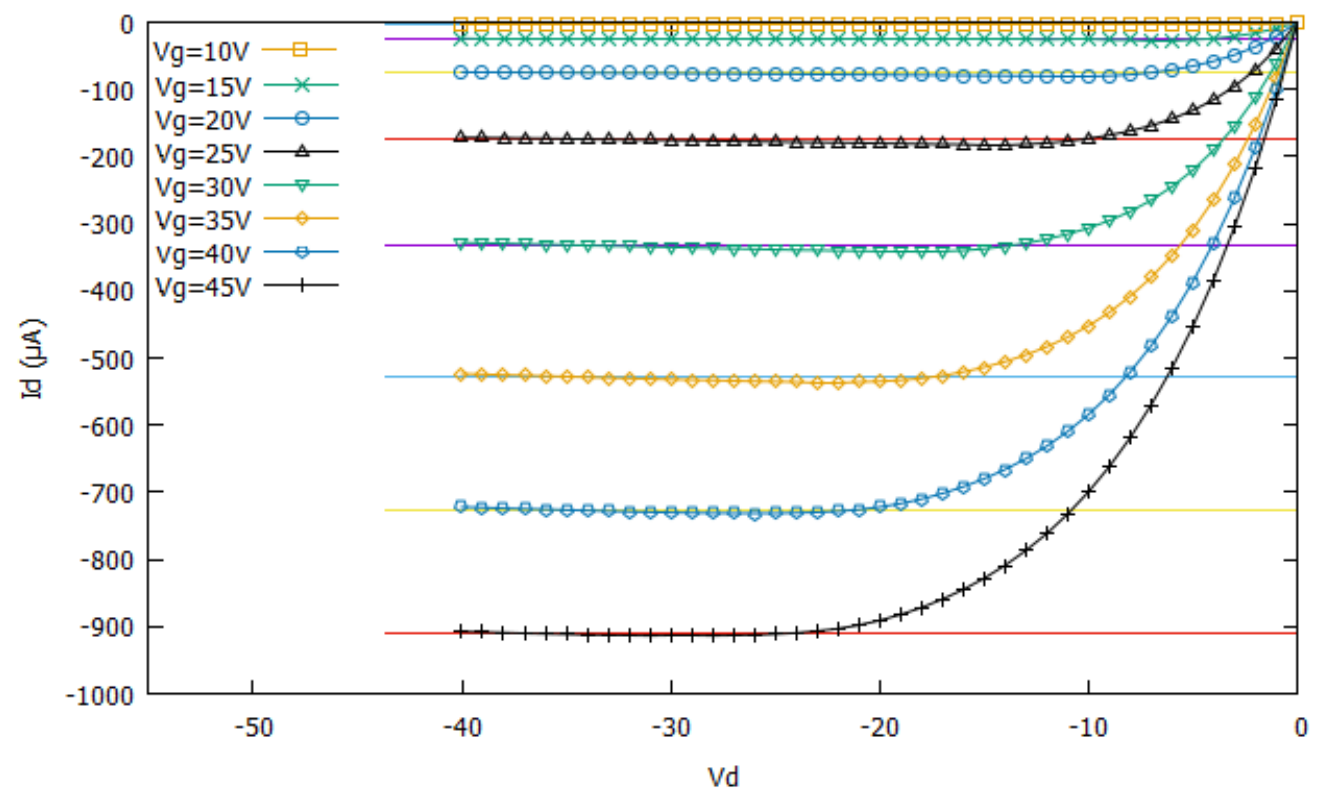

Figura 25: Família de curvas de saída com extrapolação ao eixo y das curvas no regime de saturação. $\mathrm{Vg}=-\{10$ a $45 \mathrm{~V}\}$.

Os valores em módulo de corrente elétrica no dreno e suas respectivas raizes para cada uma das extrapolações das curvas de saída foram os seguintes:

\begin{tabular}{|c|c|c|}
\hline $\mathbf{V g}$ & Raiz Id Sat & Id Sat \\
\hline 10,0 & 1,5 & 2,3 \\
\hline 15,0 & 4,9 & 24,2 \\
\hline 20,0 & 8,7 & 75,1 \\
\hline 25,0 & 13,2 & 173,6 \\
\hline 30,0 & 18,2 & 331,6 \\
\hline 35,0 & 23,0 & 527,7 \\
\hline 40,0 & 27,0 & 726,7 \\
\hline 45,0 & 30,2 & 911,1 \\
\hline
\end{tabular}

Tabela 1: Raizes da corrente Id, em $\mu A$, para cada (-)Vg.

Plotando os resultados e ajustando a curva obtemos os seguintes valores para os coeficientes angular e linear. 


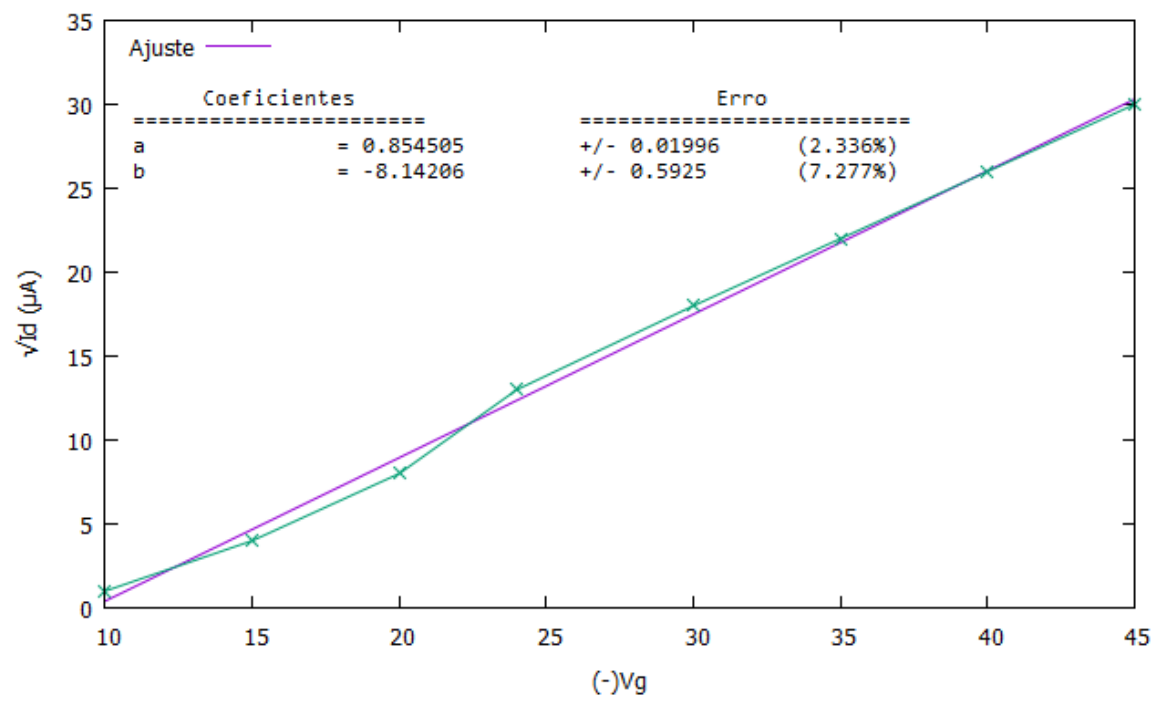

Figura 26: Raizes de corrente elétrica no dreno durante o regime de saturação para diferentes valores de voltagem na porta do transistor.

Pela equação 5.23, o termo $\sqrt{\frac{\mu C_{\Delta S} L_{y}}{2 L}}$ é o coeficiente angular "a" da reta. Assim, temos que $\sqrt{I d}=a V_{g}-a V_{L}$. O termo $-a V_{L}$ é o coeficiente linear "b" da reta. Portanto, a voltagem de limiar pode ser obtida a partir do ajuste dessa curva simplesmente calculando-se a seguinte equação:

$$
V_{L}=-\frac{b}{a}
$$

Obtivemos o valor de $-9,5 \pm 0,1 \mathrm{~V}$ para a voltagem de limiar. Esse resultado mostrou-se muito bom para sinalizar o fim do regime linear. Pelo gráfico semilog da curva de transferência (logId x Vg), podemos visualizar o fim do regime linear, o início do regime de saturação e a fase transiente entre esses dois modos de operação do transistor. Plotando, resulta em: 


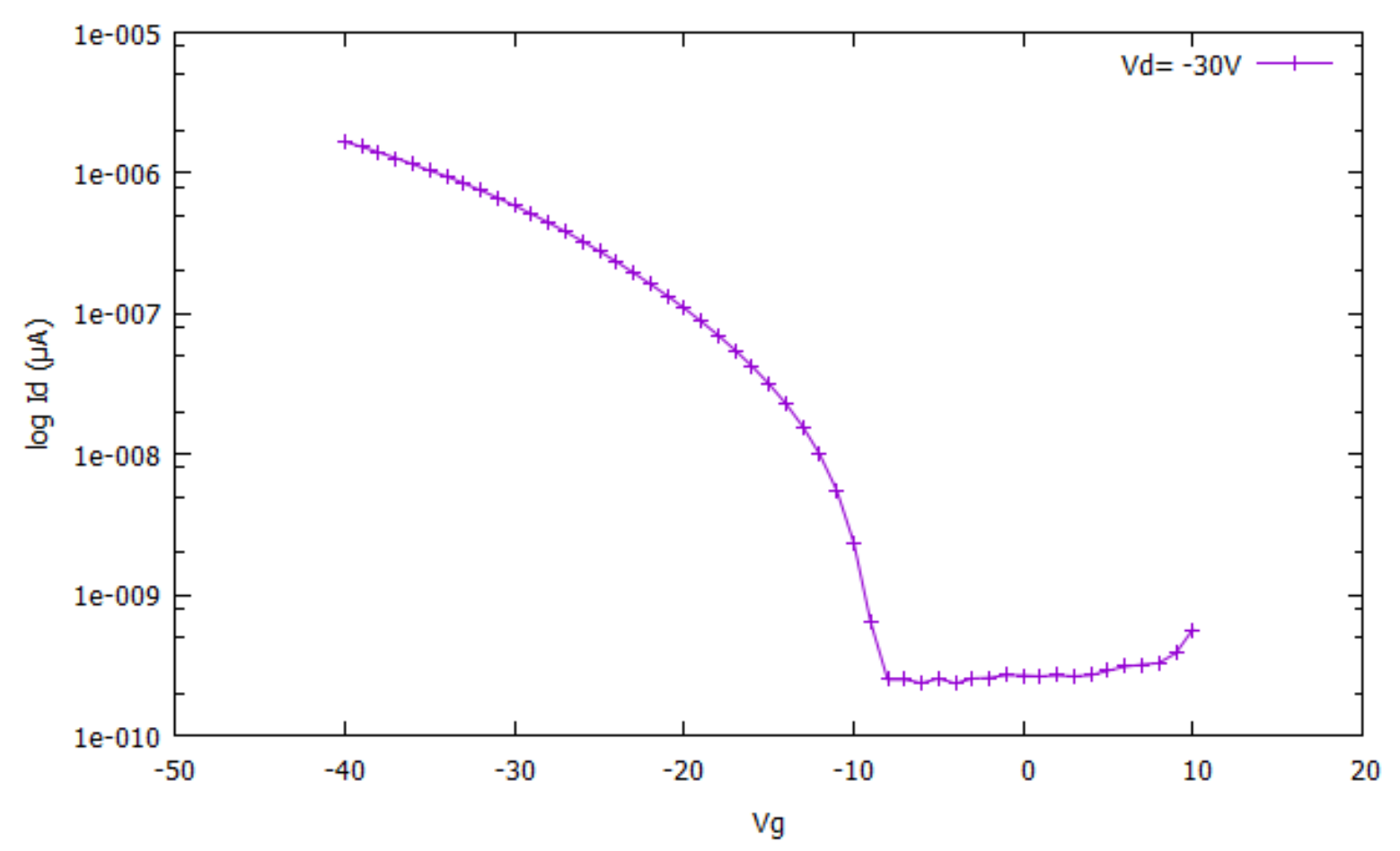

Figura 27: Plot semilog da curva de transferência.

O método indicado na figura 15 nos deu um valor de voltagem de $-16,3 \mathrm{~V}$, enquanto que o método proposto acima resultou em -9,5V. Apesar dos valores díspares, nenhum dos métodos deve ser desconsiderado; o que ocorreu foi que a extrapolação da curva de transferência indicou com precisão razoável o início do regime de saturação, enquanto que a abordagem feita pela extrapolação das curvas de saída indicou muito bem o fim do regime linear. Assim, pode-se caracterizar a fase transiente entre esses modos de operação. Além disso, verificou-se a razão on/off (estados ligado/desligado) do transistor como sendo de $10^{2}$ a $10^{3}$ para uma voltagem no dreno de $-30 \mathrm{~V}$. 


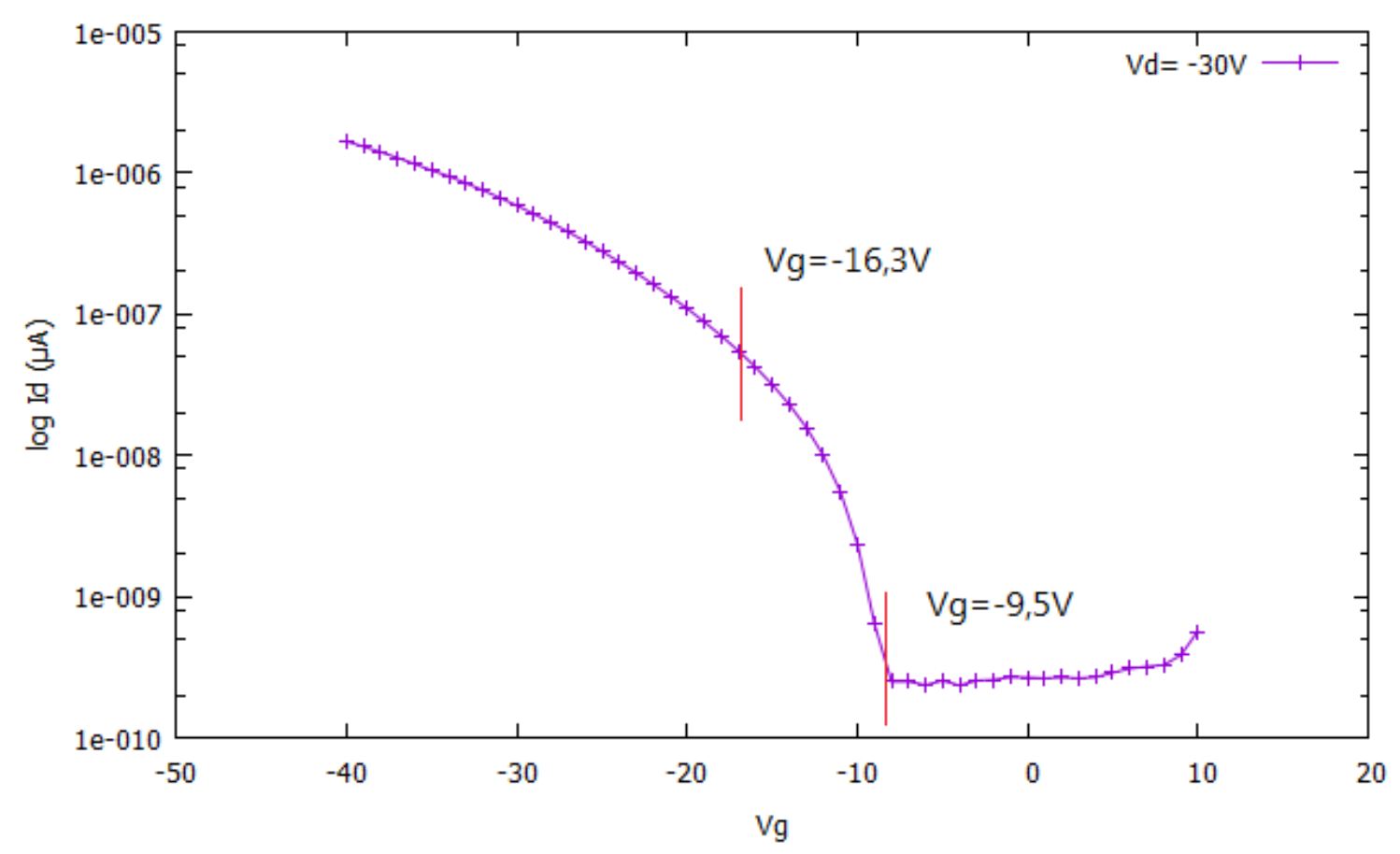

Figura 28: Fase trasiente on/off do transistor operando com Vd $=-30 \mathrm{~V}$.

\subsubsection{Mobilidade}

A mobilidade possui valores diferentes se for medida no regime linear do transistor ou no regime de saturação. Por este motivo, calcularemos os valores da mobilidade para cada um desses regimes de operação.

Quando o OFET está operando na região de saturação, isto é, quando a voltagem no dreno é maior ou igual à voltagem efetiva, a mobilidade pode ser obtida por meio da equação 5.25. Para isso, lançamos mão dos dados colhidos na curva de transferência, ilustrada na figura 19.

A extrapolação mostrada pela figura, além de ter sido utilizada para obtenção da Voltagem de Limiar, nos forneceu o valor da transcondutância $g_{t}$ do canal no regime de saturação, já que $g_{t}$ é o termo que representa o coeficiente angular da equação 5.23, que é 


$$
\sqrt{\frac{\mu C_{\Delta S} L_{y}}{2 L}} .
$$

De posse desse dado, e sabendo que os outros valores da equação são constantes que descrevem as dimensões físicas do dispositivo, isolamos $\mu \mathrm{e}$, calculando, obtivemos um valor de $0,42 \mathrm{~cm}^{2} / V s$ para a mobilidade de cargas no canal do transistor, o que já seria suficiente para trabalhar pixels em uma tela, por exemplo. Contudo, isso só seria possível se a razão on/off fosse da ordem de $10^{6}$, valor que ainda é bem maior do que o desempenhado pelo transistor em questão.

Com respeito ao regime linear, também foi calculado sua mobilidade de cargas. De modo análogo, porém, por meio das curvas de saída, obtivemos um ajuste para a parte linear, que nos fornece o coeficiente angular do gráfico Id x Vd, isto é, a condutância $\mathrm{g}_{c}$ do canal (Equação 5.18), conforme visto a seguir nas figuras 29, 30 e 31.

Cada um dos valores obtidos foi aplicado na equação 5.19 e resultou em uma mobilidade de cargas específica, ilustrada pela figura 32, sendo que o menor valor de mobilidade foi de aproximadamente $0,40 \mathrm{~cm}^{2} / V s$ quando a voltagem aplicada à porta foi de $-10 \mathrm{~V}$ e alcançou um pico de $0,96 \mathrm{~cm}^{2} / V s$ quando a voltagem na porta foi de $-40 \mathrm{~V}$, ou seja, quando a voltagem efetiva foi de $\approx-30 \mathrm{~V}$.

As curvas de saída ajustadas, agora no regime linear, foram as seguintes: 


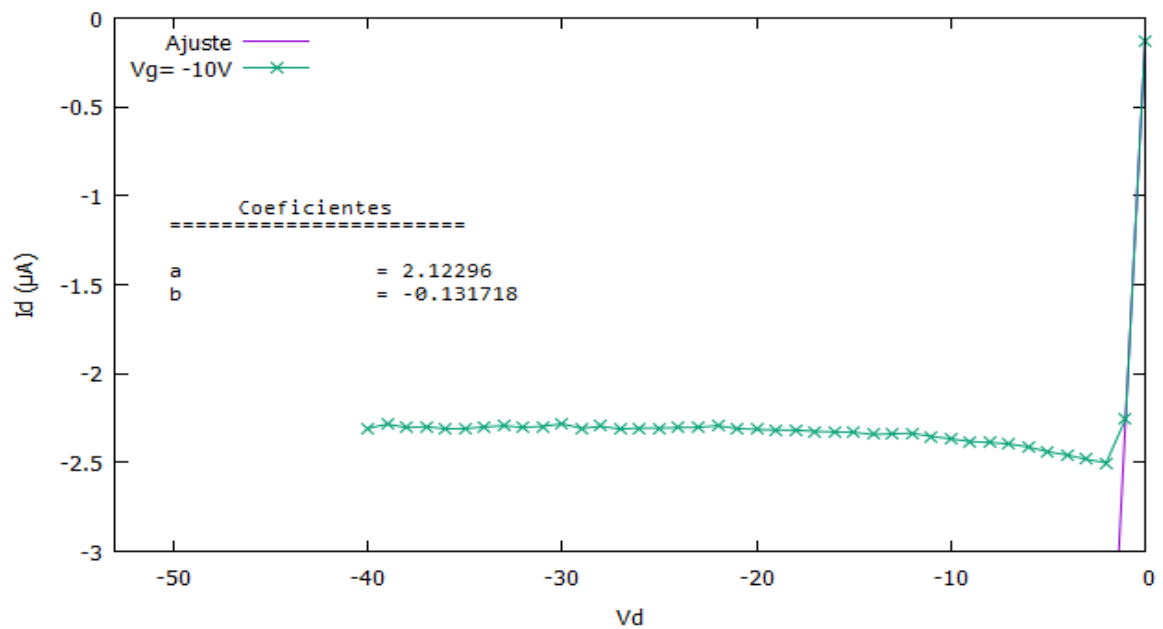

(a)

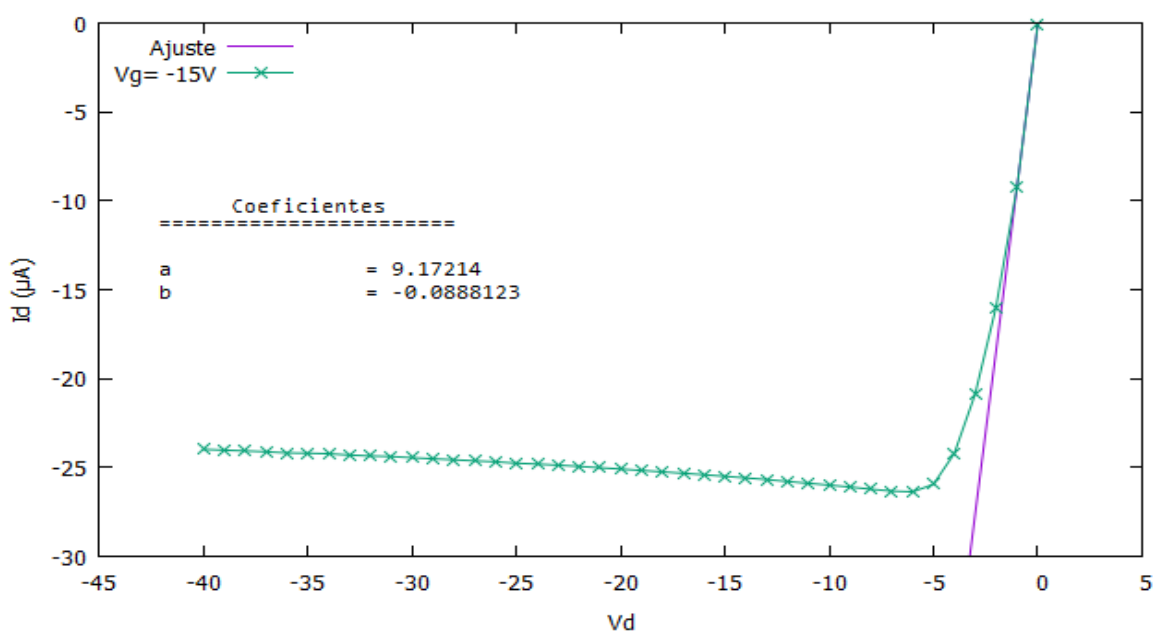

(b)

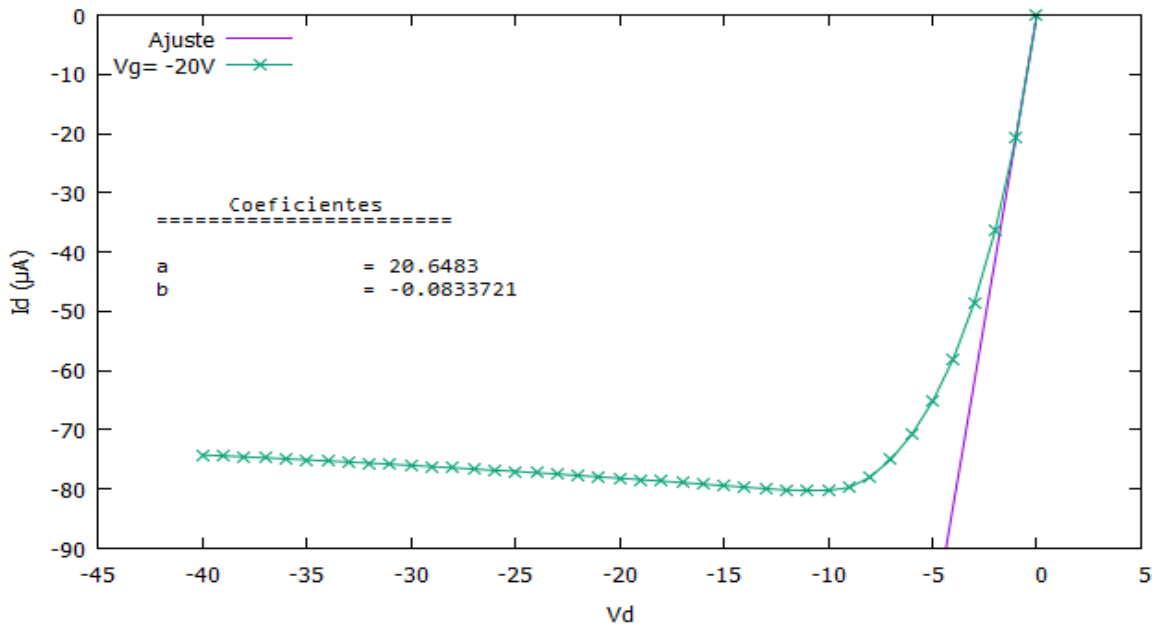

(c)

Figura 29: Família de curvas de saída ajustadas no regime linear de operação do transistor. $\operatorname{Vg}=-\{10$ a $20 \mathrm{~V}$. 


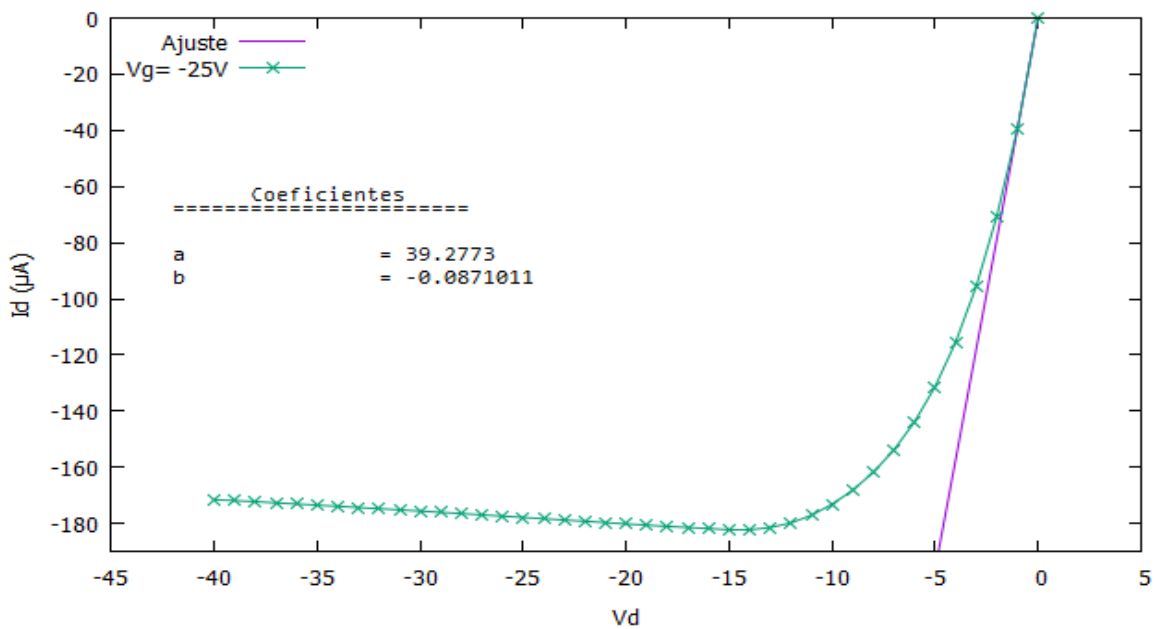

(a)

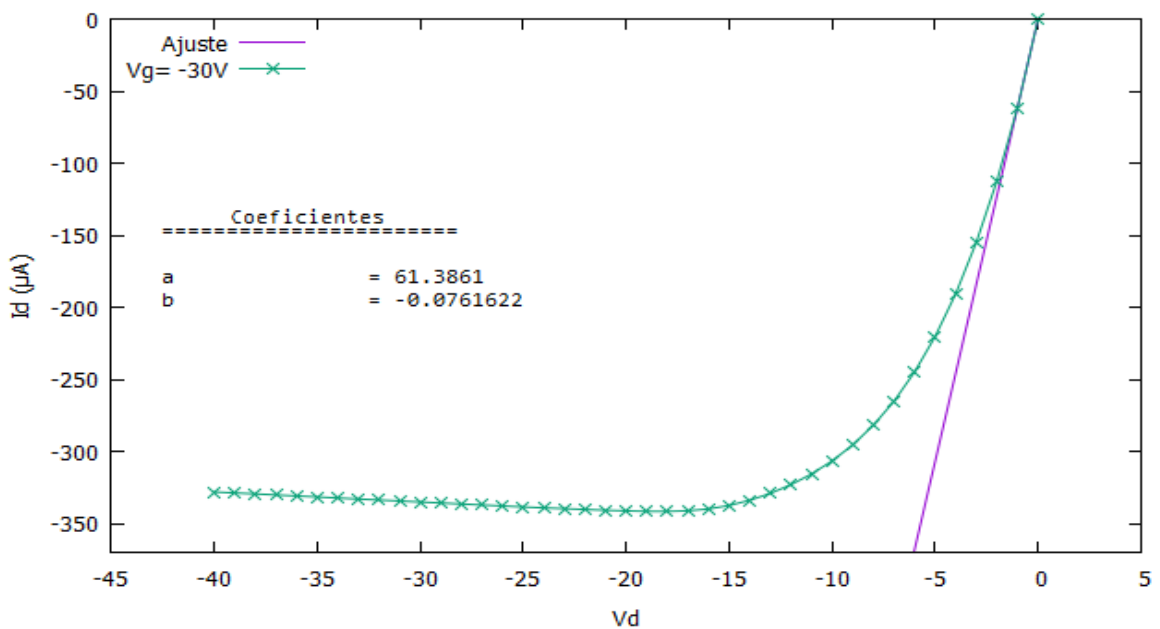

(b)

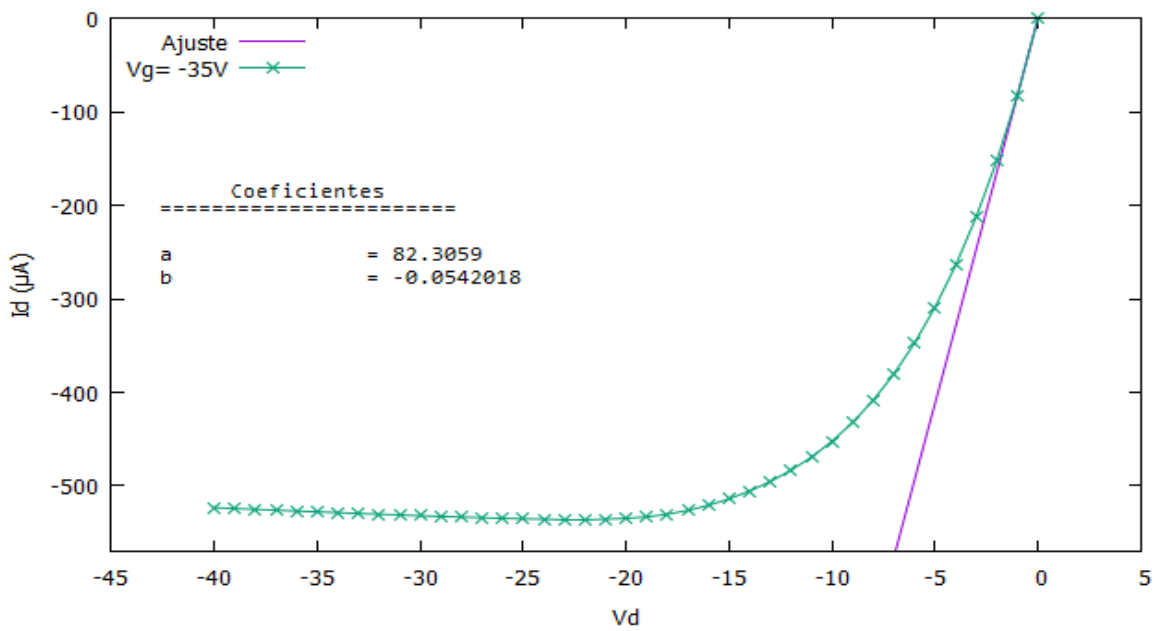

(c)

Figura 30: Família de curvas de saída ajustadas no regime linear de operação do transistor. Vg $=-\{25$ a $35 \mathrm{~V}\}$. 


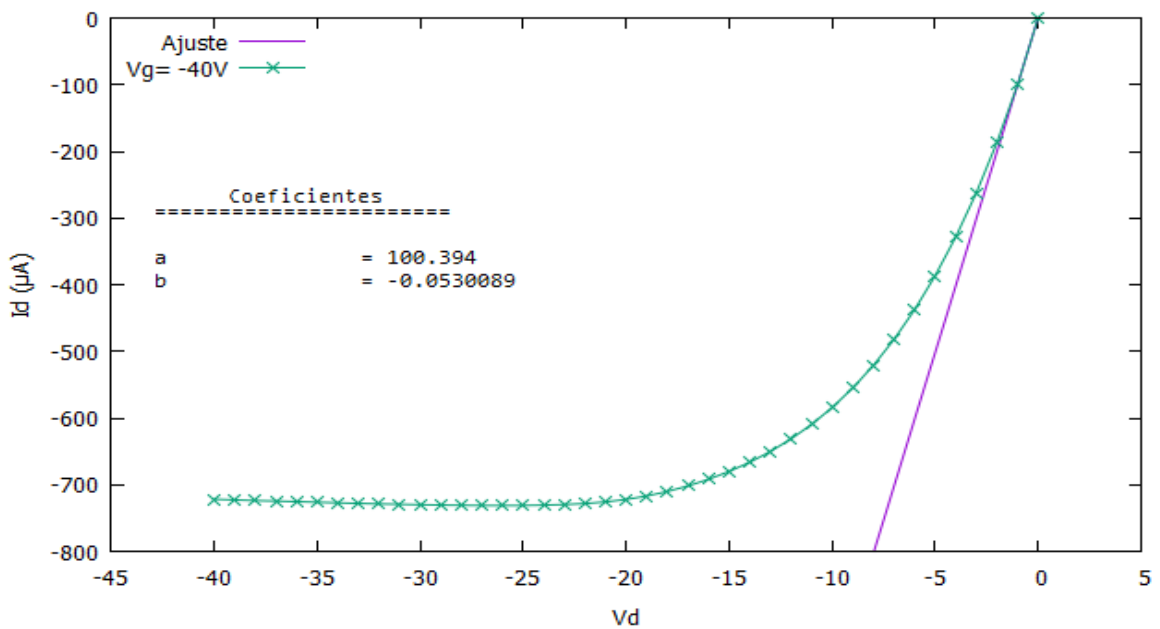

(a)

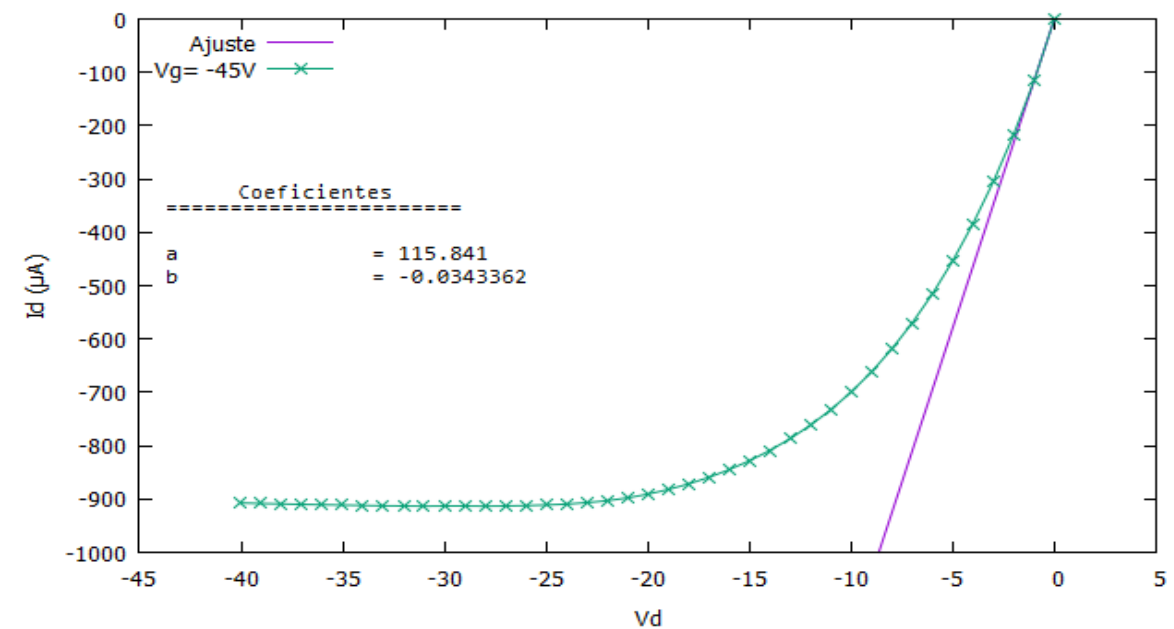

(b)

Figura 31: Família de curvas de saída ajustadas no regime linear de operação do transistor. $V g=-\{40$ e $45 \mathrm{~V}\}$.

A mobilidade de cargas no regime linear foi a seguinte: 


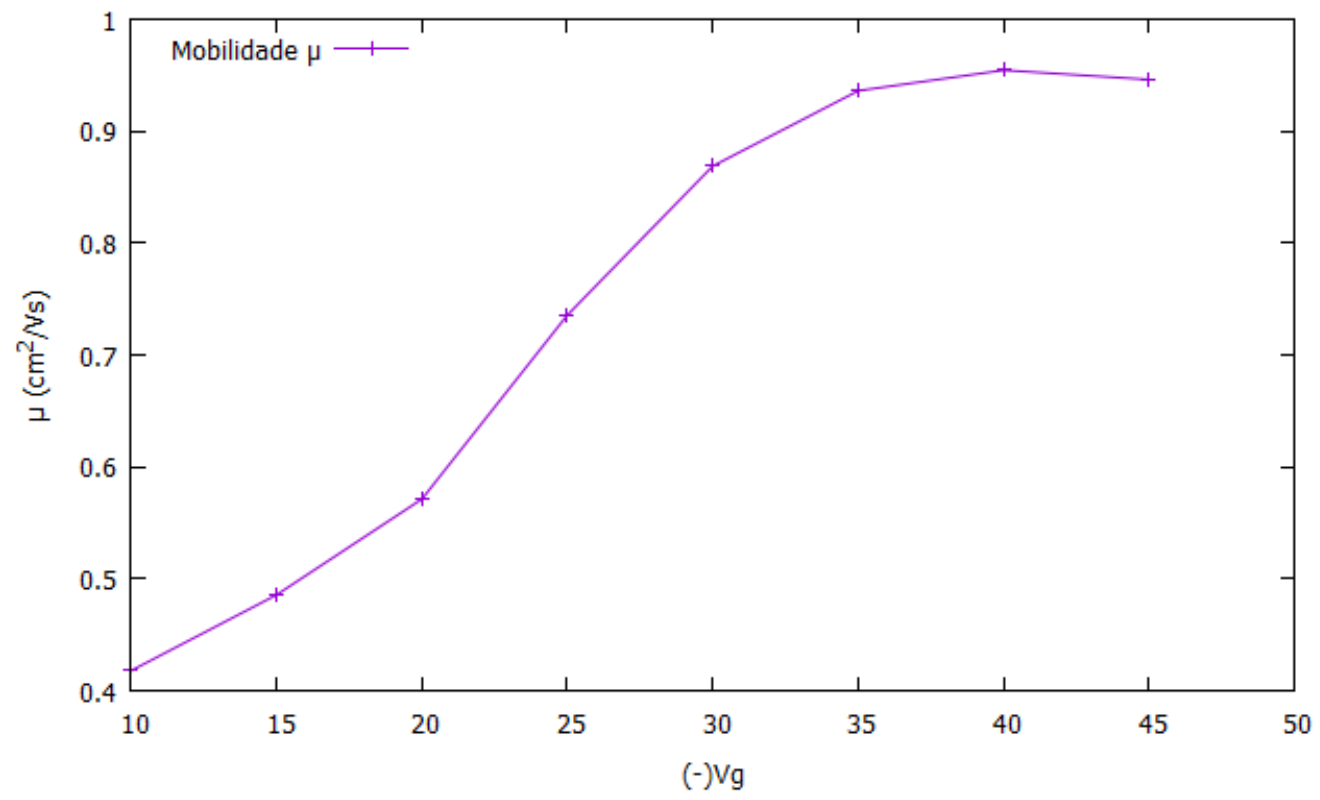

Figura 32: Mobilidade $\mu\left(\mathrm{cm}^{2} / V . s\right)$ durante o regime linear de operação do transistor para valores de voltagem na porta indo de $-\{10$ a $45 \mathrm{~V}\}$.

Uma outra possibilidade de se obter a mobilidade durante o regime linear é utilizar-se da curva de transferência e obter a trancondutância g ${ }_{t}$ do canal do OFET. O cálculo da mobilidade está proposto na equação 5.20. Porém, o resultado desse método não pode ser levado em consideração no nosso caso devido ao fato de o regime linear acontecer quando a voltagem no dreno é muito menor que a voltagem efetiva. Já que no nosso caso a única curva de tranferência foi obtida com $30 \mathrm{~V}$ no dreno, vemos que esse valor, em quase todos os pontos do gráfico, é maior e até bem maior que a voltagem efetiva; contrariando a condição precípua à aplicação do método. Sendo assim, não foi calculada a mobilidade de cargas no regime linear fazendo uso da transcondutância do canal do transistor. 


\subsection{Modelo de Vissenberg-Matters}

Esse modelo foi publicado no ano de 1998 sob o título de "Teoria da mobilidade sob efeito de campo em transistores orgânicos amorfos" (tradução livre) [1] por Michel Vissenberg e M. Matters, ambos do "Philips Research Laboratories" de Eindhoven, Holanda. Tal modelo também foi explorado na tese de doutoramento [41] de Vissenberg, um ano depois, pela Universidade de Leiden. O objetivo desse modelo proposto era o de explicar teoricamente a mobilidade de cargas em transistores orgânicos de filmes finos, porém utilizando a teoria de percolação, assunto muito utilizado nas pesquisas de sistemas complexos.

Vissenberg e Matters escolheram a teoria de percolação devido a característica dos semicondutores orgânicos de possuirem uma disposição estocástica dos átomos, ou seja, são sistemas desordenados, em oposição da estrutura regular dos semicondutores cristalinos. A proposta é que esta disposição aleatória possibilita caminhos mais prováveis nos quais os elétrons poderiam percolar no semicondutor, tal como uma difusão. Como resultado final, o modelo proporá uma equação para a corrente elétrica no semicondutor orgânico, e isso com dependências de parâmetros como a temperatura e tipo de material.

Um bom resultado foi alcançado quando compararam esse modelo com os dados obtidos experimentalmente por Brown et. al. (dos quais M. Matters também participou) [42] ao caracterizarem semicondutores poliméricos (poli[tinileno vinileno]) e de moléculas pequenas (pentaceno).

Mais detalhadamente, o modelo de percolação de Vissenberg e Matters utiliza como premissa o transporte de cargas por meio do mecanismo de hopping, isto é, o tunelamento dos portadores de carga para estados localizados. Nessa abordagem, para obter os caminhos mais prováveis de percolação, utiliza-se o conceito de Variable Range Hopping (VRH), ou seja, saltos (tunelamento) de alcance variável. Assim, um portador 
pode tunelar para um estado localizado próximo com alta energia de ativação ou pode tunelar para um estado localizado distante com baixa energia de ativação. Esse modelo é altamente dependente da temperatura e da densidade de estados localizados (DOS). Como já discutido, a aplicação de voltagem na porta do transistor de efeito de campo dá origem à acumulação de cargas na interface semicondutor-isolante. Essa acumulação ocorre, primeiramente, preenchendo os estados de menor energia; assim, posteriormente, qualquer carga adicional deverá ocupar os estados de maior energia. Consequentemente, esses portadores em estados mais energéticos, em média, necessitarão de menor energia de ativação para tunelar para outros estados localizados, resultando em uma maior mobilidade com o aumento de voltagem aplicada, e em consequência, maior percolação.

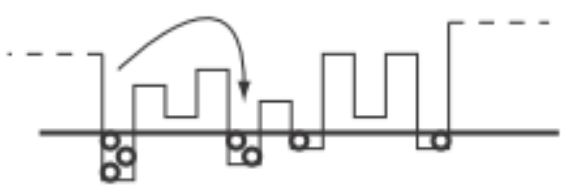

(a)

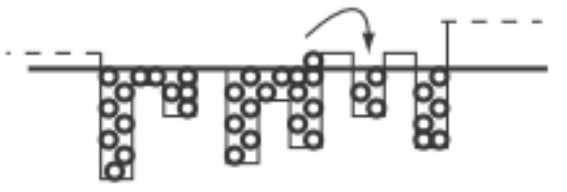

(b)

Figura 33: Esquema de transporte de cargas via hopping segundo o preenchimento de estados localizados. A) quando a interface semicondutor-isolante não está totalmente acumulada e os portadores ocupam os estados energéticos mais profundos, necessitando de maior energia de ativação para tunelar para um estado localizado vizinho. B) quando os estados mais profundos estão preenchidos e as cargas subsequentes preenchem estados mais energéticos, próximos da barreira energética de mobilidade, tendo, portanto, mais facilidade de locomoção. Por isso, a mobilidade mostra ser função da densidade de estados localizados. Retirada da referência [10].

\subsubsection{Noções do modelo matemático de Vissenberg-Matters}

Não nos aprofundaremos na formulação matemática completa do modelo de VissenbergMatters, porém apresentaremos uma noção geral da matemática do modelo e o simularemos numericamente. A formulação completa do modelo se encontra nos seguintes trabalhos: artigo de Vissenberg e Matters [1] e tese de doutorado de Vissenberg [41].

O modelo inicia considerando o material semicondutor do transistor tal como na 
figura abaixo.

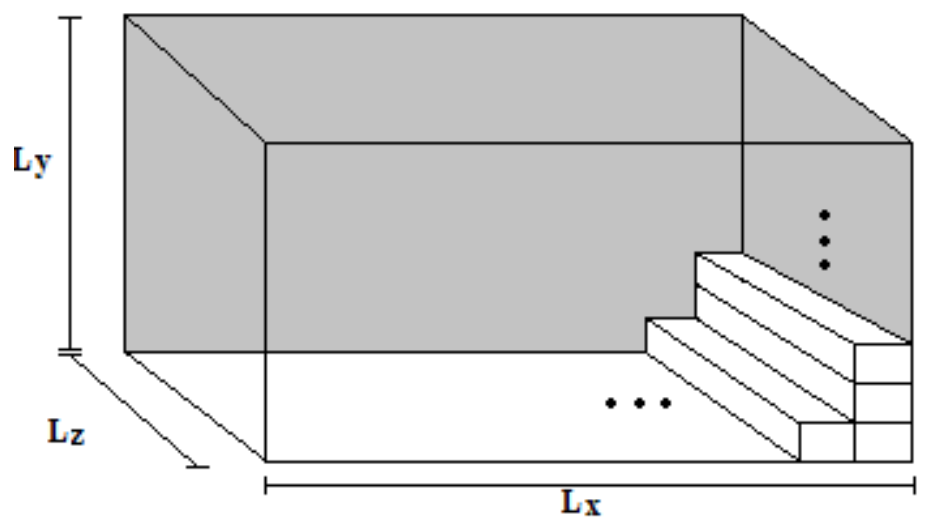

Figura 34: Discretização do semicondutor.

O semicondutor é considerado como sendo formado por uma malha de várias tiras (paralelepípedos), as quais estarão submetidas a uma determinada voltagem que varia dependendo da posição no eixo x e no eixo y, porém não varia com relação ao eixo z. Cada tira irá conter uma quantidade de portadores de carga diferente, logo elas terão resistências diferentes.

Para calcular o valor da corrente elétrica no semicondutor, usaremos a Lei de Ohm

$$
V=R . I
$$

onde $\mathrm{V}$ é diferença de potencial elétrico (voltagem), $\mathrm{R}$ é a resistência elétrica e I a intensidade de corrente elétrica. Também necessitaremos da relação entre a resistência elétrica e suas características físicas, ou seja,

$$
R=\frac{\rho l}{A}
$$

onde $\rho$ é a resistividade elétrica característica do material, $l$ é a largura do material e $A$ é a área da seção reta. Assim, quanto maior a área, menor a dificuldade que os portadores de carga encontrarão para percolar no semicondutor. 
A voltagem é variável no eixo x e no eixo y, o que repercute na acumulação e, logo, alterará o valor da resistividade local $\rho(x, y)$. Porém, no modelo de Vissenberg-Matters será considerado somente o regime linear, ou seja, os casos em que a voltagem no dreno é muito menor do que a voltagem da porta, $\left|V_{d}\right| \ll\left|V_{g}\right|$. Isto, no modelo, permite propor que a voltagem no dreno $\left(V_{d}\right)$ sirva somente para transportar cargas no eixo x, porém não alterará a densidade de carga local. A densidade de carga será alterada somente pela voltagem da porta $\left(V_{g}\right)$, pois possui valor muito maior do que a voltagem do dreno, o que provoca uma alteração da densidade de carga somente no eixo y. Logo, a resistividade local dependerá somente de y, $\rho(y)$, ou seja, em função da distância até a interface semicondutor-isolante. Esta aproximação do modelo de Vissenberg-Matters é uma redução do potencial do modelo, pois servirá somente para prever os regimes lineares. Com o intuito de ampliar a restrição de validade do modelo de VissenbergMatters, Smits et al. [43] ampliou o modelo a fim de considerar também a variação de densidade de carga em $x$, e assim, incluir os casos além do regime linear.

Portanto, considerando a resistividade, $\rho(y)$, e combinando as equações 5.27 e 5.28 , obtem-se a seguinte expressão

$$
V_{d}-V_{g}=\rho(y) \frac{L_{x}}{L_{z} d y} d I(y)
$$

onde $V_{d}$ e $V_{g}$ são, respectivamente, a voltagem no dreno e a voltagem na porta do transistor. Assim, escrevendo a equação 5.29 para a corrente elétrica $d I(y)$, obtem-se

$$
d I(y)=\left(V_{d}-V_{g}\right) \frac{L_{z}}{L_{x}} \sigma(y) d y
$$

onde o inverso da resistividade foi escrito como a condutividade elétrica, $\sigma(y)$. Com isso, sabe-se a corrente elétrica em cada ponto ao longo do eixo y. No entanto, o intuito é conhecer a corrente elétrica total no canal do semicondutor. Para isso, integra-se 
todos os valores de corrente elétrica no eixo y:

$$
\int_{0}^{I} d I(y)=\left(V_{d}-V_{g}\right) \frac{L_{z}}{L_{x}} \int_{0}^{L_{y}} \sigma(y) d y
$$

de modo que a corrente elétrica no semicondutor será da seguinte forma

$$
I=\left(V_{d}-V_{g}\right) \frac{L_{z}}{L_{x}} \int_{0}^{L_{y}} \sigma(y) d y
$$

A próxima etapa é obter a integral da condutividade elétrica.

\subsubsection{Expressão para a Condutividade}

Vissenberg e Matters utilizaram o modelo de percolação exatamente nessa etapa para obter a condutividade elétrica, $\sigma(y)$. A formulação completa desta parte não será apresentada nessa dissertação, porém, pode ser encontrada nos trabalhos já preditos [1] e [41]. Assim, a condutividade elétrica, $\sigma(y)$, segundo o modelo de Vissenberg-Matters, equivale a

$$
\sigma(\delta, T)=\sigma_{0}\left(\frac{\pi N_{t} \delta\left(T_{0} / T\right)^{3}}{(2 \alpha)^{3} B_{c} \Gamma\left(1-T / T_{0}\right) \Gamma\left(1+T / T_{0}\right)}\right)^{T_{0} / T}
$$

onde $\delta$ é a ocupação probabilística de cargas, de modo que varia de 0 a $1, N_{t}$ é o número de estados por unidade de volume, $\alpha$ é um parâmetro de sobreposição efetiva das funções de onda eletrônicas utilizado para descrever o processo de tunelamento, $B_{c}$ é uma constante que diz respeito aos parâmetros de percolação do sistema, $\Gamma$ é a função gama e surge de uma condição para a energia de Fermi em uma determinada ocupação de cargas $\delta, T_{0}$ é a temperatura característica do material para gerar a largura da distribuição gaussiana proposta no modelo como densidade de estado. Perceba que essa expressão é função da ocupação de cargas $\delta$ e das temperaturas $T$ e $T_{0}$. 
Nessa expressão, a condutividade possui dependência como lei de potência da ocupação de cargas $\sigma \sim \delta^{T_{0} / T}$. Isso surge devido à forma de preenchimento dos estados localizados dos elétrons propostos no modelo de Vissenberg-Matters. Em outras palavras, um aumento na densidade de cargas (consequentemente, na ocupação também) gera um aumento da energia média dos portadores, facilitando os saltos ativados para estados mais energéticos, o que implica no aumento da condutividade. Quando este tipo de ordem de preenchimento não é levado em consideração, a condutividade resume-se a um comportamento proporcional à ocupação de cargas.

\subsubsection{Expressão para a Ocupação de Cargas, Equação de Poisson e Corrente Elétrica no Canal}

A ocupação probabilística de cargas se relacionada com a densidade de cargas, $\rho$, pela equação

$$
\rho=N_{t} q \delta
$$

onde $N_{t}$ é a quantidade de estados localizados por unidade de volume e depende de cada material e $q$ é a carga do elétron. A expressão é intuitiva, pois ao multiplicarmos $N_{t}$, que é a quantidade de estados localizados por unidade de volume, pela carga, obteríamos a densidade de cargas, porém sabe-se que os estados não estão completamente ocupados, há uma probabilidade de ocupação, que é dado por $\delta$. Assim, multiplicando ainda por $\delta$ obtemos a procurada densidade de cargas, $\rho$.

E a densidade de cargas está conectada com a voltagem por meio da equação de Poisson:

$$
\nabla^{2} V=-\frac{\rho(y)}{\varepsilon_{s c} \varepsilon_{0}}
$$

onde $\varepsilon_{0}$ é a permissividade elétrica do vácuo e $\varepsilon_{s c}$ é a permissividade do meio. Considerando a aproximação do modelo de Vissenberg-Matters, já discutido anteriormente, 
e utilizando a equação 5.34 na expressão de Poisson, temos que

$$
\frac{d^{2} V}{d y^{2}}=\frac{N_{t} q}{\varepsilon_{s c} \varepsilon_{0}} \delta(y)
$$

A resolução analítica dessa equação de Poisson juntamente com a equação da condutividade elétrica, equação 5.33, permite realizar a integração da corrente elétrica no canal, equação 5.32, e obter

$I=\frac{L_{z} V_{D} \sigma_{0}}{L q}\left(2 \frac{T_{0}}{T}-1\right)^{-1}\left(\frac{\left(T_{0} / T\right)^{4} \operatorname{sen}\left(\pi T / T_{0}\right)}{(2 \alpha)^{3} B_{c}}\right)^{T_{0} / T}\left(2 k_{B} T_{0} \varepsilon_{S C} \varepsilon_{0}\right)^{1-T_{0} / T}\left(C_{\triangle S} V_{g}\right)^{2 T_{0} / T-1}$,

onde $q$ é a carga elementar do elétron; os outros parâmetros já foram apresentados anteriormente. Perceba que a corrente é proporcional a voltagem do dreno $\left(V_{d}\right)$, o que indica que a equação descreve uma dinâmica no regime linear. A equação acima, no modelo de Vissenberg-Matters, é a expressão analítica para a corrente elétrica no canal de um transistor orgânico operando em regime linear em função de $V_{d}, V_{g}$ e $T$.

\subsection{Métodos numéricos para aplicação do modelo de Vissenberg-Matters}

Como exposto anteriomente, nesta dissertação não resolvemos completamente, de um ponto de vista analítico, o modelo de Vissenberg-Matters, por exemplo, a parte referente a resolução da equação de Poisson. Porém, obtivemos as informações necessárias da equação de Poisson através da resolução numérica geradas através de um programa na linguagem $\mathrm{C}$ que escrevemos. E de posse dos resultados obtidos da ocupação, utilizamos as equações 5.33 e 5.32, a fim de obtermos a corrente elétrica no canal. Apresentaremos uma breve introdução à equação de Poisson e aos métodos de resolução numérica, antes de discutir nossas simulações. 
A equação de Poisson presente no modelo é uma equação elíptica de derivadas parciais. Esse tipo de equação surge no estudo de problemas físicos independentes do tempo, tais como a distribuição estacionária de calor em uma chapa e problemas estacionários 2D envolvendo fluídos incompressíveis [44]. No caso desse trabalho, ela será utilizada para determinar a densidade de cargas em todos os pontos da malha pela equação

$$
\frac{\partial^{2} V(i, j)}{\partial x^{2}}+\frac{\partial^{2} V(i, j)}{\partial y^{2}}=-\frac{\rho(i, j)}{\varepsilon_{s c} \varepsilon_{0}} .
$$

Para resolver essa equação, podem-se utilizar alguns métodos numéricos. Mas, para isso, necessitamos de condições de contorno. Neste trabalho objetivou-se resolver a equação de Poisson para valores definidos e constantes como condições de contorno, também chamado de problema de Dirichlet. Caso uma das condições de contorno fosse uma derivada, teríamos um problema de Neumann, o que não é o caso. Para a discretização dos valores das voltagens, usou-se o método das diferenças finitas, e considerou-se um conjunto finito de pontos na malha. Após isso, foram então calculados os valores de densidade de cargas. Primeiramente devem-se definir inteiros para os passos da malha, $n$ e $m$, respectivamente, para o eixo $x$ e $y$. De maneira que $\Delta x=$ $(b-a) / n$ e $\Delta y=(d-c) / m$, onde a e b são as extremidades de $L_{x}, c$ e $d$ são as extremidades de $L_{y}$. Assim, dividimos o intervalo [a,b] em n partes iguais de tamanho $\Delta \mathrm{x}$ e o intervalo $[\mathrm{c}, \mathrm{d}]$ em $\mathrm{m}$ partes iguais de tamanho $\Delta \mathrm{y}$. 


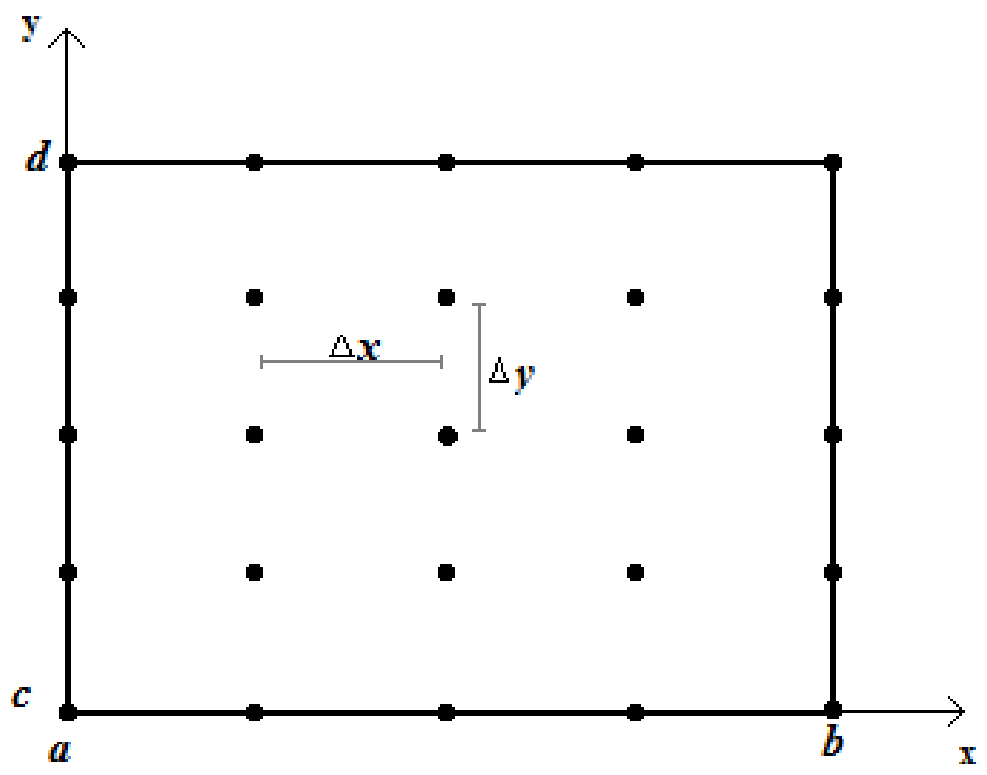

Figura 35: Malha de pontos.

\subsubsection{Método das Diferenças Finitas}

A ideia deste método é fazer a substituição das derivadas por diferenças finitas, por isso foi utilizada a expansão em Série de Taylor, mostrada a seguir, para a aproximação das equações diferenciais parciais. Supondo que $f$ seja uma função contínua no intervalo $[a, b]$ e que possua $n$ derivadas contínuas neste intervalo para todo $x \in[a, b]$. Expandindo a Série de Taylor em torno de $x_{0}$ e considerando $\Delta x=x-x_{0}$, temos

$$
f(x)=f\left(x_{0}\right)+f^{\prime}(x)(\triangle x)+\frac{f^{\prime \prime}(x)}{2 !}(\triangle x)^{2}+\frac{f^{\prime \prime \prime}(x)}{3 !}(\triangle x)^{3}+\ldots
$$

onde $f^{\prime n}$ é a derivada de ordem $n$ com relação a $x$ da função $f$. A derivada de uma função $f$ em um certo ponto $x_{i}$ será a expansão da Série de Taylor neste ponto de modo que

$$
f\left(x_{i}+\triangle x\right)=f\left(x_{i}\right)+f^{\prime}\left(x_{i}\right)(\triangle x)+\frac{f^{\prime \prime}\left(x_{i}\right)}{2 !}(\triangle x)^{2}+\frac{f^{\prime \prime \prime}\left(x_{i}\right)}{3 !}(\triangle x)^{3}+\ldots
$$


Isolando a primeira derivada e rearranjando os termos, temos

$$
f^{\prime}\left(x_{i}\right)=\frac{f\left(x_{i}+\triangle x\right)-f\left(x_{i}\right)}{\triangle x}+\left[-\frac{f^{\prime \prime}\left(x_{i}\right)}{2 !}(\triangle x)-\frac{f^{\prime \prime \prime}\left(x_{i}\right)}{3 !}(\triangle x)^{2}-\ldots\right]
$$

Sabendo que a expressão acima indica a derivada primeira, temos:

$$
f^{\prime}\left(x_{i}\right)=\frac{f\left(x_{i}+\triangle x\right)-f\left(x_{i}\right)}{\triangle x} .
$$

Os demais termos são chamados erro de truncamento local. Esse erro tende a zero quando o número de pontos da malha tende ao infinito [45]

$$
\text { ErroTrunc }=\left[-\frac{f^{\prime \prime}\left(x_{i}\right)}{2 !}(\triangle x)-\frac{f^{\prime \prime \prime}\left(x_{i}\right)}{3 !}(\triangle x)^{2}-\ldots\right]
$$

Para as derivadas de segunda ordem são necessárias as seguintes expansões em Série de Taylor:

$$
\begin{aligned}
& f\left(x_{i}+\triangle x\right)=f\left(x_{i}\right)+f^{\prime}\left(x_{i}\right)(\triangle x)+\frac{f^{\prime \prime}\left(x_{i}\right)}{2 !}(\triangle x)^{2}+O^{\prime}(\triangle x)^{3} \\
& f\left(x_{i}-\triangle x\right)=f\left(x_{i}\right)-f^{\prime}\left(x_{i}\right)(\triangle x)+\frac{f^{\prime \prime}\left(x_{i}\right)}{2 !}(\triangle x)^{2}+O^{\prime \prime}(\triangle x)^{3}
\end{aligned}
$$

Combinando os primeiros termos das duas equações acima e reorganizando-os, obtémse a derivada primeira pela fórmula chamada de diferença finita centrada, pois utiliza-se de um termo avançado $\left(f\left(x_{i}+\triangle x\right)\right)$ e um termo atrasado $\left(f\left(x_{i}-\triangle x\right)\right)$ em relação ao ponto de expansão, visto a seguir

$$
f^{\prime}\left(x_{i}\right)=\frac{f_{x_{i}+\triangle x}-f_{x_{i}-\triangle x}}{2(\triangle x)}+O(\triangle x)^{2}
$$


A equação da derivada segunda é aproximada à uma maneira análoga:

$$
f^{\prime \prime}\left(x_{i}\right)=\frac{f_{x_{i}+\triangle x}-2 f_{x_{i}}+f_{x_{i}-\triangle x}}{(\triangle x)^{2}}+O(\triangle x)^{2}
$$

Se escrevermos nossa malha $f(x, y)$ como sendo $V_{i, j}$ obtemos a seguinte discretização:

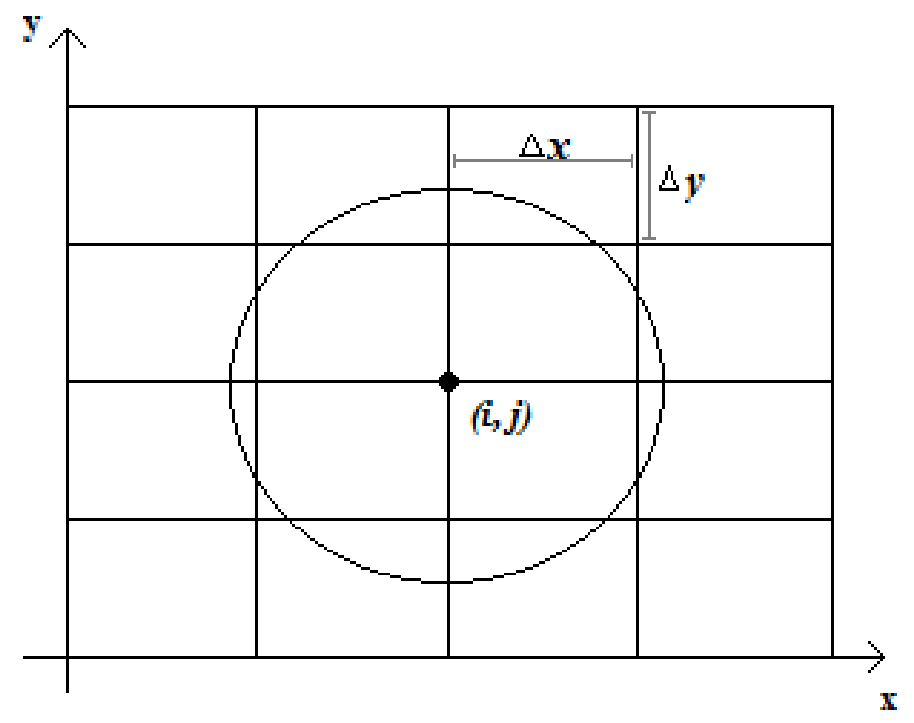

Figura 36: Discretização da malha em termos de i,j

As voltagens nos pontos da malha também podem ser discretizadas em termos de i,j da seguinte forma: 


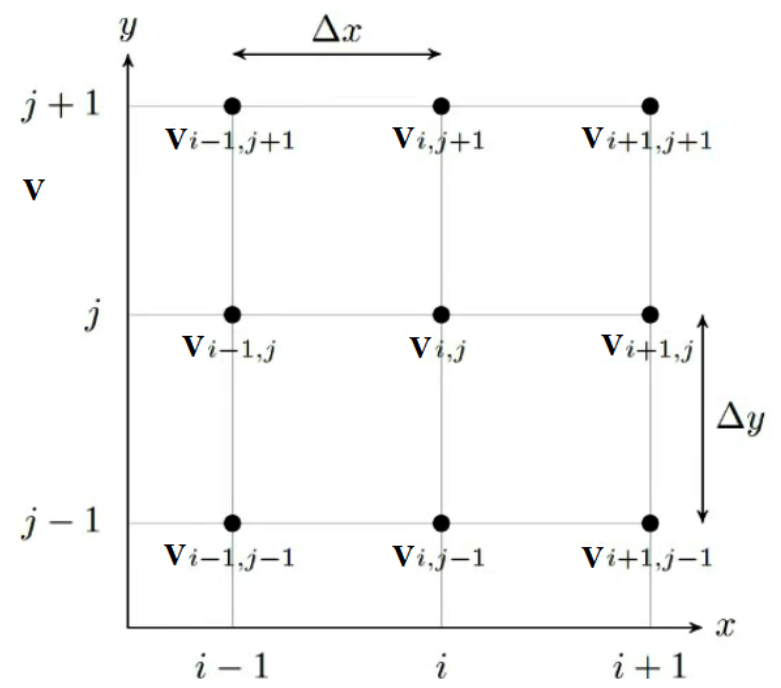

Figura 37: Discretização das voltagens em termos de i,j

Assim, a equação

$$
\frac{\partial^{2} V}{\partial x^{2}}(x, y) \approx \frac{V(x+\Delta x, y)-2 V(x, y)+V(x-\Delta x, y)}{(\Delta x)^{2}}
$$

em termos das coordenadas espaciais da malha, assume a forma

$$
V_{i, j}^{\prime \prime}=\frac{V_{i+1, j}-2 V_{i, j}+V_{i-1, j}}{(\Delta x)^{2}}
$$

De modo análogo, a equação

$$
\frac{\partial^{2} V}{\partial y^{2}}(x, y) \approx \frac{V(x+\Delta x, y)-2 V(x, y)+V(x-\Delta x, y)}{(\Delta \mathrm{y})^{2}}
$$

assume a forma

$$
V_{i, j}^{\prime \prime}=\frac{V_{i+1, j}-2 V_{i, j}+V_{i-1, j}}{(\Delta \mathrm{y})^{2}}
$$

Unindo os termos aproximados para a derivada parcial em x (equação 5.49) e para a 
derivada parcial em y (equação 5.51), podemos reescrever a equação 5.38 como sendo:

$$
\frac{V_{i+1, j}-2 V_{i, j}+V_{i-1, j}}{(\Delta x)^{2}}+\frac{V_{i+1, j}-2 V_{i, j}+V_{i-1, j}}{(\Delta y)^{2}}=-\frac{\rho(i, j)}{\varepsilon_{s c} \varepsilon_{0}}
$$

Como o valor da densidade de cargas ainda não é conhecido, fazemos o lado direito da equação acima como sendo uma constante A, pois, o problema assumido é do tipo estacionário. Além disso, assumimos que $\Delta \mathrm{x}$ e $\Delta \mathrm{y}$ são iguais, ambos valendo $\mathrm{h}$, e multiplicamos os dois lados da equação por $\mathrm{h}^{2}$. O que nós desejamos encontrar é o valor $\mathrm{V}_{i, j}$ em cada ponto da malha, logo, isolamos esse termo e rearranjamos a equação, resultando em

$$
V_{i, j}=\frac{V_{i+1, j}+V_{i-1, j}+V_{i, j+1}+V_{i, j-1}+A h^{2}}{4}
$$

Essa aproximação para cada um dos pontos é chamada de Método das Diferenças Finitas [46]. Isso resulta em um sistema linear $(n-1)(m-1) \times(n-1)(m-1)$ no qual os valores a serem calculados são as voltagens nos pontos internos. De posse dessas aproximações, podemos agora utilizar o método de Gauss-Seidel para resolver o sistema de equações.

\subsubsection{Método de Gauss-Seidel para obtenção da voltagem nos pontos da malha $2 \mathrm{D}$}

Digamos que haja uma malha composta por uma camada isolante e, acima dela, uma camada semicondutora; além disso, suponhamos que haja seis regiões de contorno (1..6) para tal malha, como mostrado na figura 38. 


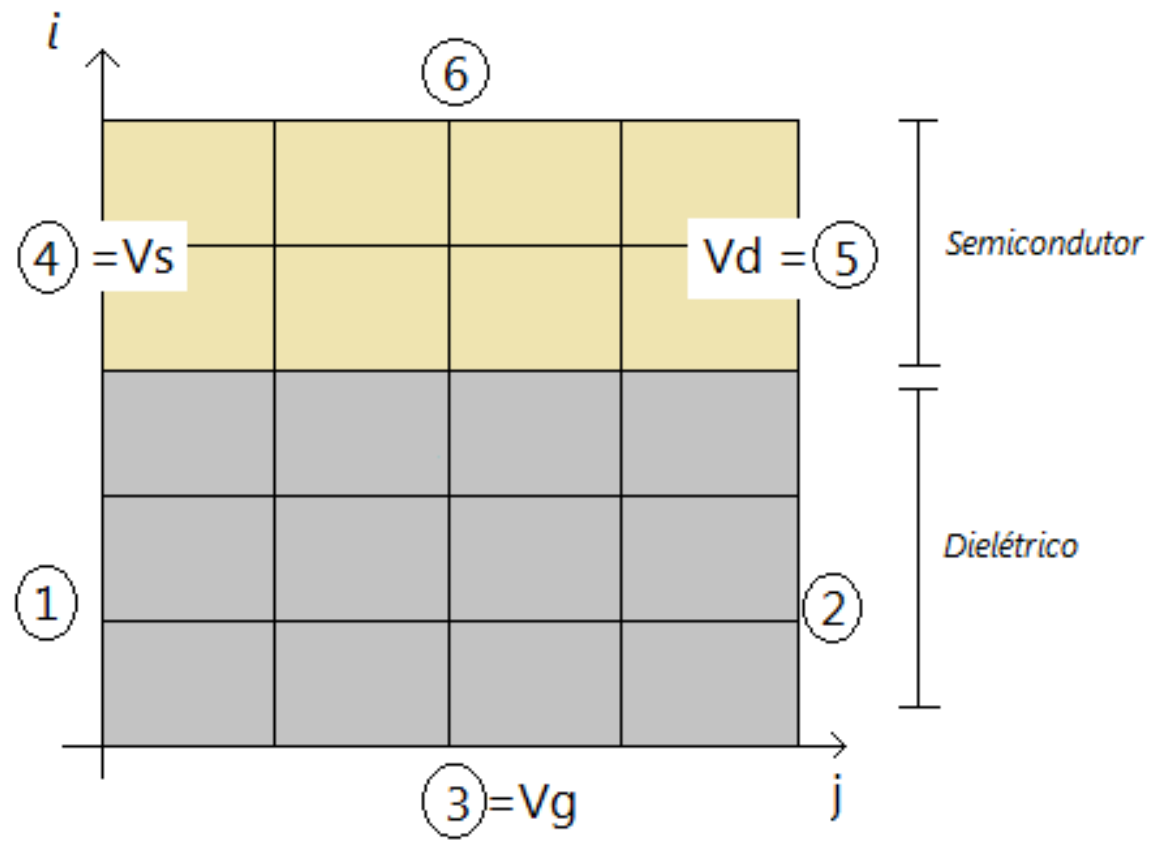

Figura 38: Camadas semicondutora e isolante na malha i,j. Presença de seis regiões de contorno (1..6).

Suponhamos também que as condições de contorno sejam essas:

- A voltagem na região 3 é voltagem na Porta $\left(V_{g}\right)$.

- A voltagem na região 4 é a voltagem na Fonte $\left(V_{s}\right)$.

- A voltagem na região 5 é a voltagem no Dreno $\left(V_{d}\right)$.

- A voltagem na região 1 cresce linearmente da porta até a voltagem na interface dielétrico-fonte. Definindo o número de pontos dessa região como $L_{d}$, podemos simplificar as voltagens em cada ponto dessa região pela seguinte equação

$$
V_{1(i, 0)}=V_{g}-i\left(\frac{V_{g}-V_{s}}{L_{d}-1}\right)
$$

- A voltagem na região 2 cresce linearmente da porta até a voltagem na interface dielétrico-dreno. De modo análogo à região 1, podemos simplificar as voltagens em cada 
ponto dessa região pela seguinte equação:

$$
V_{2(i, j=n)}=V_{g}-i\left(\frac{V_{g}-V_{d}}{L_{d}-1}\right)
$$

- A voltagem na região 6 cresce linearmente da fonte (Vs) até a voltagem (Vd) no dreno. Somando o número de pontos dessa região com $L_{d}$ e definindo-os como $L_{x}$, podemos caracterizar as voltagens pela equação:

$$
V_{6(i=m, j)}=V_{s}+j\left(\frac{V_{d}-V_{s}}{L_{x}-1}\right)
$$

Para os pontos internos, podemos iniciar o cálculo atribuindo um valor inicial para eles (espécie de "chute" inicial). Para cada um desses pontos resolveremos a equação 5.53 para obter os valores de voltagem, começando nos pontos adjacentes às regiões de fronteira, nas quais os valores já são conhecidos. Essa primeira resolução será considerada como a primeira iteração. O objetivo é resolver iterativamente essa equação até que se obtenha um valor de voltagem entre as iterações subsequentes dentro de uma tolerância pré-estipulada.

De posse desses resultados das voltagens em todos os pontos da malha, pode-se obter a densidade de cargas no material e, assim, concluir a resolução numérica do modelo de Vissenberg-Matters. Em nossas simulações, utilizamos 256 pontos para o eixo y do dielétrico, bem como 256 pontos para o eixo y do semicondutor; além de 512 pontos para o eixo $\mathrm{x}$ de todo o dispositivo.

\subsubsection{Simulação computacional}

O programa que fizemos em linguagem C para realizar o cálculo de corrente elétrica em um transistor orgânico de efeito de campo é apresentado no apêndice. A metodologia de Vissenberg-Matters se aplica ao transporte de cargas apenas quando o OFET está operando em regime linear, não sendo considerada satisfatória para modelar 
o regime de saturação. A proposição inicial é que a densidade de estados localizados (DOS) no semicondutor pode ser caracterizada por uma distribuição gaussiana. Quando a densidade de portadores de carga e a temperatura são baixas, o transporte de cargas pode ser aproximado pelo início (cauda) de uma distribuição exponencial. Esse esquema é ilustrado na figura 39 .

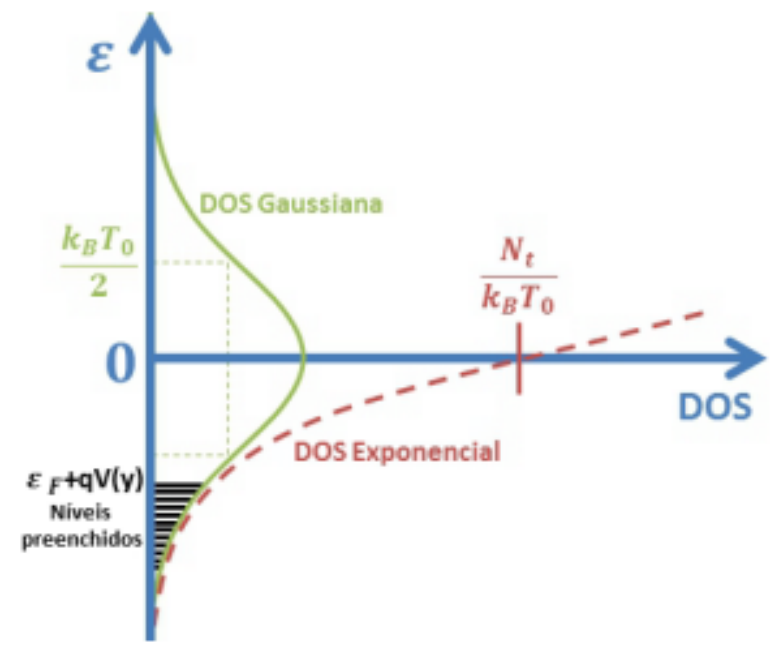

Figura 39: Distribuição gaussiana para a Densidade de Estados Localizados e uma aproximação exponencial para o início da curva, onde ocorre o regime linear de operação do OFET. Os termos das equações são descritos nas subseções anteriores. Imagem retirada da referência [9].

Sendo assim, as simulações, que ocorreram variando-se a voltagem no dreno entre 0 e $-100 \mathrm{~V}$, aqui são apresentadas apenas até -10V, já que a voltagem de limiar encontrada para o transistor estudado foi de aproximadamente $-9 \mathrm{~V}$, segundo a análise feita por meio da aproximação de canal gradual, vista na seção 4.2. No entanto, as simulações e os parâmetros encontrados para o OFET em questão não podem ser comparados; isto porque a metodologia utilizada nas simulações, via mecanismo de hopping e percolação, é altamente dependente de alguns dados que não nos foram disponibilizados, sendo o principal deles a temperatura do transistor, além de informações sobre a temperatura do ambiente, informações sobre os tipos de materiais utilizados nas ponteiras de contato do equipamento de medição Keithley 2400, resistência dos contatos, dentre outros. Por 
isso, as simulações tentaram descrever/prever apenas um comportamento linear da corrente elétrica em relação ao aumento de voltagem no dreno.

A tabela 2 mostra os valores de corrente elétrica obtidos de 0 a - $10 \mathrm{~V}$ no dreno para uma voltagem fixa de -30V na porta do OFET.

\begin{tabular}{|c|c|}
\hline Vd & Corrente Elétrica $(\mu \mathrm{A})$ \\
\hline 0 & 0 \\
\hline 1 & $3,877 \mathrm{E}-10$ \\
\hline 2 & $9,4374 \mathrm{E}-10$ \\
\hline 3 & $1,84316 \mathrm{E}-09$ \\
\hline 4 & $2,96876 \mathrm{E}-09$ \\
\hline 5 & $3,45778 \mathrm{E}-09$ \\
\hline 6 & $4,65012 \mathrm{E}-09$ \\
\hline 7 & $5,58751 \mathrm{E}-09$ \\
\hline 8 & $6,81297 \mathrm{E}-09$ \\
\hline 9 & $8,12048 \mathrm{E}-09$ \\
\hline 10 & $9,30475 \mathrm{E}-09$ \\
\hline
\end{tabular}

Tabela 2: Valores de corrente elétrica $-(\mu \mathrm{A})$ para cada valor de voltagem no dreno (-) Vd de $\{0$ a $10 \mathrm{~V}\}$.

Perceba pelo gráfico da figura 40 que os valores de 0 a $10 \mathrm{~V}$ mostram um comportamento linear, algo esperado para o trabalho do transistor antes da voltagem de limiar. Plotando tais dados, obtemos uma curva com Coeficiente de Determinação $\left(R^{2}\right)$ de 0,904, mostrando que os regressores do modelo de Vissenberg-Matters, nesse caso, conseguiram explicar muito bem o comportamento de transporte eletrônico e, além disso, serviu de parâmetro para saber se a simulação obtivera êxito. Pelos dados colhidos, vemos um resultado satisfatório, porém, deve-se levar em conta a problemática dos parâmetros citados acima que não foram obtidos e que são intrínsecos ao modelo. 


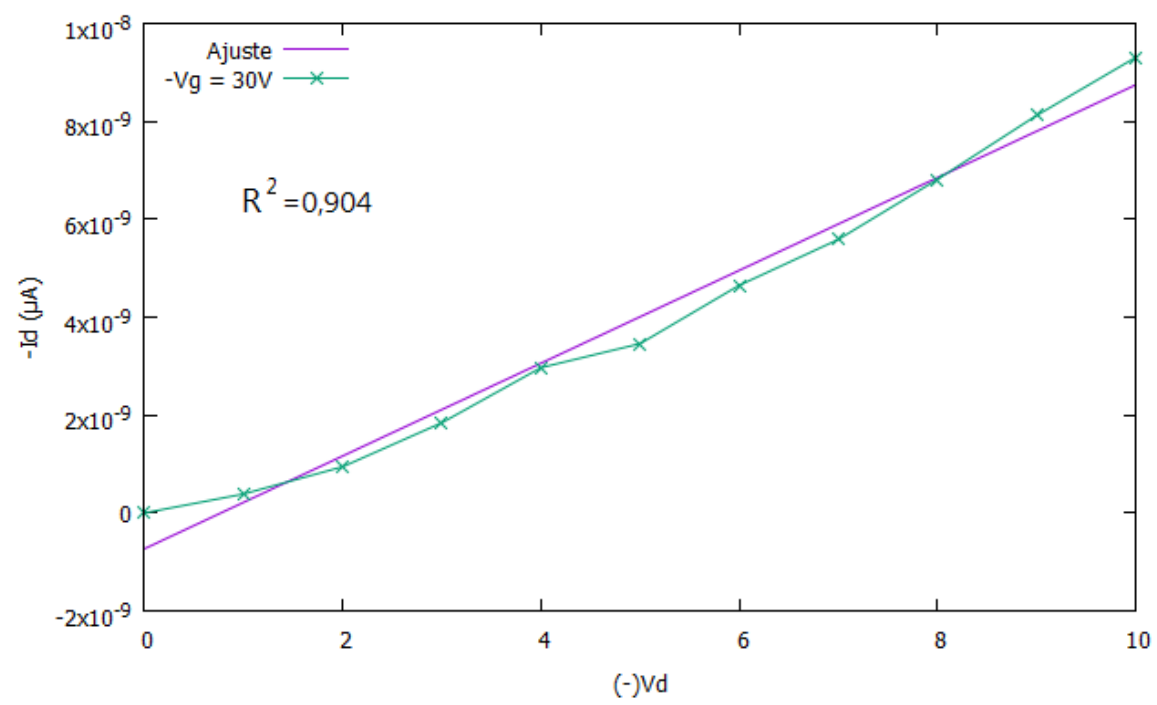

Figura 40: Curva de saída obtida pela simulação computacional do modelo de Vissenberg-Matters.

\subsubsection{Algoritmo em Português Estruturado}

/* Autor: Pedro Henrique

Assunto: Algoritmo em Português Estruturado para cálculo da corrente $x$ voltagem em OFETs utilizando metodologia

de Vissenberg-Matters

Dissertação de Mestrado

Data : $03 / 2016$

$* /$

Algoritmo ModeloVM

defina $\mathrm{Lz}, \mathrm{Lx}, \mathrm{Lz} / /$ tamanho fisico dos eixos

defina nd, nx, ny $/ / \mathrm{n}^{\mathrm{o}}$ de pontos na malha dos eixos

Inicio

$\operatorname{var}$

$$
\begin{aligned}
& \mathrm{i}, \mathrm{j}, \mathrm{k}, \text { iteracao : inteiro } \\
& \mathrm{vg}, \mathrm{vs}, \mathrm{vd}: \text { real //voltagens nos terminais }
\end{aligned}
$$


malha1[nx][ny], malha2[nx][ny] : real //voltagem atual e ant. nos pts tolerancia : real

$\mathrm{h}:$ real //passo

e0, esc, eps : real //permissividades

para vd de -10 ate 15 passo 1 Faça

//Condicoes de contorno $* * * * * * * * * * * * * * * * * * * * * * * * * * * * * * * *$

para $i$ de 0 ate nd-1 passo 1 Faça

malha1 [i $][0]=\_/ /$eq $\cdot 5.54$

malha1 [i $][\mathrm{nx}-1]=\_/ / \mathrm{eq} \cdot 5.55$

FimPara

para $i$ de nd ate ny-1 passo 1 Faça

malha1 $[\mathrm{i}][0]=\mathrm{vs}$

malha1 $[\mathrm{i}][\mathrm{nx}-1]=\mathrm{vd}$

FimPara

para $j$ de 0 ate $n x-1$ passo 1 Faça

$$
\begin{aligned}
& \text { malha } 1[0][j]=\mathrm{vg} \\
& \text { malha } 1[\mathrm{ny}-1][\mathrm{j}]=\_-/ / \mathrm{eq} \cdot 5.56
\end{aligned}
$$

FimPara

$/ /$ Voltagens in i ciais $* * * * * * * * * * * * * * * * * * * * * * * * * * * * * * * * * * *$

para i de 1 ate ny-2 passo 1 Faça

para j de 1 ate $n x-2$ passo 1 Faça

malha1 $[\mathrm{i}][\mathrm{j}]=-$ - $/ /$ chute inicial

malha2[i][j]=_- / / chute inicial

FimPara

FimPara

//Iteracoes para resolver eq. Poisson $* * * * * * * * * * * * * * * * * *$

para i de 1 ate ny-2 passo 1 Faça

para j de 1 ate nx-2 passo 1 Faça 


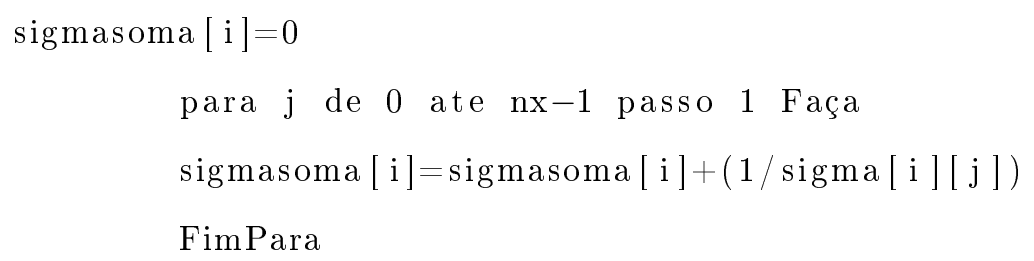

Var

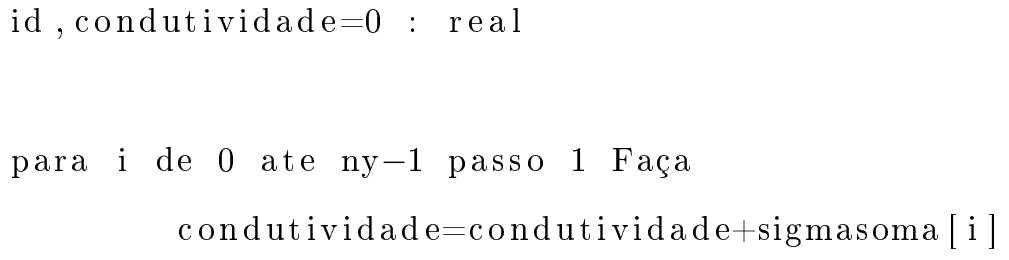

Fim Algoritmo . 


\section{Conclusão}

A meta alcançada por este trabalho foi a de corroborar para a crescente pesquisa que vem ocorrendo no últimos anos no campo da eletrônica orgânica. A contextualização histórica dos semicondutores orgânicos foi apresentada para que, assim, haja uma melhor visualização do desenvolvimento desse ramo industrial, cujos objetos de pesquisa começam a se materializar em nosso dia a dia por meio de insumos eletroeletrônicos cada vez mais intrínsecos à nossas rotinas, tais como os OLEDS em faróis de carros, telas AMOLED de televisores e aparelhos celulares, células fotovoltáicas em nossos telhados, enfim. Mostramos ainda como é a atual situação desse setor no Brasil, tanto na parte de pesquisa como na parte econômica, e também na esfera política, com a ilustração de algumas leis que favorecem a produção de semicondutores.

Realizamos a modelagem do comportamento das cargas presentes em semicondutores orgânicos quando submetidos a uma diferença de potencial, tanto por meios teóricos como por meios práticos. Tratamos de algumas teorias que envolveram diferentes abordagens para explicar como se dá o transporte de cargas em tais sistemas orgânicos desordenados. Sendo que, os métodos mais detalhados foram a Aproximação de Canal Gradual (GCA) e o modelo de hopping por percolação criado por Vissenberg-Matters. Tanto analiticamente quanto numericamente, expomos tais modelos e mostramos todos os aspectos teóricos e suas aplicações em situações práticas para a pesquisa científica, ilustrando como são realizadas as pesquisas com dispositivos eletrônicos por meio desses métodos, envolvendo a caracterização física e modelagem operacional.

Uma abordagem especial foi feita a um dos principais elementos da eletrônica orgânica - os transistores de efeito de campo (OFETs), que podem ser construídos tanto com moléculas pequenas quanto com polímeros. Detalhamos os padrões necessários para se caracterizar um OFET segundo a norma internacional vigente, estabelecida pela IEEE. Além disso, fizemos a análise de um OFET, cujo material semicondutor foi 
pentaceno, por meio da GCA. Além de mostrar todos os valores das curvas de saída e transferência dos testes que realizamos com o OFET, extraímos e explicamos todas as características necessárias à operação desse transistor orgânico segundo o padrão internacional; evidenciando, assim, que apesar de o modelo GCA ser o mais simples, também é relevante para o estudo do regime de operação destes dispositivos orgânicos. Além disso, propusemos um novo método para se obter a Voltagem de Limiar por meio de um ajuste às curvas de saída, o qual se mostrou bastante eficaz para determinar o fim do regime linear de operação do transistor.

Em uma abordagem mais didática, escrevemos um algoritmo em Português Estruturado com vistas à uma maior intuição de programação. O programa que desenvolvemos em linguagem $\mathrm{C}$ para realizar as simulações computacionais e explicar o modelo de Vissenberg-Matters obteve resultados extremamente satisfatórios, revelando o porquê de esse método ser um dos mais utilizados ao se estudar e modelar o comportamento das cargas de um transistor orgânico durante o regime linear de operação.

Dentre as propostas que surgiram no trato dessa pesquisa fica a possibilidade de desenvolver o método de condutividade por hopping via percolação também para o regime de saturação do transistor, obtendo, assim, os valores da razão entre os estados on/off do dispositivo e a mobilidade de cargas quando operando em saturação. Uma outra proposta que surge é a de, por dopagem, criar-se barreiras dielétricas no semicondutor para que, quando a voltagem entre fonte e dreno rompesse o dielétrico desse material dopante, um novo pico de corrente elétrica fosse obtido, criando-se, assim, um dispositivo que poderia chavear três estados diferentes de operação, e não somente dois como é comumente feito para transistores. Esse tipo de abordagem de engenharia de canal e sua respectiva modelagem também ficam sugeridas para trabalhos posteriores, sendo que podem ser aplicadas tanto para transistores orgânicos quanto para inorgânicos. 


\section{Referências}

[1] M. Vissenberg and M. Matters. Theory of the field-effect mobility in amorphous organic transistors. Physical Review B, 57(20):12964, 1998.

[2] Abinee. Balanço comercial. Disponível em: http://www.abinee.org.br/abinee/decon/decon15.htm. Acesso em 01/08/2015.

[3] T. J. Chow. Organic Structures Design - Applications in Optical and Electronic Devices. Pan Stanford, 2014.

[4] P. Muller-Buschbaum. Polymerphysik. http://www.e13.physik.tumuenchen.de/Muellerb/Uebung/chapter05.pdf. Lehrstuhl fur Funktionelle Materialien, Technische Universitat Munchen.

[5] A. S. Sedra and K. C. Smith. Microelectronic circuits, volume 1. Oxford university press, 1998.

[6] A. V. S. Parry. Small Molecule Organic Field Effect Transistors: Vacuum Evaporation And Solution Processable Monolayer Devices. PhD thesis, School of Chemistry, University of Manchester, 2013.

[7] L. Gross et al. The chemical structure of a molecule resolved by atomic force microscopy. Science, 325(5944):1110-1114, 2009.

[8] A. Takshi. Organic metal-semiconductor field-effect transistor (OMESFET). PhD thesis, University of British Columbia, Canada., 2007.

[9] A. C. Maciel. Fabricao e estudo das propriedades de transporte de transistores de filmes finos organicos. PhD thesis, Universidade de Sao Paulo, 2012. 
[10] F. A. Castro. Estudo de processos eletronicos em dispositivos a base de semicondutores organicos. PhD thesis, Instituto de Fisica de Sao Carlos, Universidade de Sao Paulo, 2004.

[11] B. Amaral. Indústria mundial de consumo de eletrônicos. Disponível em: http://exame.abril.com.br/tecnologia/noticias/industria-mundial-deeletronicos-de-consumo-desacelera. Acesso: 01/08/2015.

[12] Exame. Desoneração de semicondutores. Revista online. Disponível em http://exame.abril.com.br/geral/noticias/senado-aprova-projeto-parasetor-de-semicondutores-2. Acesso em 01/08/2015.

[13] Exame. Faturamento do setor de eletrônicos deve crescer. Revista online. Disponível em http://exame.abril.com.br/economia/noticias/faturamento-do-setor-deeletroeletronicos-deve-crescer-2. Acesso em 30/09/2015.

[14] Brasil. Centro de Gestão e Estudos Estratégicos. Eletrônica orgânica: contexto e proposta de ação para o brasil, 2011.

[15] S. M. Rezende. Materiais e dispositivos eletrônicos. Editora Livraria da Física, 2004.

[16] W. Brinkman et al. A history of the invention of the transistor and where it will lead us. Solid-State Circuits, IEEE Journal of, 32(12):1858-1865, 1997.

[17] Nobel Prize. $\quad$ Physics $1956 . \quad$ Disponível em http://www.nobelprize.org/nobelprizes/physics/laureate s/1956. Acesso em $03 / 08 / 2015$.

[18] Computer History Museum. The european transistor invention. Disponível em http://www.computerhistory.org/semiconductor/timeline/1948-European.html. Acesso em 02/08/2015. 
[19] R. Shrout. Intel xeon e5-2600 v3 processor overview: Haswell-ep up to 18 cores. Disponível em http://www.pcper.com/reviews/Processors/Intel-Xeon-E5-2600-v3Processor-Overview-Haswell-EP-18-Cores. Acesso em 03/08/2015.

[20] H. Shirakawa et al. Electrical conductivity in doped polyacetylene. Physical Review Letters, 39(17):1098, 1977.

[21] Nobel Prize. Chemistry 2000. Disponível em http://www.nobelprize.org/nobelprizes/chemistry/lau reates/2000. Acesso em $03 / 08 / 2015$.

[22] Z. Bao. Organic materials for thin film transistors. Volume 3, Number 4, Material Matters, 2007.

[23] M. Pope and C. E. Swenberg. Electronic processes in organic crystals and polymers. Oxford University Press on Demand, 1999.

[24] J-L. Brédas, D. Beljonne, V. Coropceanu, and J. Cornil. Charge-transfer and energy-transfer processes in $\pi$-conjugated oligomers and polymers: a molecular picture. Chemical Reviews, 104(11):4971-5004, 2004.

[25] J-L. Brédas, J. P. Calbert, D. A. da Silva Filho, and J. Cornil. Organic semiconductors: A theoretical characterization of the basic parameters governing charge transport. Proceedings of the National Academy of Sciences, 99(9):5804-5809, 2002.

[26] V. Coropceanu, J. Cornil, D. A. da Silva Filho, Y. Olivier, R. Silbey, and J-L. Brédas. Charge transport in organic semiconductors. Chemical reviews, 107(4):926952, 2007.

[27] W. A. Little. Possibility of synthesizing an organic superconductor. Physical Review, 134(6A):A1416, 1964. 
[28] M. Fowler. Electrons in one dimension: the peierls transition. http://galileo.phys.virginia.edu/classes/752.mfli.spring03/PeierlsTrans.htm, 2007.

[29] J-L. Brédas and G. B. Street. Polarons, bipolarons, and solitons in conducting polymers. Accounts of Chemical Research, 18(10):309-315, 1985.

[30] L. D. Landau and S. Pekar. Effective mass of the polaron. J. Exp. Theor. Phys, 18:419-423, 1948.

[31] N. E. Gruhn et al. The vibrational reorganization energy in pentacene: molecular influences on charge transport. Journal of the American Chemical Society, 124(27):7918-7919, 2002.

[32] A. J. Chiquito and F. Lanciotti Jr. Semiconductor superlattices: a quantum mechanics laboratory. Revista Brasileira de Ensino de Fúsica, 26(4):315-322, 2004.

[33] G. Horowitz et al. Organic field-effect transistors. Advanced Materials, 10(5):365$377,1998$.

[34] H. Bässler and A. Köhler. Charge transport in organic semiconductors. In Unimolecular and Supramolecular Electronics I, pages 1-65. Springer, 2012.

[35] M. Weis. Gradual channel approximation models for organic field-effect transistors: The space-charge field effect. Journal of Applied Physics, 111(5):054506, 2012.

[36] M. Weis, T. Manaka, and M. Iwamoto. Origin of electric field distribution in organic field-effect transistor: Experiment and analysis. Journal of Applied Physics, 105(2):024505, 2009.

[37] D. Gundlach et al. Pentacene organic thin-film transistors-molecular ordering and mobility. Electron Device Letters, IEEE, 18(3):87-89, 1997. 
[38] H. B. Akkerman et al. Tips-pentacene crystalline thin film growth. Organic Electronics, 13(10):2056-2062, 2012.

[39] R. T. Weitz et al. The importance of grain boundaries for the time-dependent mobility degradation in organic thin-film transistors. Chemistry of Materials, 21(20):4949-4954, 2009.

[40] G. Horowitz et al. The concept of threshold voltage in organic field-effect transistors. Advanced Materials, 10(12):923-927, 1998.

[41] M. C. J. M. Vissenberg. Opto-electronic properties of disordered organic semiconductors. PhD thesis, University of Leiden, The Netherlands, 1999.

[42] A. R. Brown, C. P. Jarrett, D. M. De Leeuw, and M. Matters. Field-effect transistors made from solution-processed organic semiconductors. Synthetic metals, 88(1):37-55, 1997.

[43] E. Smits et al. Ambipolar charge transport in organic field-effect transistors. Physical Review B, 73(20):205316, 2006.

[44] R. Burden, J. Faires, and A. Burden. Numerical analysis. Nelson Education, 2008.

[45] V. R. Rocho. Métodos Iterativos para a Solução da Equação de Poisson. PhD thesis, Universidade Federal do Rio Grande do Sul, 2012.

[46] S. C. Chapra and R. P. Canale. Numerical methods for engineers, volume 2. McGraw-Hill, 2012. 


\section{A Apêndice - Proposta de programa em linguagem C para mo- delo de transporte eletrônico em OFET (Vissenberg-Matters)}

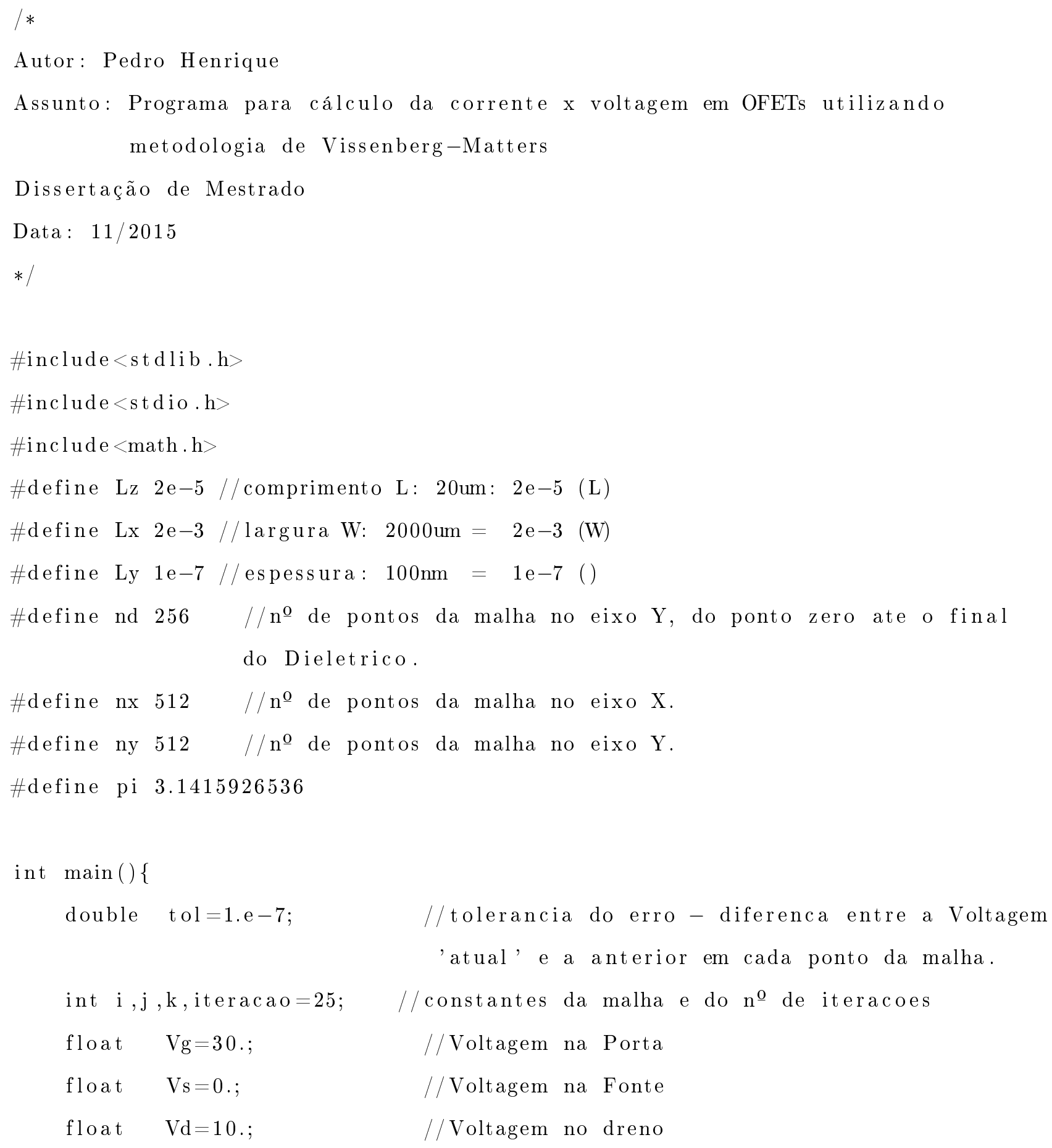




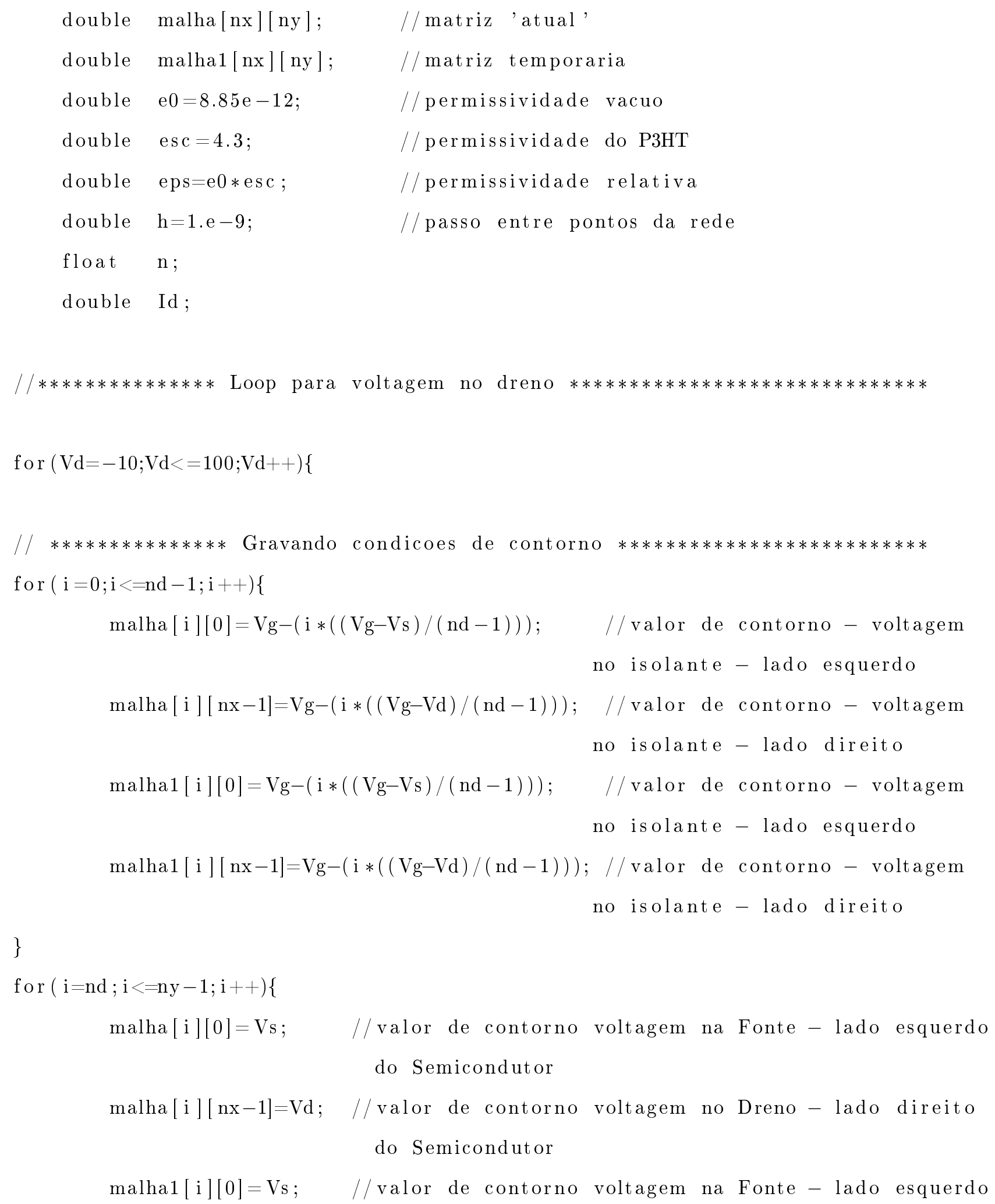


do Semicondutor

malha1[i][nx-1] $=\mathrm{Vd}$; //valor de contorno voltagem no Dreno - lado direito do Semicondutor

\}

for $(\mathrm{j}=0 ; \mathrm{j}<=\mathrm{nx}-1 ; \mathrm{j}++)\{$

malha $[0][j]=V g ; \quad$ / valor de contorno voltagem na Porta malha $[\mathrm{ny}-1][\mathrm{j}]=\mathrm{Vs}+(\mathrm{j} *((\mathrm{Vd}-\mathrm{Vs}) /(\mathrm{nx}-1))) ; \quad / /$ valor de contorno parte superior do Semicondutor malha1 $[0][\mathrm{j}]=\mathrm{Vg}$; $\quad$ //valor de contorno voltagem na Porta malha1 $[\mathrm{ny}-1][\mathrm{j}]=\mathrm{Vs}+(\mathrm{j} *((\mathrm{Vd}-\mathrm{Vs}) /(\mathrm{nx}-1))) ; / /$ valor de contorno parte superior do Semicondutor

\}

$/ / * * * * * * * * * * * * * * *$ Matriz Inicial $* * * * * * * * * * * * * * * * * * * * * * * * * * *$

for $(\mathrm{i}=1 ; \mathrm{i}<=\mathrm{ny}-2 ; \mathrm{i}++)\{$

for $(\mathrm{j}=1 ; \mathrm{j}<=\mathrm{nx}-2 ; \mathrm{j}++)\{$ malha[i][j]=0; //chute inicial $\mathrm{V}=0$ nos pontos internos malha1 $[i][j]=0 ; / /$ chute inicial $V=0$ nos pontos internos

\}

\}

$/ / * * * * * * * * * * * * * * *$ It eracao $* * * * * * * * * * * * * * * * * * * * * * * * * * *$

$\mathrm{k}=1$

int imprecisao $=1$;

while $(\mathrm{k}<$ iteracao $\|$ imprecisao $==1)\{\quad / /$ condicao de parada .

// Criação da malha1[i][j] - Metodo de Gauss-Seidel 


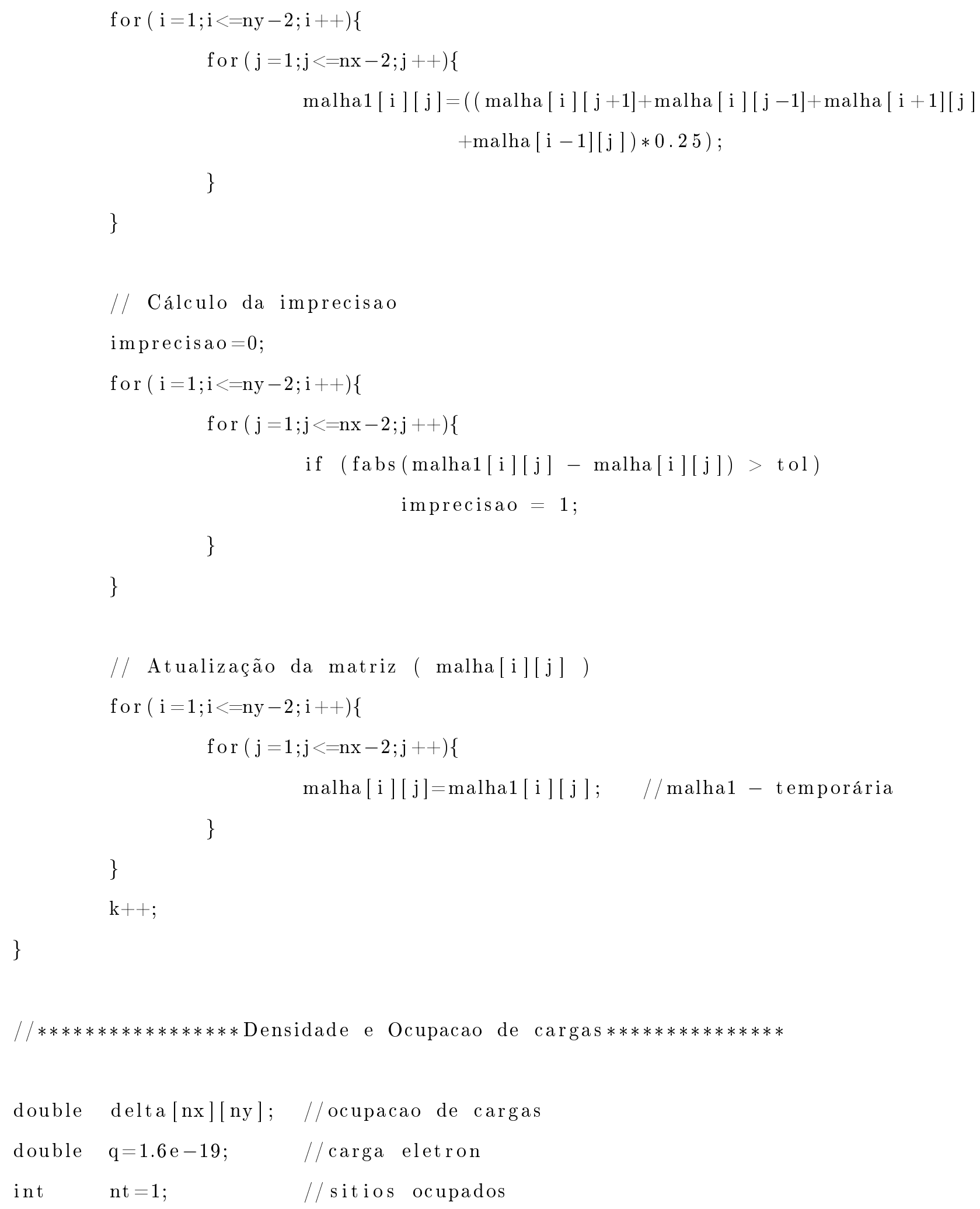


double $\quad \mathrm{ds}=1 . \mathrm{e}-9$

for $(\mathrm{i}=1 ; \mathrm{i}<=$ ny $-2 ; \mathrm{i}++)\{$

for $(\mathrm{j}=1 ; \mathrm{j}<=\mathrm{nx}-2 ; \mathrm{j}++)\{$

delta $[\mathrm{i}][\mathrm{j}]=(-\operatorname{eps} * \mathrm{~h} /(\mathrm{nt} * \mathrm{q} * \mathrm{ds})) *($ malha $[\mathrm{i}][\mathrm{j}-1]+$ malha $[\mathrm{i}][\mathrm{j}+1]$

+ malha $[i-1][j]+$ malha $[i+1][j])$;

\}

\}

for $(\mathrm{i}=1 ; \mathrm{i}<=\mathrm{ny}-2 ; \mathrm{i}++)\{$

delta $[\mathrm{i}][0]=(-\operatorname{eps} * \mathrm{~h} /(\mathrm{nt} * \mathrm{q} * \mathrm{ds})) *($ malha $[\mathrm{i}][0]+$ malha $[\mathrm{i}][1]$

+malha $[\mathrm{i}-1][0]+$ malha $[\mathrm{i}+1][0]-4 *$ malha $[\mathrm{i}][0])$;

delta [i ] [nx-1] $=(-\operatorname{eps} * \mathrm{~h} /(\mathrm{nt} * \mathrm{q} * \mathrm{ds})) *($ malha $[\mathrm{i}][\mathrm{nx}-2]+$ malha [i $][\mathrm{nx}-1]$

+ malha $[\mathrm{i}-1][\mathrm{nx}-1]+$ malha $[\mathrm{i}+1][\mathrm{nx}-1]-4 *$ malha $[\mathrm{i}][\mathrm{nx}-1])$;

\}

for $(\mathrm{j}=1 ; \mathrm{j}<=\mathrm{nx}-2 ; \mathrm{j}++)\{$

$\operatorname{delta}[0][\mathrm{j}]=(-\operatorname{eps} * \mathrm{~h} /(\mathrm{nt} * \mathrm{q} * \mathrm{ds})) *($ malha $[0][\mathrm{j}-1]+$ malha $[0][\mathrm{j}+1]$

+ malha $[0][\mathrm{j}]+$ malha $[1][\mathrm{j}]-4 *$ malha $[0][\mathrm{j}])$;

$\operatorname{delta}[n y-1][j]=(-\operatorname{eps} * \mathrm{~h} /(\mathrm{nt} * \mathrm{q} * \mathrm{ds})) *($ malha $[n y-1][j-1]+$ malha $[n y-1][j+1]$

+ malha $[n y-2][j]+$ malha $[n y-1][j]-4 *$ malha $[n y-1][j])$;

\}

$\operatorname{delta}[0][0]=(-\operatorname{eps} * \mathrm{~h} /(\mathrm{nt} * \mathrm{q} * \mathrm{ds})) *($ malha $[0][0]+$ malha $[0][1]$

+malha $[0][0]+$ malha $[1][0]-4 *$ malha $[0][0])$;

$\operatorname{delta}[0][\mathrm{nx}-1]=(-\mathrm{eps} * \mathrm{~h} /(\mathrm{nt} * \mathrm{q} * \mathrm{ds})) *($ malha $[0][\mathrm{nx}-2]+$ malha $[0][\mathrm{nx}-1]$

+malha $[0][\mathrm{nx}-1]+$ malha $[1][\mathrm{nx}-1]-4 *$ malha $[0][\mathrm{nx}-1])$;

delta $[\mathrm{ny}-1][0]=(-\mathrm{eps} * \mathrm{~h} /(\mathrm{nt} * \mathrm{q} * \mathrm{ds})) *($ malha $[\mathrm{ny}-1][0]+$ malha $[\mathrm{ny}-1][1]$

+malha $[\mathrm{ny}-2][0]+$ malha $[\mathrm{ny}-1][0]-4 *$ malha $[\mathrm{ny}-1][0])$;

$\operatorname{delta}[\mathrm{ny}-1][\mathrm{nx}-1]=(-\mathrm{eps} * \mathrm{~h} /(\mathrm{nt} * \mathrm{q} * \mathrm{ds})) *($ malha $[\mathrm{ny}-1][\mathrm{nx}-2]+$ malha $[\mathrm{ny}-1][\mathrm{nx}-1]$ 
+malha $[\mathrm{ny}-2][\mathrm{nx}-1]+$ malha $[\mathrm{ny}-1][\mathrm{nx}-1]-4 *$ malha $[\mathrm{ny}-1][\mathrm{nx}-1])$;

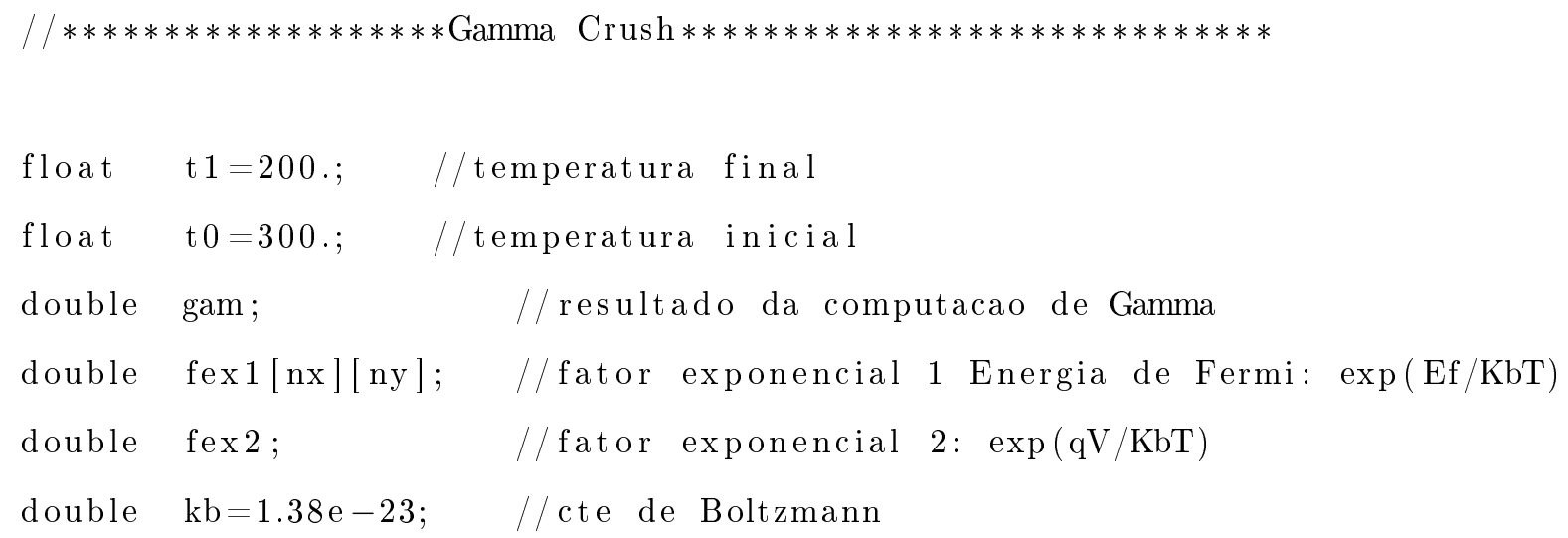




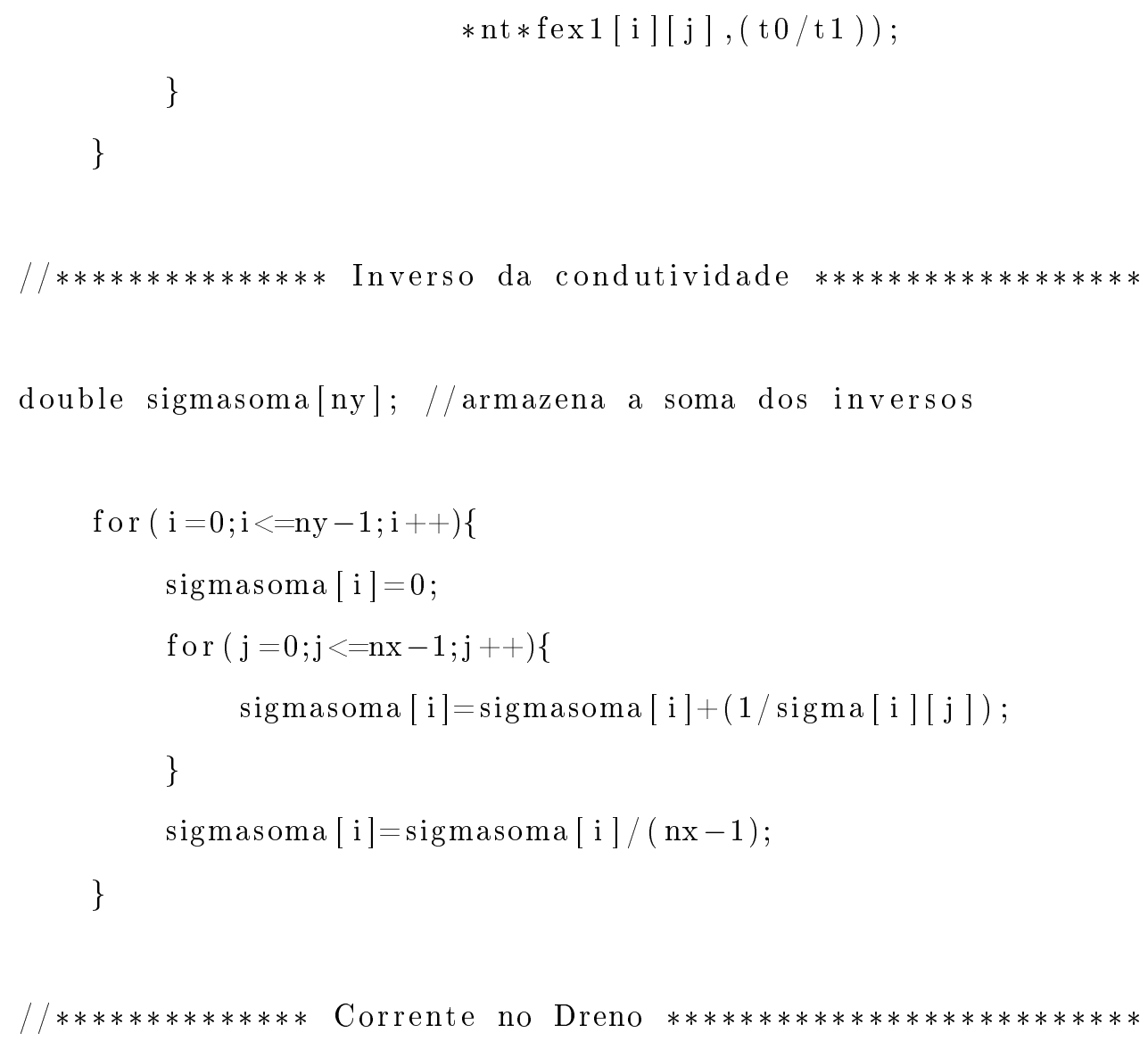




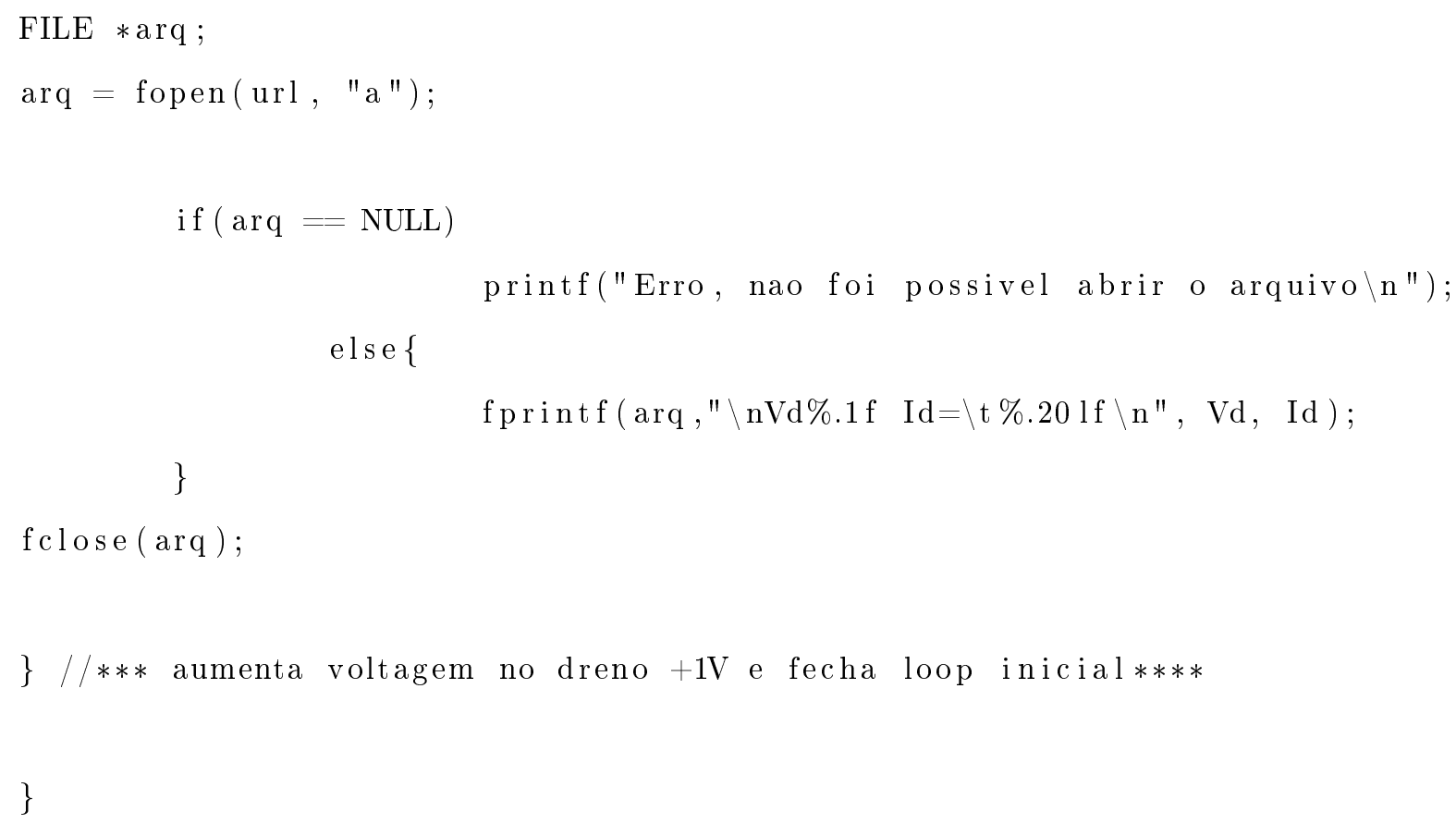

